Florida International University FIU Digital Commons

FIU Electronic Theses and Dissertations

University Graduate School

$11-9-2010$

\title{
Community Development Districts: The Entrepreneurial Side of Government
}

Gina Scutelnicu

Florida International University, gscut001@fiu.edu

DOI: $10.25148 /$ etd.FI10120103

Follow this and additional works at: https://digitalcommons.fiu.edu/etd

Part of the Infrastructure Commons, and the Public Affairs Commons

\section{Recommended Citation}

Scutelnicu, Gina, "Community Development Districts: The Entrepreneurial Side of Government" (2010). FIU Electronic Theses and Dissertations. 314.

https://digitalcommons.fiu.edu/etd/314

This work is brought to you for free and open access by the University Graduate School at FIU Digital Commons. It has been accepted for inclusion in FIU Electronic Theses and Dissertations by an authorized administrator of FIU Digital Commons. For more information, please contact dcc@fiu.edu. 


\title{
FLORIDA INTERNATIONAL UNIVERSITY \\ Miami, Florida
}

\section{COMMUNITY DEVELOPMENT DISTRICTS: THE ENTREPRENEURIAL SIDE OF GOVERNMENT}

\author{
A dissertation submitted in partial fulfillment of the \\ requirements for the degree of \\ DOCTOR OF PHILOSOPHY \\ in \\ PUBLIC AFFAIRS \\ by \\ Gina Scutelnicu
}

2010 
To: Dean Kenneth G. Furton

College of Arts and Sciences

This dissertation, written by Gina Scutelnicu, and entitled Community Development Districts: The Entrepreneurial Side of Government, having been approved in respect to style and intellectual content, is referred to you for judgment.

We have read this dissertation and recommend that it be approved.

$\begin{array}{r}\hline \text { Nazife E. Ganapati } \\ \hline \text { Richard Tardanico } \\ \hline \text { Sukumar Ganapati } \\ \hline \text { Howard A. Frank, Major Professor }\end{array}$

Date of Defense: November 9, 2010

The dissertation of Gina Scutelnicu is approved.

Dean Kenneth G. Furton

College of Arts and Sciences

Interim Dean Kevin O'Shea

University Graduate School

Florida International University, 2010 
(C) Copyright 2010 by Gina Scutelnicu

All rights reserved. 


\section{DEDICATION}

This dissertation is dedicated to my husband, Paul, who fully supported and encouraged me to complete this important milestone in my life. To my son Tudor, who inspired me with his lovely smile throughout this challenging process. To my sister Teodora, who guided me to pursue a doctoral degree. To my parents who always encouraged me in my life journeys. 


\section{ACKNOWLEDGMENTS}

I wish to thank from the bottom of my heart to my committee members for their support, guidance and patience. Without your help, this dissertation might have not been accomplished. Thank you, Dr. Nazife Ganapati for your thorough feedback and comments which helped me tell a coherent story. Thank you, Dr. Richard Tardanico for your objective view on my manuscript. Thank you, Dr. Sukumar Ganapati for guiding me towards this research topic and for your continuous encouragement along the way. Finally, thank you Dr. Howard Frank, for your support and extraordinary experiences throughout the work. As my major professor you had confidence in my abilities to successfully complete this arduous process. Your professional involvement nourished my intellectual maturity that I will benefit from, for a long time to come.

I am truly indebted to Eugenio Pino Entrepreneurship Center and the University Graduate School at Florida International University for providing financial support. Kauffman Doctoral Student Assistantship helped me conduct my preliminary research and complete my dissertation proposal. Doctoral Evidence Acquisition Fellowship helped me collect the necessary data for the study and the Dissertation Year Fellowship provided financial relief during my analysis and writing phase.

Special thanks also go to my fellow colleagues who helped me in many ways throughout this challenging journey. 


\title{
ABSTRACT OF THE DISSERTATION \\ COMMUNITY DEVELOPMENT DISTRICTS: THE ENTREPRENEURIAL SIDE OF GOVERNMENT
}

\author{
by \\ Gina Scutelnicu \\ Florida International University, 2010 \\ Miami, Florida \\ Professor Howard A. Frank, Major Professor
}

In an effort to reduce the cost and size of government public service delivery has become more decentralized, flexible and responsive. Public entrepreneurship entailed, among other things, the establishment of special-purpose governments to finance public services and carry out development projects. Community Development Districts (CDDs) are a type of special-purpose governments whose purpose is to manage and finance infrastructure improvements in the State of Florida. They have important implications for the way both growth management and service delivery occur in the United States.

This study examined the role of CDDs for growth management policy and service delivery by analyzing the CDD profile and activity, the contribution of CDDs to the growth management and infrastructure development as well as the way CDD perceived pluses and minuses impact service delivery. The study used a mixed methods research approach, drawing on secondary data pertaining to CDD features and activity, semistructured interviews with CDD representatives and public officials as well as on a survey of public officials within the counties and cities that have established CDDs. 
Findings indicated that the CDD institutional model is both a policy and a service delivery tool for infrastructure provision that can be adopted by states across the United States. Results showed that CDDs inhibit rather than foster growth management through their location choices, type and pattern of development. CDDs contributed to the infrastructure development in Florida by providing basic infrastructure services for the development they supported and by building and dedicating facilities to general-purpose governments. Districts were found to be both funding mechanisms and management tools for infrastructure services. The study also pointed to the fact that specialized governance is more responsive and more flexible but less effective than general-purpose governance when delivering services. CDDs were perceived as being favorable for developers and residents and not as favorable for general-purpose governments.

Overall results indicated that the CDD is a flexible institutional mechanism for infrastructure delivery which has both advantages and disadvantages. Decision-makers should balance districts' institutional flexibility with their unintended consequences for growth management when considering urban public policies. 


\section{TABLE OF CONTENTS}

CHAPTER

PAGE

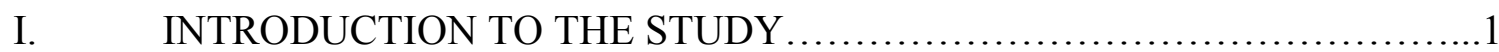

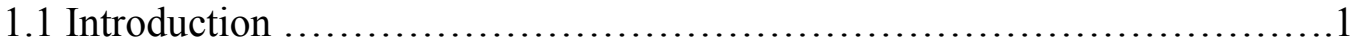

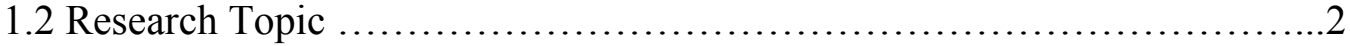

1.3 Purpose and Objectives of the Study ..................................

1.4 Overview of the Research Design .................................... 9

1.5 Research Questions .................................................. 10

1.6 Significance of the Study..............................................

1.7 Organization of the Dissertation ...........................................

II. THEORETICAL FRAMEWORK AND LITERATURE REVIEW .................. 14

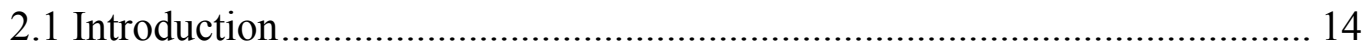

2.2 New Public Management and Service Delivery …………………………... 14

2.3 Theories of Special-Purpose Governments................................................. 18

2.4 Special-Purpose Governments and Service Delivery …………………........ 20

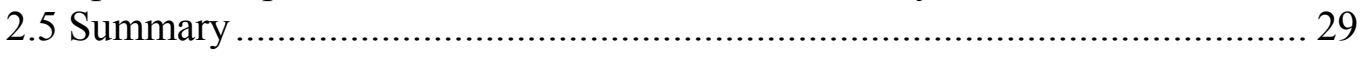

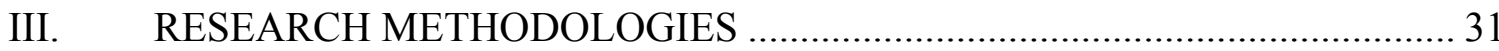

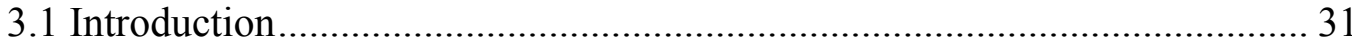

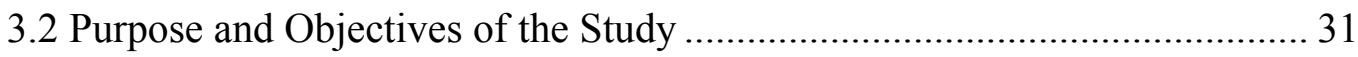

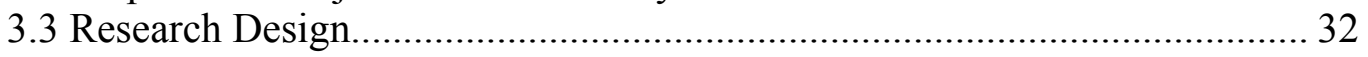

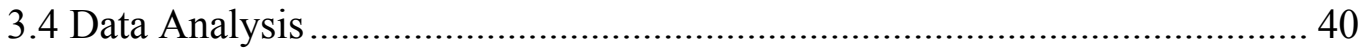

3.5 Reliability and Validity Issues ................................................................ 45

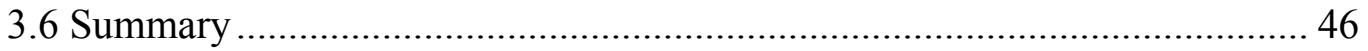

IV. TOWARDS A BETTER UNDERSTANDING OF SPECIAL DISTRICTS: THE CASE OF COMMUNITY DEVELOPMENT DISTRICTS....................... 48

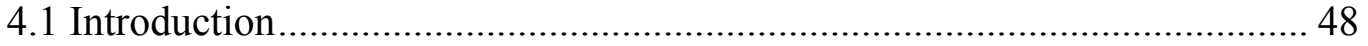

4.2 Special Districts ........................................................................................ 49

4.3 Special Districts in Florida....................................................................... 55

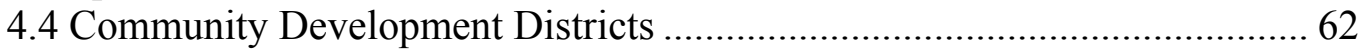

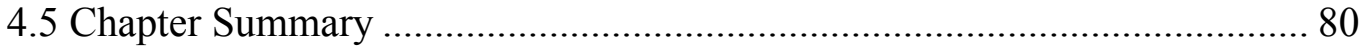

V. THE ROLE OF COMMUNITY DEVELOPMENT DISTRICTS IN

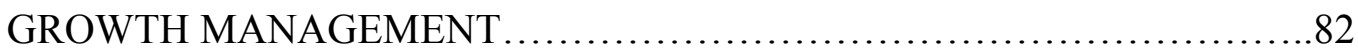

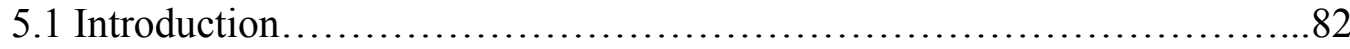

5.2 Growth Management Legislation....................................... 83

5.3 CDD Profile and Growth Management Implications ......................86

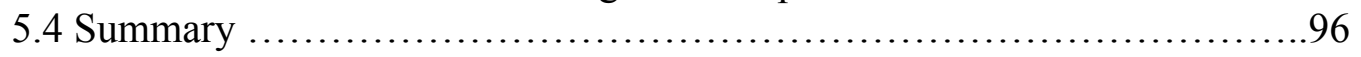

VI. THE ROLE OF COMMUNITY DEVELOPMENT DISTRICTS FOR

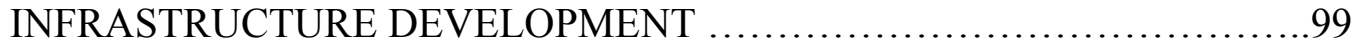




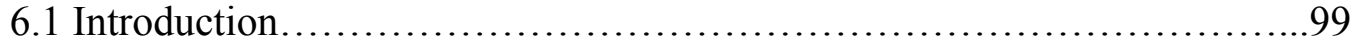

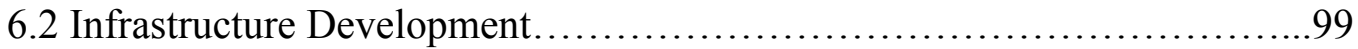

6.3 Types of Infrastructure Provided by CDDs...............................101

6.4 Infrastructure Provision and Maintenance................................... 104

6.5 Indicators of Infrastructure Variation................................... 108

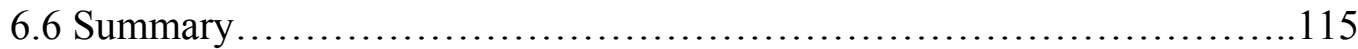

VII. THE PERCEIVED EFFECTIVENESS AND RESPONSIVENESS OF COMMUNITY DEVELOPMENT DISTRICTS AS SERVICE

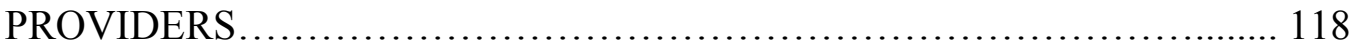

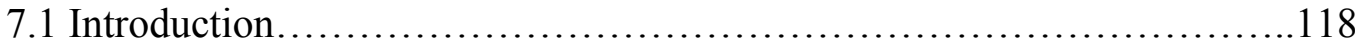

7.2 CDD Perceived Pluses and Minuses...........................................119

7.3 Factor Analysis and Indexes Creation..................................... 135

7.4 Qualitative Analysis of Survey ......................................

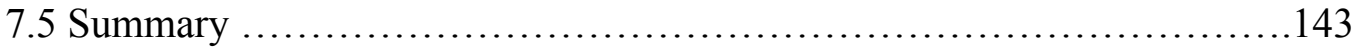

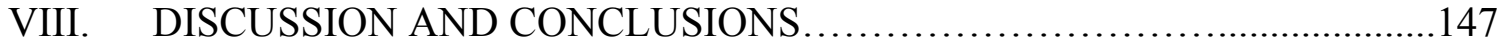

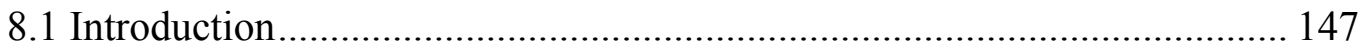

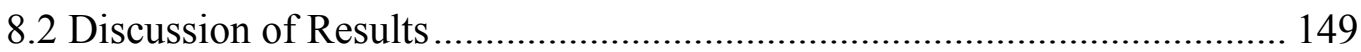

8.3 Implications for Further Research ........................................................... 166

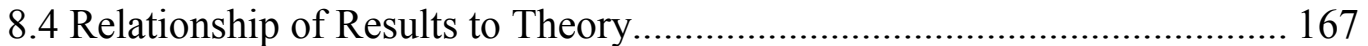

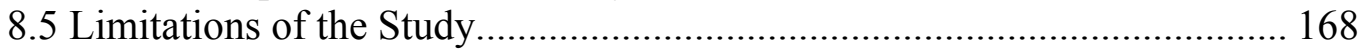

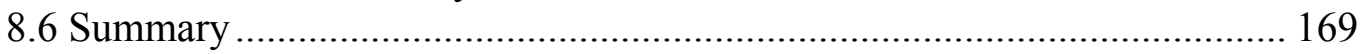

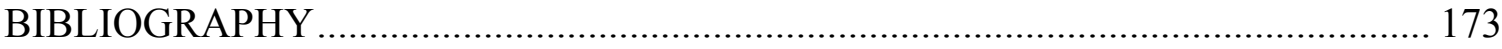

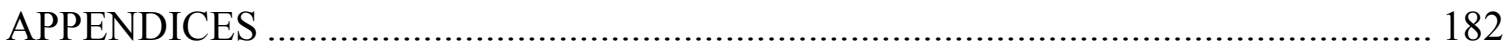

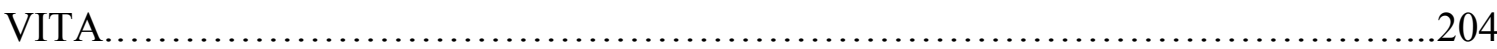




\section{LIST OF TABLES}

TABLE

PAGE

3.1 Selection of Survey Participants ............................................. 37

4.1 The Status of Special Districts in Florida ..................................57

4.2 Types of Functions by Dependent Status ...................................58

4.3 Types of Functions by Independent Status ..................................59

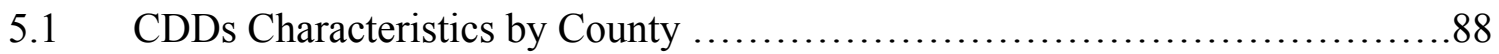

5.2 CDD Financial Characteristics ..............................................91

6.1 Differences in the Number of Services Provided by CDDs .....................109

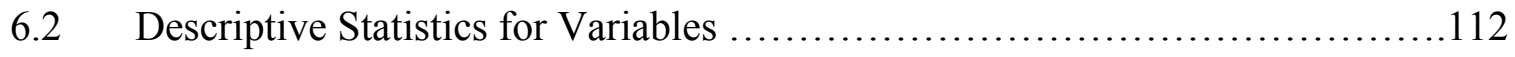

6.3 Bivariate Correlations between Predictor Variables ...........................113

6.4 Stepwise Multiple Regression Analysis of Factors that Influence the CDD Infrastructure Variation........................................ 114

7.1 Demographic and Professional Characteristics of Participants ................120

7.2 Descriptive Statistics for Age and Years in Current Position ..................122

7.3 Differences between On-line and Mail Surveys .............................123

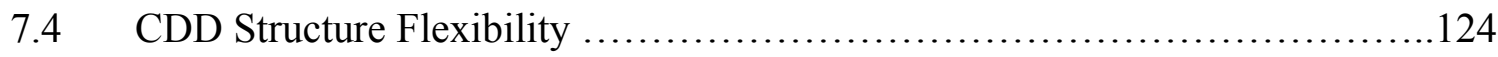

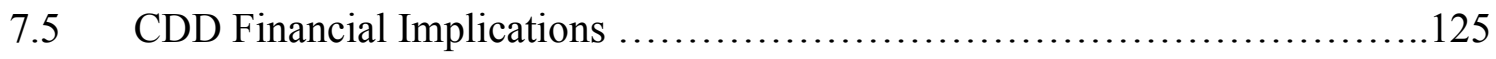

7.6 CDD Economic Development Implications ..............................126

7.7 CDD Accountability Issues ............................................127

7.8 Type of Professional Certification .......................................131

7.9 Association of Survey Items by Individual Characteristics ..................132 
7.10 Factor Loadings and Communalities

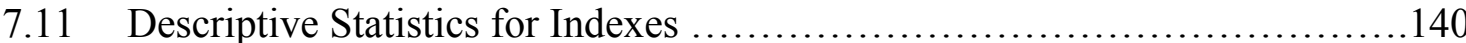




\section{LIST OF FIGURES}

FIGURE

PAGE

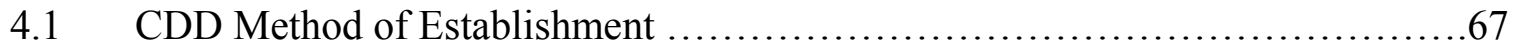

4.2 Creation of CDDs by Year ............................................... 69

4.3 CDD Geographic Distribution ........................................ 70

4.4 Percent of Revenues by Type of Local Government .........................74

4.5 Percent of Expenditures by Type of Local Government .....................75

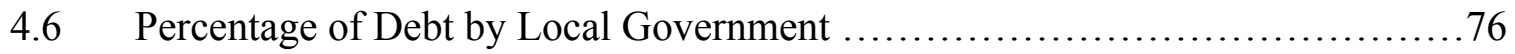

$5.1 \quad$ Type of Development by County ....................................... 93

7.1 CDDs' General Overview ........................................... 129 


\section{LIST OF ABBREVIATIONS AND ACRONYMS}

Admin.

BCC \& LG

BIDs

CDDs

Const.

CPI

DFS

DRI

DV

EXP

ELMS

FA

Fla.

GMA

GP

HSM

INFRCOST

LGCPA

LGINFRCOST

LOC

Max

Min.
Administrative

Board Certified in City County and Local Government Law

Business Improvement Districts

Community Development Districts

Constitution

Consumer Price Index

Department of Financial Services

Development of Regional Impact

Dependent Variable

Expenditures

Environmental Land and Management Study

Factor Analysis

Florida

Growth Management Act

General-Purpose Government

Hollow State Model

Infrastructure Cost

Local Government Comprehensive Planning Act

Logarithm of Infrastructure Cost

Location

Maximum

Minimum 
N. d.

No.

NPM

REV

Stat.

Std.

St. dev.

TELs

US
No date

Number

New Public Management

Revenues

Statute

Standard

Standard deviation

Tax and Expenditure Limitations

United States 


\section{CHAPTER I}

\section{INTRODUCTION TO THE STUDY}

\subsection{Introduction}

Community Development Districts (CDDs) are localized governmental entities which provide fundamental infrastructure improvements that are geared toward new development. They are both a policy and service delivery tool. From a development perspective CDDs can be considered important tools for local growth policies. They have significant implications for growth management by coordinating the timing and financing of infrastructure provision with development as well as by making choices about location, type and pattern of development. From a service delivery perspective CDDs can be considered flexible institutional choices for providing and maintaining efficient and responsive public services. In an effort to reduce the cost and size of government, public service delivery is no longer a direct function of the government. In the United States, public service provision has been devolved from state governments to local levels of government or other governmental entities and agencies. Therefore, special-purpose governments such as CDDs are providing more and more services due to their flexibility in delivering services.

In considering the issue of how to better coordinate infrastructure provision with urban development this study examines the role CDDs play in growth management and service delivery. By trying to answer the major question: What are the benefits and downsides of CDD for both growth management policy and public service delivery in Florida? the study contributes to a better understanding of specialized governance 
through a critical analysis of CDDs' performance. The terms special-purpose governments, specialized governance and special districts are interchangeably used throughout the study and they refer to local governmental entities which provide one or a limited number of functions.

\subsection{Research Topic}

Community Development Districts (CDDs) are specialized governments, created by a state charter, whose main purpose is to manage and finance infrastructure services that accommodate new development within the State of Florida. They are a specific subtype of special districts which are independent, special-purpose units of local government (other than counties, municipalities, townships or school districts) that have administrative and financial independence from general-purpose governments (US Census, 2007).

Like any other independent special districts CDDs differentiate themselves from local governmental entities of general-purpose through their specific characteristics. These are: narrow specialization (districts are authorized to provide specific types of infrastructure services), administrative and financial independence (districts are governed by independent boards of supervisors and levy ad-valorem taxes on property, impose special assessments, charges and fees and issue bonds), geographic flexibility (districts partially or totally overlap other jurisdictions) and low political visibility (districts are

often being characterized as "shadow governments" because the general public is unaware of the functions they perform).

These entities can be categorized as entrepreneurial governments because of their administrative autonomy, their perceived fiscal independence from general-purpose governments that facilitates efficiency in delivering services as well as because of the 
belief that CDDs are a means for development to pay its own way (Bartling, 2007; Nicholas \& Chapin, 2007). Public entrepreneurship has been defined as "a process of introducing new procedures, policies or organizational forms to the public sector" (Daft \& Becker, 1978 (as cited in Roberts \& King, 1991, p. 150)). Public entrepreneurship enables government to provide more services without increasing its size, by delegating part of its functions to other public, private or non-profit entities. Thus, government becomes more decentralized, flexible and responsive. For the purposes of this study public entrepreneurship refers to the establishment of special-purpose governments to finance and manage public services and to carry out development projects.

The CDDs are similar to other multi-purpose special districts, especially Business Improvement Districts (BIDs). The CDDs are similar to BIDs because they fulfill multiple functions and because they have financial and administrative autonomy from other local governments. The CDDs differ from BIDs with regard to their process of establishment, the array of services they are authorized to provide and the type of development they support (residential development vs. business-oriented development).

The State of Florida enabled the creation of CDDs as a response to the inability of local general-purpose governments to provide adequate infrastructure to service projected growth. Even though the enabling legislation for CDDs was passed in 1980, their proliferation increased significantly in the 1990s and 2000s. According to the Florida Department of Community Affairs, as of September 1, 2010 there were 579 active CDDs in the State of Florida. Districts are concentrated in the counties and cities located within the southern and central parts of Florida. Famous examples of CDDs include New Urbanism type of communities such as Celebration - a master-planned community which was developed by Walt Disney Corporation in Osceola County and Tradition - a mixeduse community comprising of ten CDDs located in Port St. Lucie. Other examples of famous CDDs are known under the name of census designated places and refer to The 
Villages - a residential retirement community comprised of twelve CDDs that are located in Sumter, Lake and Marion counties or Westchase - one of the wealthiest communities in Hillsborough County that is organized into twenty eight neighborhoods. Finally, the City of Weston located in the western part of Broward County was originally developed as a CDD in 1981 and then, was incorporated as a city in 1996.

The CDDs are authorized to manage, fund and construct basic infrastructure facilities and services such as water management and control, water supply, water and wastewater, bridges and culverts, district roads and certain projects for concurrency as well as parks and recreation facilities, security, fire prevention, education-related facilities and the like. In doing so, they enjoy administrative and financial independence from general-purpose governments. The CDDs are governed by an elected board of supervisors initially comprised of landowner's representatives and, subsequently, after certain requirements are met, by residents within the district. Districts may levy advalorem taxes, impose special assessments, charges and fees and, most importantly, they can issue tax-exempt bonds.

The use of CDDs to provide public infrastructure services has engendered praise and criticism. On the one hand, CDDs are praised because they deliver efficient services that are managed and financed primarily through special assessments that are paid by residents. Districts allow communities to raise revenues without increasing general taxes, thus taking the financial burden for major infrastructure improvements off the shoulders of general-purpose governments. Because of their financial capacity CDDs provide communities with infrastructure services and facilities that are completed in a timely manner. Finally, CDDs create new communities or improve the existing ones through their ability to incorporate into new municipalities or to be annexed into the existing ones. On the other hand, CDDs are open to criticism because they encourage governmental fragmentation, they seek mainly the interests of developers and ignore 
those of residents or they can abuse their powers due to a lack of traditional local generalpurpose government oversight.

Since CDDs are a functional subtype of special districts, they should be understood in the context of formation and proliferation of special-purpose governments. Special-purpose governments were created as a consequence of the federal government intervention in local service delivery and the use of revenue bonds to finance public services (Foster, 1997; Porter, Lin, Jakubiak \& Peiser, 1992; Sbragia, 1996).

Special-purpose governments' formation and proliferation has been well documented in the scholarly literature. Special districts were created for several reasons among which are: addressing a public or a private market failure in service provision (Porter et. al, 1992), fulfilling a demand for new services (Burns, 1992; McCabe, 2000) and overcoming state imposed limits and constraints placed on the taxing and borrowing capacity of local general-purpose governments (Bowler \& Donovan, 2004; Carr, 2006; Foster, 1997; McCabe, 2000) or on municipal and county formation and boundary change (Carr, 2004; Foster, 1997).

The creation of CDDs should be related to the tax and expenditure limitations imposed by states on local governments as a consequence of the tax rebellion of the 1970s. In Florida such constraints have been instituted since 1980 with the adoption of millage caps, followed by referendum requirements for issuing general obligation bonds and limits on the annual increase in the assessed values of homestead properties. From this perspective CDDs represent an alternative solution for funding infrastructure services since they do not contribute to raising ad-valorem taxes for the Florida taxpayers.

The context within which CDDs were created should also be related to the concurrency requirement of the Florida Growth Management Act. Concurrency is a growth management tool which requires that adequate public facilities be available or fiscally accounted for prior to or concurrent with new development. The Florida Growth 
Management Act requires every local government to adopt a capital improvement program for public facilities and to establish minimum level-of-service standards for certain public facilities to accommodate projected growth. Through its requirements, concurrency was intended to control growth and to foster economic development (BenZadok, 2007).

The growth management legislation had been criticized because it addressed the concurrency requirement without state commitment to fund it, the so-called "unfunded mandate of concurrency" (Ben-Zadok \& Gale, 2001; Connerly, Chapin \& Higgins, 2007; Pelham, 2001). Therefore, local governments had to identify financial sources for infrastructure development.

Today infrastructure management and financing represent a thorny issue for policy-makers in Florida and across the country. While local taxes such as increases in local sales taxes and local gas taxes as well as impact fees and connection charges constituted a temporary solution for the infrastructure funding problem, researchers argue that independent special districts, in general, and CDDs, in particular, can fund infrastructure improvements (Bartling, 2007; Porter, 2008; Porter, Lin, Jakubiak \& Peiser, 1992) as opposed to or in addition to traditional financing sources.

It is within this context that the present study aims at describing CDDs as both as a policy development tool and a flexible institutional framework for delivering public services. On one hand, CDDs are innovative financing mechanisms that link the costs of public facilities to the development that benefits from them. In theory, CDDs may be considered adequate managerial and financial mechanisms for infrastructure provision and maintenance. Considering their administrative and financial autonomy, CDDs can provide and maintain infrastructure facilities and services for new development, thus funding the "unfunded mandate of concurrency." 
On the other hand, CDDs are flexible institutional alternatives for delivering public infrastructure services. In theory, they are expected to deliver services in a business-like and responsive manner and to provide high quality services due to their narrow functional purpose and their small size.

The existing empirical literature on special-purpose governments focuses on the implications of specialized governance on service delivery. It discusses special districts in general and subtypes of special districts such as BIDs but is almost silent on the effects of CDDs. Even though CDDs have been around since the early 1980s there is a lack of systematic scholarly studies on their effects. This study fills in this gap in the literature by analyzing the impacts of CDDs from the perspectives of development policy and service delivery.

Most of the reviewed studies analyzed the effects of special-purpose governments in general rather than differentiating them according to their functions or purpose. The literature typically neglects to address the impacts of multi-purpose special districts. Districts that fulfill multiple functions such as CDDs might yield different results than the single-function ones since their functions are broader and governance implications are more varied. By focusing on a subtype of multi-purpose governments that provide infrastructure-related services, the present study fills up another important gap in the extant literature.

The largest body of literature about special-purpose governments has dealt with explaining the determinants of formation and use of specialized governance. There is little empirical research on impacts such as efficiency, responsiveness, accountability and/ or equity of special-purpose governments on service delivery. This study partially addresses these issues by analyzing the perceived efficiency and responsiveness of CDDs in delivering services. 
The present study also tries to overcome methodological shortcomings previously identified in the literature by using primary data coming from semi-structured interviews and a self-administered survey as well as secondary data coming from the state level and from local general-purpose governments in Florida. The extant studies on special-purpose governments rely heavily on data provided by the Census Bureau. These data have been criticized for not being accurate enough because of inconsistencies between Census and state-level data (Axelrod, 1992; Leigland, 1990).

\subsection{Purpose and Objectives of the Study}

The purpose of the study is to analyze how CDDs function as an institutional choice for managing and funding public infrastructure services. It discusses the CDD profile and activity, the contribution of CDDs to the infrastructure development and growth management in Florida, the drivers of variation for CDDs-supported infrastructure as well as the way CDD perceived pluses and minuses impact service delivery.

The specific objectives of the study are:

- to offer an overview about CDD institutional structure with regard to districts' powers, functions and activity;

- to assess the role of CDDs to the growth management in Florida;

- to assess the role of CDDs to the infrastructure development in Florida and

- to determine the role of CDDs for service delivery by assessing districts pluses and minuses as well as their efficiency and responsiveness as service providers

The overall contribution of the study is to offer a better understanding of the specialized governance with an eye to the effective practice of CDDs. 


\subsection{Overview of Research Design}

The research design for the present study consists of a three-stage sequential mixed methods approach. The first stage is an exploratory analysis which uses secondary data sources and document analysis of different official documents and legislation to provide a general overview about how CDDs operate and the magnitude of their activity. The next stage is comprised of a combination of qualitative and quantitative analysis. The author employs the qualitative methodology of semi-structured interviews for a detailed exploration of CDDs, specifically the manner in which infrastructure development occurs in local communities. Quantitative analysis draws on state-level secondary data and intends to complement the qualitative inquiry with numerical data about the contribution of CDDs to the growth management and infrastructure development. Finally, the last stage employs common themes and patterns derived from the qualitative analysis to develop and execute survey analysis. The author uses a survey of public officials to assess the pluses and minuses of CDDs as well as their degree of efficiency and responsiveness in delivering public infrastructure services.

There are two reasons for combining qualitative with quantitative methodologies. The first one is to better understand the impact of CDDs on infrastructure development by combining the in-depth analysis of qualitative inquiry with the numerical form of quantitative inquiry. The second one is to use qualitative research as a means of generating variables for developing a survey instrument. The expectation is that combining "words and numbers" will add to the reliability and validity of findings. 


\subsection{Research Questions}

This study seeks to answer the following major question:

What are the benefits and downsides of CDDs for both growth management policy and public service delivery in Florida?

and sub-questions:

1. Which are the contributions of CDDs to the growth management in Florida?

2. Which are the contributions of CDDs to the infrastructure development in Florida?

3. Are CDDs perceived to be an efficient and responsive institutional model for infrastructure delivery?

This study is conducted with the purpose of shedding light on "shadow governments" and providing an assessment of CDDs more than twenty five years after their inception. The study focuses on the implications CDDs have for the way growth occurs, the type of infrastructure services provided and the effectiveness and responsiveness through which infrastructure services are delivered.

The choice of focusing on these particular research questions resides in the fact that CDDs have significant implications for both growth management and urban service delivery. The CDDs have broader implications for growth management than solely securing availability of financial resources to build infrastructure. This study aims at assessing not only their obvious benefit of coordinating timing and financing of infrastructure provision with new development but also at analyzing districts consequences with regard to the location, type and pattern of development they support.

Moreover, in order to provide a realistic assessment of CDDs activity it is important to analyze the types of public improvements that CDD actually finance and to determine the role districts play in infrastructure provision and maintenance. This part of 
the study intends to shed light on whether CDDs help general-purpose governments or themselves to finance the needed infrastructure.

Finally, this study intends to determine how effective and responsive CDDs are when delivering services. Evaluating CDDs' performance has significant implications for the way urban service delivery occurs today in the United States. Since service delivery has become extremely decentralized, it is important to assess whether one type of local government (specialized government) is better than another (generalized government).

\subsection{Significance of the Study}

The significance of this study resides in its original contributions to the scholarly research, to practitioners and to the public policy process. The contribution of the present study to the academic literature is multifold. The CDDs have been an understudied mechanism for infrastructure development and this work will help fill in the knowledge gap. The study addresses the need expressed in the literature for analysis of specific subtypes of special-purpose governments by thoroughly investigating the contribution of CDDs to the infrastructure development and service delivery within the State of Florida. The study also assesses the efficiency and responsiveness of CDDs in delivering services when compared to general-purpose governments through the perceptions of public officials, thus filling up another important gap in the literature. Finally, another original contribution of this study to the scholarly literature resides in using a mixed- methods approach with data coming from semi-structured interviews, CDD-provided secondary data and a self-administered survey. Thus, the present study addresses past methodological shortcomings by relying on primary and state-level secondary data rather than on US Census data. 
By examining the role of CDDs for growth management and service delivery this study will make a significant contribution to the fields of public policy and public management. It will provide decision-makers with useful information about the pros and cons of CDD deployment and will shed light on their implications for growth management policy and infrastructure delivery.

The findings of the study will provide evidence that the CDD is a flexible model of institutional design for infrastructure provision that has both advantages and disadvantages. The CDDs can be a useful institutional model with potential for other states, especially those that need to accommodate their growth needs. However, decisionmakers should balance districts pluses and minuses when considering urban public policies. Similar districts are already in place in states such as Arizona (county improvement districts), Colorado (metropolitan districts), Georgia (community improvement districts), Tennessee (utility districts) and Texas (municipal utility districts) and are on the rise in others. Therefore, the experiences in Florida reported herein will offer lessons to be learned for other states that favor multi-purpose independent special districts.

\subsection{Organization of the Dissertation}

This dissertation is divided into seven chapters. Chapter one introduced the problem statement, purpose of the study, a brief overview about the research design, the research questions and sub-questions, and the importance and contribution of the study. Chapter two describes the theoretical framework for the study, reviews the theoretical and empirical literature about special-purpose governments and comments on the contribution of the present study to the existing literature. Chapter three presents the research methodology for this study. It includes the description of the purpose and 
objectives of the study, the research questions to be addressed, the mixed-methods research design, target population and sample selection, data collection sources and research instruments, data analysis as well as reliability and validity issues of this study. Chapter four places CDDs within the broader context of specialized governance. It provides background information about special districts and CDDs in the State of Florida by describing districts characteristics, functions and activity. Chapter five describes the role of the CDDs to the infrastructure development and growth management in Florida by analyzing the type of infrastructure provided by CDDs as well as the location, size and type of development they support. Chapter six identifies the drivers of infrastructure variation to determine the role of CDDs in providing and maintaining infrastructure for new development. Chapter seven describes how favorable of an institutional choice for infrastructure delivery CDDs are by analyzing the perceived strengths and weaknesses of CDDs as well as their efficiency and responsiveness in delivering services. The final chapter, chapter eight, discusses the implications of the present research and suggests further research venues. 


\section{CHAPTER II}

\section{THEORETICAL FRAMEWORK AND LITERATURE REVIEW}

\subsection{Introduction}

Special-purpose governments are entities which provide one or a limited number of public services. They are known under different names such as special districts, public authorities, public corporations and the like. In the present chapter the term specialpurpose governments includes special districts, public authorities and subtypes of special districts such as Business Improvement Districts (BIDs), Community Development Districts (CDDs) or Community Improvement Districts. In this study the terms specialpurpose governments and specialized governance are interchangeably used. The review focuses on the literature concerning special-purpose governments because they provide a general conceptual framework for the present study and because CDDs have occasionally been researched empirically.

This chapter is comprised of three sections. First it describes the theoretical framework of the New Public Management. Then it presents both the theoretical perspectives and empirical literature on special-purpose governments. The final section summarizes the gaps in the literature and comments on the way this study addresses them.

\subsection{New Public Management and Service Delivery}

New Public Management (NPM) is a public management reform movement comprised of a set of core principles that have been developed in the 1970s as an 
alternative to the traditional theory of public administration. The term was coined in 1989 by Christopher Hood to describe the common features of the administrative reforms undertaken in the 1970s and 1980s in countries such as Australia, Canada, New Zeeland, United Kingdom and later in the United States (Lynn, 2006, p. 107).

Based on the theoretical assumptions of economic theory and business management, NPM was embraced with the intent of reducing the cost and the size of government. The aim of NPM is to make the public sector act more like the private one and it calls for government to focus on results rather than on procedures, adopt marketlike competition and entrepreneurial strategies, become customer-driven and rely on market-based mechanisms to deliver public services.

There are as various definitions and descriptions of the NPM values as the number of authors who wrote about it. To shed light on the concept of NPM this study describes the six fundamental NPM values identified by Kettl (2000) which successfully summarize the core concepts of this public management doctrine. These values are:

- Making government more efficient and effective by achieving more things with less resources;

- Using market-like mechanisms to make government more competitive;

- Treating citizens as customers or clients and make government a consumer-driven one with choices of public services;

- Using decentralization to make government more flexible and responsive;

- Improving the process of policy adoption and implementation by revisiting the role of government in the provision and delivering of public services and

- Focusing on outputs and outcomes instead of processes and structures.

According to Osborne \& Gaebler (1992) NPM is a customer-driven government which is more entrepreneurial and more accountable to the public and which generates 
more services choices than the traditional bureaucracy (p.180). Therefore, NPM replaced the principles of "Old Public Administration" with a set of new principles. These are: contracting out, decentralization, granting more freedom to managers, availability of customer choices, deregulation, competition and performance measurement (Frederickson \& Smith, 2003).

The contracting out phenomenon is a fundamental feature of NPM (Frederickson \& Smith, 2003) and has been on the rise in the last twenty years. It has been identified in the public management literature under different names - the "hollow state" (Milward \& Provan \& Else, 1993), government by proxy (Kettl, 1993), third party government (Smith \& Lipsky, 1993), and shadow government and the contracting regime (Kettl, 1988). This study will use the term "hollow state" for the remainder of the chapter as it appears more appealing to the scope of the research.

Today, public services delivery is no longer a direct function of national governments. It is taking place within "the hollow state" framework where state governments are sharing or devolving authority to local levels of government or other governmental entities and agencies. Under NPM public managers are challenged either to find new ways to achieve results or to privatize functions previously provided by government. They should "steer not row", meaning they should not assume the burden of service delivery themselves, but (...) others would carry them out (Denhardt \& Dendardt, 2007, p. 13).

The "hollow state" model (HSM) was introduced to the public sector by Milward, Provan \& Else (1993). It was borrowed from the private sector where "the hollow corporation" (Business Week, 1986) replaced the internal process of production with a network of subcontractors. In the public sector, hollow state refers to a system of third party governance. Within the hollow state framework policy design becomes the responsibility of state governments and policy implementation the responsibility of a 
network of local governmental agencies, non-profit organizations and private companies (Milward \& Provan, 2000).

The hollow state is also used to pinpoint the importance of adopting public policies in the context of governance rather than government (Frederickson, 1996). While government refers to the traditional institutions of government that are dealing with direct service delivery, governance is a broader term that refers to "the traditions, institutions and processes that determine the exercise of power in society, including how decisions are made on issues of public concern and how citizens are given voice in public decisions" (Denhardt \& Denhardt, 2007, p.86). Milward \& Provan (2000) state that governance also includes agents in the private, non-profit and public sectors. Therefore, governance implies the presence of a network of institutions that are involved in delivering public services, possibly outside of direct public provision.

The HSM is perceived both in terms of strengths and weaknesses. On the one hand, the hollow state is seen as a solution to a lack of federal funding and service provision and it focuses on the privatization as well as on the efficiency and flexibility of public service delivery (Milward \& Provan, 2000). Devolution is a means of assuring more flexibility in service provision by decentralizing services to local institutions that are more responsive to a community's needs (Kettle, 1988; Milward, Provan \& Else, 1993 ) and provide more efficient and cost-effective services (Smith \& Smyth, 1996). On the other hand, the HSM is weak in addressing issues of accountability and coordination (Fredericksen \& London, 2000; Lynn, 2006; Milward \& Provan, 2000), especially "with application to control for abuse of out-sourced providers of services through reporting, supervision and oversight" (Fredericksen \& London, 2000, p.231). Moreover, critics of NPM argue that in this management model the accountability is fragmented (Haynes, 2003), political control and accountability are weak (Pollitt \& Bouckaert, 2000) and there is a disconnection between specialization and coordination (Pollitt \& Bouckaert, 2000). 
Within the NPM framework, CDDs represent one of the "hollowed-out" alternatives for delivering public infrastructure services. Special-purpose governments were created in order to professionalize the management of public services and to deliver them in an efficient and business-like manner (Blair, 1986). Administrative and fiscal decentralization for service delivery in the field of economic development is encouraged within the HSM (Milward, Provan \& Else, 1993). The CDDs as localized entities of government can be seen as a flexible alternative means for service delivery. In theory, consistent with tenets of NPM, they are expected to provide more responsive and more efficient services. Since CDDs are smaller in size than general-purpose governments, they should, in theory, better consider the needs of a community. Districts' functional specialization is supposed to offer higher quality services thus, making them more efficient than general-purpose governments. The present study aims at demonstrating that CDDs represent a flexible institutional choice for public infrastructure delivery.

\subsection{Theories of Special-Purpose Governments}

As stated earlier, the doctrine of NPM encouraged the rise of varied administrative arrangements such as special-purpose governments for public service delivery. The scope of this section is to describe the two competing theories about specialized governance. The theoretical views about special-purpose governments focus on a debate between two main theories describing specialized governance: metropolitan reform theory and public choice theory. The debate refers to issues of consolidation vs. fragmentation when discussing efficiency, responsiveness, accountability and equity of specialized governance.

Metropolitan reform theory favors governmental consolidation as a way of maximizing benefits within a region. It supports governmental consolidation of all local 
governmental entities into a single (Bish \& Ostrom, 1973, p. 9) or a small number (Miller, 2002) of jurisdictions for each metropolitan area and it encourages increasing coordination of existing governments with a higher level of government (Miller 2002, p. 94). Metropolitan reformers consider special-purpose governments as contributing to the fragmentation of government. Fragmentation drives confusion among citizens with regards to which governmental entity is responsible for providing public services. Therefore, specialized governments are perceived as inefficient and wasteful because they increase the cost of government and contribute to duplication of services (Bollens, 1957). Fragmentation also contributes to inequality of distribution in service delivery since special-purpose governments do not provide equal access to all citizens but only to those who pay for them. In this theoretical view special-purpose governments are seen as unaccountable to the public.

As a result of their small size special-purpose governments provide more expensive and less efficient services than general-purpose governments. Metropolitan reformers consider the activity of specialized governance as not being coordinated with that of general governance. Moreover, reformers view special-purpose governments as focusing on the interests of those who initiated their creation, mainly developers.

Public choice theory favors the polycentric model of governance that describes the interactions of multiple local governments which are independent of each other (Ostrom, 1999; Ostrom, Bish \& Ostrom, 1988). Public choice theorists support fragmentation because it offers a variety of choices for the services and taxes offered (Bish \& Ostrom, 1973; Ostrom, 1999). Within the public choice framework fragmentation encourages competition among local governments which leads to efficiency and effectiveness of service provision (Miller, 2002). Tiebout (1956) asserted that competition among local governments allows citizens to choose where to live according to the choices of taxes and services that fulfill their needs. Fragmentation 
supporters view efficiency in terms of benefits exceeding costs and higher quality for services. Equity of service delivery is not a principal focus.

Public choice theory distinguishes between the production and provision of services. Service provision is achieved through a variety of local entities such as counties, cities, public authorities, special districts and the like. Special-purpose governments are created to address the need of efficient service delivery. The polycentric model views special-purpose governments as a flexible and responsive means of delivering services. The smaller the units of government the better they will satisfy the preferences of citizens (Ostrom, 1999). Special-purpose governments are accountable to the citizens they serve through their elected boards of supervisors. Public choice perspective also addresses issues of distribution equity since the establishment of special districts is seen as an alternative to an increase in taxes. Specialized governance relies on the benefit principle: those who benefit pay for it (Oakerson, 1999).

In summary, the two theories about specialized governance offer two competing views. On the one hand, metropolitan reformers criticize special-purpose governments and consider them as undesirable because they contribute to the fragmentation of a metropolitan area. On the other hand, public choice theorists favor them as contributing to the efficiency and responsiveness of a metropolitan area through competition and flexibility. Both theories discuss special-purpose governments in general and do not differentiate them according to their functions, structure or authority (Foster, 1997; Mullin, 2009) or the politics of special-purpose governments (Berry, 2009).

\subsection{Special-Purpose Governments and Service Delivery}

This section discusses the contribution of the empirical literature on specialpurpose governments and service delivery by classifying the reviewed studies into four 
main categories: determinants of special-purpose governments' formation, determinants of their use, efficiency of specialized governance in delivering services as well as descriptive functional impacts of special-purpose governments.

The first line of research about special-purpose governments refers to the determinants of their formation and proliferation. Specialized governance was found to be a consequence of several factors. First, special-purpose governments were created because of the inability and inflexibility of general-purpose governments to provide services for current needs (Bollens, 1957). Thus, specialized governance was created to address a public or a private market failure (Porter et. al., 1992) by providing services in areas where other public or private entities were not able or not willing to.

Second, special-purpose governments were created to fulfill a demand for new services (Billings \& Leland, 2009; Burns, 1994; McCabe, 2000). Billings \& Leland (2009) argued that population, income and urbanization contributed to an increase in the number of Business Improvement Districts. Special-purpose governments were initiated by citizens, by specific interests of individuals and groups (Bollens, 1957) such as developers (Burns, 1994; McCabe, 2000) or by general-purpose governments which had a desire for special districts to perform certain functions (Bollens, 1957). Burns (1994) indicated that the formation of special districts varied according to the historical context. Therefore, from 1950s until 1970s district creation reflected the desire of citizens for new services while in the 1980 s special districts were created both as a consequence of the tax and debt limits placed by states on local general-purpose governments and as an initiative of developers to provide new services.

Third, there are studies that explained the creation and proliferation of specialpurpose governments as a result of state legislation. Some authors found that district enabling legislation is the determinant of their creation (Billings \& Leland, 2009; Foster, 1997). Special-purpose governments were more likely to form in states that had more 
permissive statutes about district formation and powers (Foster, 1997) or did not have such legislation in place (Billings \& Leland, 2009). Other scholars explained that growth management legislation led to the formation of specialized governance (Bartling, 2007). Thus, as the Florida Growth Management legislation requires, Community Development Districts could provide the necessary infrastructure at the time growth occurs.

Fourth, there are numerous studies that explain the formation of special-purpose governments as a means of overcoming state-imposed limits and constraints on the taxing and borrowing capacity of the local general-purpose governments (Bowler \& Donovan, 2004; Carr, 2006; Foster, 1997; MacManus, 1981; Marlow, 1995; McCabe, 2000). From this perspective the creation of new local governments represents an institutional mechanism that continues to provide services when tax and expenditure limitations (TELs) are adopted. MacManus (1981) considered that an increase in the number of property-based tax special districts was a consequence of restrictions placed both on advalorem taxes and on borrowing capacities of local governments. Partially consistent with MacManus (1981), Foster (1997) found that states with debt limits experienced an increase in the number of special districts while those with property tax limits had a reduced number of special districts.

McCabe (2000) focused on a wider array of state limitations such as property tax and debt constraints, expenditure limits and income tax measures placed both on municipalities and counties. Evidence suggests that states with TELs and debt limits placed both on cities and counties tended to create more special districts. Also, special districts were more likely to occur in states that allowed sales and income taxes to both municipalities and counties or to municipal governments only.

Bowler and Donovan (2004) did not consider typologies of constraints; they focused on whether the adoption of TELs by states had any influence on the creation of 
special-purpose governments. Results indicated that special districts are unintended consequences of TELs.

Unlike previous scholars who used only fiscal autonomy measures Carr (2006) employed four different measure of local autonomy - fiscal, functional, administrative and structural. He found that states that TELs were the only category of limitations that had an impact on the number of special districts. Moreover, states that had less restrictive TELs were associated with a higher reliance on special-purpose governments.

While some studies explained the relationship between TELs placed by states on cities or municipalities and the number of special-purpose governments (MacManus, 1981; Marlow, 1995), others considered constraints placed both on municipalities and counties and found that special-purpose governments/special districts were more likely to occur in states that adopted revenue and expenditure limitations on both categories of general-purpose governments (Carr, 2006; McCabe, 2000). The results about the impact of TELs on special-purpose governments were consistent for both the creation of new districts (McCabe, 2000) and the assessment of existent districts (Bowler \& Donovan, 2004).

Other type of legislation that contributed to the creation of special-purpose governments is represented by state imposed limitations on municipal and county formation and boundary changes (Carr, 2004b; Foster, 1997). Special districts are preferred to consolidation because their formation is easier to accomplish (Carr, 2004b) and because districts are flexible, self-supporting mechanisms that fulfill service provision demands, provide citizens with choices in the services and taxes offered and provide services that distinguish a district supported community by a city or a county (McCabe, 2004).

The majority of studies within the state legislation framework explained district formation and proliferation as a consequence of one type of state legislation such as 
district enabling legislation (Billings \& Leland, 2009), growth management legislation (Bartling, 2007), tax and expenditure tax limitations (Bowler \& Donovan, 2004; Carr, 2006; MacManus, 1981; Marlow, 1995; McCabe, 2000) and state limitations on municipal and county consolidation and boundary changes (Carr, 2004b). Foster (1997) acknowledges that special districts formation is a consequence of different types of state legislation such as statues and constitutions regarding the creation of special districts, state-imposed limitation on municipal and county formation, boundary changes, service provision, revenue raising capacity and federal income tax laws. Furthermore, Foster (1997) pointed to the fact that not all special districts are the same and different subtypes of districts have different reasons for their formation. Therefore, the creation of specialized governance should be understood as a combination of different factors such as legal, institutional and political factors (Foster, 1997).

The literature in this category does not distinguish among different districts subtypes. Even though special-purpose governments have been differentiated by their geographical location there is a need for explaining the creation of specialized governance by functional subtypes of districts since different subtypes of districts have different reasons for their formation (Burns, 1994; Foster, 1997). Furthermore, the studies focusing on the determinants of special-purpose governments' formation used simplistic measures for the operationalization of specialized governance such as number of special districts instead of relying on more standardized measures.

The second line of research on special-purpose governments deals with studies that try to explain how and why these entities are used. Reliance on special-purpose governments was explained primarily through these entities' character of financial mechanisms. Special-purpose governments were considered "tax-relief mechanisms" (MacManus, 1981) that take the financial burden off general-purpose governments shoulders, "borrowing machines" (Leigland, 1994) that try to escape constitutional debt 
limits (Bunch, 1991) and alternative funding mechanisms for infrastructure provision due to their ability to finance themselves and to their access to bond markets (Porter et. al., 1992).

Reliance on special-purpose governments was also seen beyond their revenue raising capacities. There are scholars who demonstrated that there are alternative reasons for state and local use of these entities besides their financial abilities. Special-purpose governments are used also because of demographic indicators such as population, area and urbanization (Frant, 1997) as well as for their institutional characteristics which were expected to solve service delivery concerns in a framework of political competition (Bourdeaux, 2005). The reliance on special-purpose governments is also seen as a means of overcoming collective action problems such as coordination (Baer \& Feiock, 2005; Mullin, 2010) and division (Baer \& Feiock, 2005). Mullin (2010) argued that the boundary flexibility of special districts led to their likelihood of entering into interlocal agreements, thus solving local coordination issues.

A third line of research on special-purpose governments looks at their efficiency in delivering services when compared to general-purpose governments. The studies in this category point to a consensus that specialized governance is less efficient than general-purpose governance (Berry, 2009; Bourdeaux, 2007; Foster, 1997; Mullin, 2009; Nunn \& Schoedel, 1997). The evidence in this category is not convincing since there is no consistent measure to assess efficiency. Efficiency was measured in different ways as follows: capital spending patterns to determine the quantity of infrastructure that gets built by both specialized and general governmental entities (Nunn \& Schoedel, 1997), cost of services provided by comparing metropolitan areas that had special-purpose governments with those that had only general-purpose governments (Foster, 1997), rate of completed projects for solid waste projects for both public authorities and counties (Bourdeaux, 2007), quality of services for library services offered by both special- 
purpose and general-purpose governments (Berry, 2009) and adoption of progressive rates for potable water by special districts and general-purpose governments (Mullin, 2009). The diversity of measures operationalizing efficiency makes it difficult to generalize findings beyond the context under analysis.

Unlike the supporters of public choice theory who view special-purpose governments as being more efficient than the general-purpose ones these empirical studies suggest the opposite. Specialized governance costs more due to its focus on longterm strategic reasons vs. short-term political and financial reasons for general-purpose governments (Foster, 1997). It costs more even when it does not provide higher quality services when compared to general-purpose governance (Berry, 2009). Therefore, the magnitude of special-purpose governments' budgets does not justify the quality of services they offer (Berry, 2009). Moreover, special-purpose governments' contribution to service provision is modest in comparison to that of general-purpose governments (Bourdeaux, 2007; Nunn \& Schoedel, 1997). Bourdeaux (2007) showed that specialized governance was less efficient than general-purpose government in delivering solid waste services because the completion rate of public authorities was low (15\%) in comparison to that of counties (67\%). Nunn and Schoedel (1997) compared the capital spending of cities with that of special districts among metropolitan areas and found that cities were the main providers of infrastructure because their capital spending was significantly higher than the spending of special districts.

Mullin (2009) is the only one that found that specialized governance is more efficient than general-purpose governments but only in certain circumstances. She investigated the efficiency and responsiveness implications for local policymaking in municipal water provision by analyzing the relationship between governing structure (special districts vs. general-purpose governments) and the adoption of progressive rates for water utilities. Findings demonstrated that specialized governance had a significant 
effect on the adoption of progressive water prices but only in communities with low temperature values.

When assessing the efficiency of special-purpose governments in comparison to general-purpose governments the scholarly literature investigated both special districts, in general (Foster, 1997; Nunn \& Schoedel, 1997) and subtypes of single-function districts: water districts (Mullin, 2009), library districts (Berry, 2009) and solid waste authorities (Bourdeaux, 2007). The studies in this category are scarce and efficiency of multipurpose governments has not been addressed.

Other impacts of specialized governance such as responsiveness have not been rigorously investigated. Even though, in theory, specialized governance is considered to be more responsive than general-purpose governments (McCabe, 2004) empirical evidence about the responsiveness of special-purpose governments is almost nonexistent. This study seeks to fill this void in the literature by analyzing both efficiency and responsiveness of specialized governance.

Finally, there is a fourth line of research that provides a descriptive perspective about the impacts of organizational and functional characteristics of subtypes of multipurpose special districts such as Business Improvement Districts (Becker, 2010; Gross, 2005; Mitchell, 2001; Mitchell, 2008), Community Development Districts (Florida Atlantic University/Florida International University Joint Center for Environmental Studies, 1995) and Community Improvement Districts (Morcol \& Zimmerman, 2006). What these subtypes of districts have in common is their multi-purpose focus, among other things, on infrastructure/capital improvement projects.

Business Improvement Districts (BIDs) provide services that cover the areas of management and maintenance of public space, public safety and the promotion of business functions (Becker, 2010). Their functions have been classified into seven main categories: marketing, cleaning and maintenance, capital improvement, security, 
economic development, policy advocacy and community development (Mitchell, 2008). Scholars explained that BIDs differ in providing services according to the city size within which they are located (Mitchell, 2001) or according to the district size (Gross, 2005). On one hand, BIDs located in large cities focused more on marketing, security and public space while districts in small cities were involved in capital improvements projects and marketing. On the other hand, large BIDs focused on capital improvement projects, medium districts on marketing and promotional activities and small districts on maintenance activities.

The Florida Atlantic University/Florida International University Joint Center for Environmental and Urban Problems (1995) created a comprehensive database about the number, size and type of CDDs, the type of land-use developed as well as housing units and the type of infrastructure services provided. The study found that CDDs focus on providing basic infrastructure such as water, sewer, drainage, groundwater recharge, roads, parks and recreation facilities and solid waste. However, districts relied on general-purpose governments for service maintenance.

Morcol \& Zimmerman (2006) presented an exploratory analysis of the activity and functions of Community Improvement Districts (CIDs) in Georgia to offer a general understanding on how these districts operate. Findings showed that CIDs are governmental entities created to accommodate economic growth. Their functions focused on transportation and capital improvements, safety, cleanliness and traffic congestion.

Although informative in scope this body of literature does not adequately address the impacts of multi-purpose special districts. Districts that fulfill multiple functions might have different consequences than the districts which pursue single-functions since the former's implications are broader. 


\subsection{Summary}

There are two main issues to consider when discussing the contribution of the extant literature about special-purpose governments and service delivery: content and methodological issues. First, there are content issues that need to be emphasized. Most of the studies under review analyzed the effects of special-purpose governments in general rather than differentiating them according to their functions or purpose. The largest body of literature referred to determinants of district formation and use in general and it did not make any difference among various district subtypes.

The literature fails to consistently address the impacts of multi-purpose special districts. Multi-purpose districts may be a solution to the criticism that the single function districts do not justify the addition of another layer of government (Carr, 2004). Several functions such as those relating to infrastructure might actually make districts efficient and responsive enough to justify their addition to the governance system.

The empirical literature points to a consensus that specialized governance is less efficient than general-purpose government. The studies about the efficiency impacts of specialized governance are scarce and they used different measures to assess efficiency, fact that makes it difficult to generalize their findings beyond the context under analysis. Other impacts of specialized governance such as responsiveness have not been rigorously investigated while accountability or equity issues are addressed only in theory.

There are also methodological issues that need to be addressed. The reviewed literature relies heavily on secondary data while primary data are scarce. Most of the empirical studies rely on data coming from United States Census of Governments to determine the number and types of special districts. The Census Bureau data have been criticized for not being accurate enough due to inconsistencies between U. S. Census and state-level data (Axelrod, 1992; Leigland, 1990). The Census Bureau either undercounts 
special districts by not including the dependent districts or overcounts them by including inactive districts. Recently, there have been attempts to overcome this issue (Berry, 2009; Mullin, 2010) but only in the case of single-purpose districts. Moreover, the literature uses simple measures for counting special-purpose governments such as number of special districts rather than more standardized measures. The studies are cross-sectional in nature.

The contribution of the present study to the literature concerning special-purpose governments and service delivery is multifold. First, it addresses the need expressed in the literature for the analysis of specific types of special-purpose government. It completes the descriptive perspective in the literature about multi-purpose districts by thoroughly analyzing the contribution of the CDDs to infrastructure development in the State of Florida. Second, the study assesses the efficiency and responsiveness of CDDs in delivering services when compared to general-purpose governments through the perceptions of public officials, thus filling an important gap in the literature. Third, the study analyzes the utility of an institutional choice for infrastructure delivery by relying both on secondary and primary data. The study also addresses past methodological shortcomings by relying on state-level data rather than U.S. Census data. Last but not least, the study fills another important gap in the literature by providing a comprehensive analysis for a specific subtype of multi-purpose districts. 


\section{CHAPTER III}

\section{RESEARCH METHODOLOGIES}

\subsection{Introduction}

This chapter describes the research approach and methods for this study. It is comprised of three sections. The first section describes the purpose and objectives of the study as well the research questions. The second section describes the research design together with the research instruments and procedures used for data collection. The last section presents the data analysis procedures and discusses reliability and validity issues.

\subsection{Purpose and Objectives of the Study}

The purpose of this study is to empirically analyze CDDs and to determine their benefits and downsizes for growth management policy and service delivery. The specific objectives of the study are:

The specific objectives of the study are:

- to offer an overview about CDD institutional structure with regard to districts' powers, functions and activity;

- to assess the role of CDDs to the growth management in Florida;

- to assess the role of CDDs to the infrastructure development in Florida and

- to determine the role of CDDs for service delivery by assessing districts pluses and minuses as well as their efficiency and responsiveness as service providers The overall contribution of the study is to provide a better understanding of the multipurpose specialized governance through the specific analysis of CDDs. 
In order to achieve the aforementioned objectives the study seeks to answer the following major research question:

What are the benefits and downsides of CDDs for both growth management policy and public service delivery in Florida?

and sub-questions:

1. Which are the contributions of CDDs to growth management in Florida?

2. Which are the contributions of CDDs to infrastructure development in Florida?

3. Are CDDs perceived to be an efficient and responsive institutional model for infrastructure delivery?

\subsection{Research Design}

The present study employs a mixed methodologies approach consisting of both qualitative and quantitative research methods. According to Patton (2002) mixed methodology strengthens the study design because different types of data are expected to offer a better understanding of the subject matter. When used for the same study qualitative and quantitative methods complement each other. While qualitative research focuses on in-depth study of specific cases and contexts, quantitative research follows a linear path focusing on testing hypotheses that are derived from existing theories (Neuman, 2004).

The research design for this study is cross-sectional. The study uses sequential research procedures (Creswell, 2003) consisting of the following steps. The author first uses secondary data sources and document analysis of different official documents and legislation to get a general overview about how CDDs operate and the magnitude of their activity. The second step involves a combination of qualitative and quantitative 
methodologies. The author employs semi-structured interviews for a detailed exploration of CDDs, specifically in the area of the way infrastructure service delivery occurs in local communities. Quantitative analysis draws on secondary data and intends to complement the qualitative inquiry with numerical data about the contribution of CDDs to the infrastructure development in Florida. Last, the author uses a survey of public officials to assess CDDs' pluses and minuses as well as their degree of efficiency and responsiveness.

The document analysis and secondary data analysis aim at providing background information about CDDs and place the districts within a contextual framework. Semistructured interviews serve two purposes. First, they offer a detailed exploration of the CDDs' impacts as institutions of specialized purpose. Second, interviews serve as a means of generating variables to help construct the survey instrument. Since little research has been conducted about CDDs, qualitative research is a useful means of identifying the important variables to be included in the survey. The survey serves as a valuable data collection technique whose purpose is to develop indexes of favorability for CDDs and to assess their strengths and weaknesses.

\subsubsection{Qualitative Methodology}

According to Neuman (2004) "qualitative data (...) involve documenting real events, recording what people say, observing specific behaviors, studying written documents or examining visual images“ (p. 87). Qualitative methods are primarily preferred because they offer an in-depth view about CDD impacts. In qualitative research investigators follow a non-linear path to better understand the details of a particular context (Neuman, 2004). Qualitative methods are very helpful in this instance because it is difficult to quantify something that has not been defined. 
The qualitative data for the present study come from twelve semi-structured interviews which were conducted both on-site and via telephone between January and March 2009. The interviews' participants comprised of seven public officials (four representatives of Planning Departments, one Financial Manager, one Manager of Public Works Division and one County Attorney) and five CDD representatives (three attorneys and two district managers).

The semi-structured interviews are based on an interview guide that is comprised of a list of topics that need to be covered in a particular order (Bernard, 2000, p. 191). Semi-structured interviews are suitable for situations in which the participants comprise of managers, public officials and any other persons with supervisory functions who want to efficiently use their time (Bernard, 2000). Also, semi-structured interviews will allow "elites" to define issues to be used in subsequent research. This type of interview allows the author to use flexibility within a guided framework.

The sampling technique for selecting participants was purposive. Purposive sampling refers to selecting cases with a specific purpose in mind. In this study the purpose was to select participants from the categories of public officials and CDD representatives within the six counties in Florida that had more than thirty CDDs: Hillsborough, Lee, Manatee, Miami-Dade, Pasco and St. Lucie. Since almost half of the CDDs are located within these six counties, the selection of the participants provided valuable information. This type of non-random sampling is adequate when the investigator wants to select unique cases that are informative as well as when the researcher wants to identify certain cases for in-depth investigation (Neuman, 2004).

In order to obtain access to the participants the author followed the following steps. First, the author decided on the categories of participants to be included in the study: public officials and CDD representatives. Then, the author contacted each of the six counties to identify the most knowledgeable public officials about CDDs. With the 
exception of Pasco county the other five (Hillsborough, Lee, Manatee, Miami-Dade and St. Lucie) responded. Cities that have established CDDs within the boundaries of the six counties were also contacted. The only city that responded to the author's request was the City of Ft. Myers. Obtaining participation to CDD representatives involved a selection of representative persons for the six counties according to the list provided by the Florida Department of Community Affairs ${ }^{1}$.

The author developed an interview guide to assure the collection of consistent and reliable data. The research instrument covered the following main areas: CDD functions and activities, services provided and the type of development supported, the way service delivery occurs in local jurisdictions and CDD benefits and costs. The interview guide is attached in Appendix 1. Interviews were recorded with the consent of the participants.

Data obtained from interviews were supplemented with data from document analysis. Document analysis entailed the following types of legal and official documents, reports and publications:

- State Legislation: Florida Statutes, Chapters 163, 189, 190 and Chapter 9J-5 from the Florida Administrative Code

- Petitions for CDD creation in the six aforementioned counties which were obtained from cities, counties and directly from CDDs where necessary

- Official reports and documents from both state and county levels (financial reports, activity reports about special districts and the Florida Special Districts Handbook)

\footnotetext{
${ }^{1}$ The on-line data set about special districts to be found at www. Floridaspecialdistricts.org contains a detailed list for each CDD where the name and contact information for each CDD representative is displayed.
} 


\subsubsection{Quantitative Methodologies}

Quantitative methodologies consisted of both secondary and primary data collection strategies. Secondary data come from Florida Department of Community Affairs, Florida Department of Financial Services and US Census of Governments.

Primary data are the result of a hybrid on-line/mail survey which was administered between February $23^{\text {rd }}$ and mid April, 2010. The survey seemed to be the appropriate means of collecting consistent primary data. At the moment, the Florida Department of Community Affairs is the only agency that collects and publicly releases limited data about special districts, in general, and CDDs, in particular. In order to conduct the present research more detailed data were needed.

The survey design was used because it provides descriptive assertions about a population by analyzing samples of respondents' perceptions (Axinn \& Pearce, 2006; Babbie, 1990; Creswell, 2003). To assess the efficiency of CDDs, a structured method such as a survey instrument provides consistent measures for respondents' perceptions. It is also a fairly rapid and convenient way of collecting primary data regarding perceptions and attitudes of public officials. The author opted for a cross-sectional survey instrument because of time and financial constraints.

The target population for the survey comprised of public officials within all local general-purpose governments (counties and cities) that have established at least one CDD. When selecting the survey respondents the author used cluster sampling. Cluster sampling is appropriate in this instance because there is no good sampling frame (Neuman, 2004). The procedure involved several stages. First, the author selected all the cities and counties that have established CDDs according to the data provided by the Florida Department of Community Affairs. In Florida there are a hundred and three local general-purpose jurisdictions that have established at least one CDD. Thirty four local jurisdictions are counties and sixty nine are cities. The next step of sampling consisted of 
selecting all the departments or divisions that have been involved in the CDD establishment and activity overview. The author searched the websites of local generalpurpose jurisdictions and identified the departments that dealt with the CDD process of establishment. These are: planning and zoning, growth management, county/city manager's office, budget and financial management office, county/city attorney and utilities services. Since not all public officials within these departments were knowledgeable about CDD activity and not all the departments were actually involved in any way, the author obtained names of knowledgeable individuals by e-mailing one or two representatives in each local jurisdiction (usually a member of the Planning and Zoning Department, Growth Management Department or the County/City Attorney's Office). In instances where no recommendation was provided, the author chose the heads of these three departments. The sample consisted of 197 persons. The number of individuals to be surveyed was decided according to the number of CDDs in each county/ municipality as depicted in Table 3.1. The ranges depicted in Table 3.1 were selected according to the suggestions of recommenders and to the minimum knowledgeable persons within any local jurisdiction.

\section{Table 3.1 Selection of Survey Participants}

\begin{tabular}{cc}
\hline Number of CDDs/local jurisdiction & Number of participants selected \\
\hline 1 & 1 \\
$2-7$ & 2 \\
$8-12$ & 3 \\
$13-40$ & 4 \\
$41+$ & 5 \\
\hline
\end{tabular}


Even though cluster sampling is considered less accurate than the simple random sampling (Neuman, 2004, p. 151) in this case the first cluster consisted of the entire population (all the cities and counties that have established CDDs), fact that yielded a representative sample. This is also a subject that does not constitute general knowledge for every staff member within a local jurisdiction's department or division and, therefore, identifying the knowledgeable persons offered meaningful results and a fairly high response rate.

The survey instrument was specifically designed for this study according to the categories identified from the semi-structured interviews and according to the suggestions previously identified in the literature review about special-purpose governments. The content areas addressed in the survey are: CDD structure flexibility, financial implications for general-purpose governments, developers and residents, CDD economic development impacts concerning infrastructure provision and maintenance and CDDs relationship with general-purpose governments. The scales used to measure items in the survey consist of Likert and semantic differential scales. The entire instrument is attached in Appendix 2.

The survey instrument was pilot tested on six persons who were knowledgeable on the subject before the final version was sent out. Pilot testing was important to establish the content validity of the survey instrument and to improve the format of the questions.

The survey was administered as a combination of on-line and mail selfadministered questionnaires. The data were collected in three waves. The first two waves consisted of an on-line survey that was sent out through www.surveymonkey.com. The first electronic wave was sent out on February 23, 2010. A second electronic wave followed up one week and a half after the first one. A third wave consisting of mail selfadministered questionnaires was sent out three weeks after the initial wave. The author 
followed up with phone calls and e-mails two weeks after the third wave as a reminder for those who did not complete the survey.

When administering mail questionnaires, the author followed the principles suggested by Neuman (2004) to increase the response rate. Thus, the questionnaire was accompanied by a cover letter printed on Florida International University's letterhead, which explained the purpose and usefulness of the survey, the selection of participants, statement of confidentiality and willingness to answer, included a small monetary inducement and specified the name and contact information of the researcher. The length of the questionnaire was five double-sided pages. Each mailing was comprised by a cover letter, questionnaire and a post-paid, self-addressed envelope.

The survey response rate was $51 \%$. This rate is fairly realistic these days when 40 to $50 \%$ response rate is the average in social sciences, especially in the United States where "there are refusal rates as high as 30\%" (Neuman, 2004, p. 179). Moreover, the $51 \%$ response rate is consistent with the results of other recent studies (Frank, Philip \& Scutelnicu, 2009) that reported a mean response rate of $49.1 \%$ for survey studies conducted in the public budgeting discipline.

The choice of administering the survey both on-line and by mail was determined by the author's desire to achieve a high response rate given the limited financial resources. While on-line surveys have the advantages of low administering cost and ease in collecting and analyzing data, their disadvantage resides in their low response rate (Dooley, 2001; Neuman, 2004). Mail self-administered questionnaires were needed to boost up the response rate. The two electronic waves collected $23 \%$ of the data the difference up to $51 \%$ was gathered through mail. 


\subsection{Data Analysis}

Data analysis followed three main steps whose findings are presented in Chapters four, five, six and seven respectively. First, an exploratory analysis was conducted to

provide a general overview about special districts in general as well as background information about CDDs' powers, functions, proliferation and activity. Chapter four describes the results for the first step of the analysis. This exploratory analysis consisted of document analysis and secondary data analysis. Document analysis focused mainly on state legislation comprised of Florida Statutes, Chapters 163, 189, 190 and Chapter 9J-5 from the Florida Administrative Code and Florida Special Districts Handbook - a publication of the Florida Department of Community Affairs. Secondary data are publicly accessible data and come from Florida Department of Community Affairs, Florida Department of Financial Services and U.S. Census. Their purpose is to support the narrative part with empirical data about the districts' proliferation and activity.

The second step of the analysis consisted of analyzing the results of the semistructured interviews in conjunction with secondary data coming from the petitions that CDDs have submitted when they were established. The results of this step of the analysis are presented and discussed in detail in chapters five and six.

The qualitative analysis was administered first in order to identify common themes and patterns in the interviews and to find connections among them. As specified before, one of the interviews' purposes was to determine the contribution of CDDs to the public infrastructure in Florida. After transcribing the recorded interviews word-by-word, the analysis focused on identifying common themes, patterns and differences about the impacts of CDDs. In the initial stage of the analysis the author created a list of codes based on a line-by-line analysis of the transcribed interviews. Then, the initial list of codes was reduced to a matrix that served as the basis for the qualitative analysis. The 
last step of the qualitative analysis tried to relate the common themes and patterns among them and generate more general explanations.

The qualitative analysis revealed emerging themes related to CDD profile, the types of infrastructure provided by districts, the role of CDDs as both providers and maintainers of infrastructure services, the type of development they support as well as the CDDs' perceived advantages and disadvantages. In order to validate the findings from the qualitative analysis the author followed-up with a quantitative analysis of secondary data coming from the petitions which CDDs submitted when they were established as well as financial reports from the Florida Department of Financial Services. Thus, the results of the qualitative analysis were supplemented with descriptive secondary data analysis about CDD characteristics, their financial activity and the types of development they support within the six aforementioned counties.

Considering the fact that the CDD process of establishment by local and state authorities differs considerably, this study considered only those CDDs that were established through ordinances of local general-purpose governments (counties and cities) and not those established through the Rule of the Florida Land and Water Adjudicatory Commission. Copies of the CDD petitions located within six Florida counties (Hillsborough, Lee, Manatee, Miami-Dade, Pasco and St. Lucie) were obtained from the local general-purpose governments within which districts are located. The missing data were partially completed from requests submitted directly to CDDs. Secondary data consisted only of the petitions of the active districts that were established by local general-purpose governments until April 2009. Out of a total of 274 active CDDs, the author was able to obtain pertinent data for 257 districts. The missing data could not be collected either because they were not on file anymore with local generalpurpose governments or the CDDs did not respond to the author's information request. 
The variables included in the second step of the analysis consisted of the following. The dependent variable was the total number of services provided by CDDs. Independent variables referred to district size, district year of establishment, the county in which CDDs were located, CDD status location (CDDs located in unincorporated areas vs. districts located in incorporated areas), geographical location (CDDs located on the west coast vs. districts located on the east coast), the type of development CDD support, three dummy variables measuring whether districts have special powers, whether districts provide off-site improvements and whether districts have outstanding debt, number of public facilities owned and maintained by CDD as well as financial characteristics such as total revenues, expenditures, amount of outstanding debt and CDD estimated infrastructure costs.

The secondary data were analyzed by using univariate descriptive statistics, contingency tables and multiple regression analysis which were performed using the SPSS statistical package. Each method of analysis served different purposes. Univariate descriptive statistics described trends and patterns across CDD characteristics and, thus, supplemented the findings from the qualitative analysis. Contingency tables identified significant differences for the infrastructure provided by CDDs. They represent a reliable visual way of presenting the frequency of each value of the dependent variable for each value of the independent variable (O’Sullivan, Rassel \& Berner, 2003). Furthermore, contingency tables are useful in analyzing relationships between variables that are measured at nominal and ordinal level (Frankfort-Nachmias \& Leon-Guerrero, 2006).

Finally, multiple regression analysis was employed to determine the factors that contributed to the infrastructure variation among CDDs. Multiple regression analysis was used to examine the effect of different independent variables on a single dependent variable and to estimate the magnitude of that effect (Aiken, West \& Pitts, 2003; Allison, 1999). The usefulness of multiple regression analysis is that it separates and examines the 
effects and contribution of each independent variable on the dependent variable (Allison, 1999).

The regression analysis used the stepwise method for exploratory purposes. Initially, a number of seven independent variables were retained for the multivariate regression analysis because they had significant correlations with the dependent variable. Four out of the seven selected independent variables were significant in explaining the variance in the final model. These were: number of services that were owned and maintained by CDDs, whether CDDs had optional special powers or not, CDD estimated infrastructure costs and whether CDDs were located in unincorporated vs. incorporated areas.

The final step of data analysis refers to the analysis of the data collected through the survey. The results for this step are described in chapter seven. The analysis of the survey data served two main purposes. First, the survey aimed at analyzing the perceived advantages and disadvantages of CDDs on service delivery by using univariate and bivariate descriptive statistics. Descriptive statistics helped at describing the demographic and professional composition of the survey participants as well as at summarizing key information about survey items. Cross-tabulations intended to identify significant relationships between the demographic and professional indicators and the survey items. The study used Gamma as a measure of association because all of the survey items are measured at the ordinal level and the demographic and professional indicators have dichotomous values. Dichotomous nominal variables may be analyzed using ordinal measures of association (Frankfort-Nachmias \& Leon-Guerrero, 2006; O’Sullivan et. al., 2003).

The second purpose of this analysis was to assess the efficiency and responsiveness of CDDs by constructing indexes of favorability. To achieve this scope factor analysis was conducted in order to reduce the survey data to an appropriate number 
of common factors. Factor analysis (FA) is a data reduction statistical analysis technique that aims at identifying factors that explain the variation among variables (Green \& Salkind, 2005, p. 312). It is derived from the concept of association among variables and it shows the degree to which variables are measuring common factors (O'Sullivan et. al., 2003). The scope of conducting exploratory FA was to reduce the number of variables into common factors that helped construct composite measures reflecting CDD favorability. Principal component analysis was chosen because it is more common in exploratory studies and its usefulness resides in the fact that it generates factors that are used in subsequent analysis (Bryant \& Yarnold, 1995).

Principal component FA with varimax rotation was conducted to explore seventeen items of the CDDs survey. There were four problematic items that were eliminated from the analysis because they were cross-loading with several variables and they did not belong to the factor structure. Principal component analysis indentified five major factors as representatives for the perceptions of public officials. These are: CDD cost-effectiveness, managerial responsiveness, institutional flexibility, financial mechanisms and developers' interests.

On the basis of the results of FA three indexes reflecting CDD favorability on part of public officials were constructed and described. These indexes measure practitioners' general perceptions about developing and implementing CDDs. The option of developing composite measures resides in the fact that indexes are expected to have higher reliability and validity than individual variables (Babbie, 1990; Neuman, 2004; O’Sullivan, et al., 2003). The composite measures were created by adding up the scores for the survey items comprising the first three extracted factors in the principal component analysis. The items in each index were given equal values. Index items are supposed to be weighted equally unless there are theoretical or methodological reasons for weighing them differently 
(Babbie, 1990; Neuman, 2004). The three indexes were validated by conducting reliability analysis.

Finally, the last stage of the survey analysis focused on the qualitative analysis of one survey item that described the perceived drawbacks of CDD implementation in the State of Florida. Common themes and patterns were first identified to summarize the views of the respondents into six main categories that reflected CDDs' shortcomings. Then, additional recommendations that might be changed in the future implementation of CDDs were presented to offer a comprehensive view of the respondents.

\subsection{Reliability and Validity Issues}

Although triangulation is probably the most complex way of researching the subject, there might be some threats to the reliability and validity of the study. Reliability means consistency or dependability of the researched constructs. The semi-structured interviews may generate low reliability since they are difficult to replicate and interviewees might not have expressed their honest views. Using a pilot test increased the reliability of the survey constructs. Also, the creation of indexes improves reliability by using multiple indicators for a construct, by weighing and standardizing data (Neuman, 2004).

Validity refers to the truthfulness of a measurement. In this study, mixed methodology is perceived as a means of assuring validity of the data. The accuracy of the findings is ensured by the review provided by experts in the field. The study may suffer of low external validity since the results of this study cannot be directly generalized to other states in the United States. However, CDDs have definitely potential for other states that need to manage and finance infrastructure improvements. 
Another issue of this study refers to the non-involvement of developers. This fact may bias the research findings towards the views of public officials and CDD representatives. Initially developers were considered for inclusion in the study. In order to identify developers who initiated CDDs in Florida the author both requested information from the interview participants and conducted an internet search. The result was the creation of a developers' database. After several failed attempts (e-mails and telephone calls) to get in touch with developers the author decided to exclude them from the present study and acknowledge this limitation.

The author also acknowledges the fact that both the interviewees and the respondents to the survey might not offer honest and complete answers. The findings of the study are expected to point at the advantages and disadvantages of CDD as an institutional means of financing infrastructure and creating new communities for other states that favor special-purpose governments.

\subsection{Summary}

The present chapter described how the research methodology is used in this study. It started with the description of the purpose and objectives of the study as well as the research questions to be addressed. Then, it presented the research design as a sequential mixed-methods one and detailed each approaches to research (qualitative and quantitative) according to the following elements: target population and sampling techniques, data collection sources and the research instruments for data collection. Data analysis was described as a series of steps, beginning with an exploratory analysis that offered background information about CDDs, following up with a combination of semistructured interviews and secondary data analysis and finishing with a quantitative 
analysis that draws on survey collected-data. Finally, the author acknowledges possible limitations of the study. 


\section{CHAPTER IV}

\section{TOWARDS A BETTER UNDERSTANDING OF SPECIAL DISTRICTS: THE CASE OF COMMUNITY DEVELOPMENT DISTRICTS}

\subsection{Introduction}

The scope of this chapter is to place and explain the specific case of Community Development Districts (CDDs) within the broader context of specialized governance. The present chapter is divided into two main parts. The first part provides a descriptive overview of special districts by focusing on the characteristics that differentiate them from general-purpose governments (narrow function, institutional independence, geographic flexibility and low political visibility) as well as on the districts' advantages and disadvantages. Further, the chapter briefly portrays the picture of the special districts within the State of Florida by discussing the main provisions of Chapter 189 Florida Statutes as well as the functions that special districts fulfill. The second part presents an exploratory analysis about CDDs. It describes CDD creation, the planning and financial contexts within which CDDs should be understood, it presents an outline of CDDs by documenting their proliferation and distribution throughout Florida as well as their powers, functions and financial activity. 


\subsection{Special Districts}

\subsubsection{General Overview}

Special districts represent an important component of the American governing structure. They are independent, special-purpose units of local government (other than counties, municipalities, townships or school districts) that have administrative and financial independence from general-purpose governments such as counties and cities (US Census, 2007). These entities of government are established by a legislative body to provide specialized services within limited boundaries (Mitchell, 1999).

Special districts are the most common form of local government. According to US Census (2007) there are 89,425 local governments in the United States. Special districts represent $41.8 \%$ of the total number of local governments, followed by municipalities with $21.80 \%$, townships with $18.47 \%$ and counties with $3.39 \%$. Besides being the most common form of local government, special districts have also increased dramatically in the last five decades. Districts more than doubled their number in the last 55 years in comparison with a $16 \%$ increase for municipalities and a slight decrease of $0.62 \%$ for counties and $4 \%$ for townships. This increase of special districts is explained through different reasons: service delivery for certain areas is better handled by special districts (Bollens, 1957), districts were created as a consequence of legal, institutional and political factors (Foster, 1997) and districts are financial mechanisms (Leigland, 1994; Porter et. al., 1992) whose proliferation overcomes the fiscal restrictions placed on local general-purpose governments (Bowler \& Donovan, 2004; McCabe, 2000).

The extant literature distinguishes special purpose governments by different names. Eger III (2006) views special purpose entities as theoretical entities that have different names: "public authorities," “special districts," and "government corporations." Porter et. al. (1992) acknowledge that special districts are known by 
different names such as districts, authorities, boards and commissions. Foster (1997) divides special-purpose governments in two categories: "taxing districts" which are local governmental entities with the power to tax and levy special assessments and "public authorities" which are government corporations without property taxing powers. Even though the aforementioned typologies "public authorities," "special districts," “"government corporations," "boards" and "commissions" are used interchangeably in the literature, the present study will focus on the category of special districts.

\subsubsection{Characteristics of Special Districts}

To better understand what special districts are and how they operate, it is imperative to briefly describe their characteristics. This section focuses on those features that distinguish special-purpose from general-purpose governments.

Special districts are governmental entities with narrow functions that combine features of both public and private governmental units (Foster, 1997). Special districts are similar to other forms of local government by exercising powers such as: the right to enter into contracts and expend monies, to sue and be sued, to obtain and dispose of property, to raise funds through taxes, fees and assessments as well as to borrow money, to enter into agreements with other governmental entities, to exercise the power of eminent domain and to use public easements and rights-of-way and so on. What differentiates special districts from general-purpose governments is what districts cannot do. They lack police powers, land-use control powers and they require state legislative approval to change their functions. Special districts resemble private companies because they are exempt from state constitutional limits on borrowing and property taxation (Bunch 1991; MacManus, 1981; McCabe, 2000) and because they are exempt from civil service, procurement and pension fund requirements (Foster, 1997). 
Special districts are characterized by functional specialization. Foster (1997) defines special districts as "autonomous local governments that provide a single or limited services" (p. 2). Most special districts are established to perform a single function, but some are authorized to provide several types of services. The 2002 US Census shows that most $(91 \%)$ of special districts performed a single function while $9 \%$ of them performed multiple functions. Some states (such as Illinois, Texas, California, Florida and Pennsylvania) enabled the creation of multipurpose districts that can supply most of the infrastructure needed for new development (Porter, 2008).

According to Porter et. al. (1992) special districts were traditionally established in the 1800 's to cover functions such as toll roads and canal corporations. Among the initial reasons that accounted for special districts proliferation were federal government intervention in local service delivery and the possibility of using revenue bonds to finance local government services (Foster, 1997; Porter et. al., 1992). Many states adopted legislation pertaining to the creation of special districts due to public debt limits on local general purpose governments (Bunch, 1991), tax and expenditure limitations imposed on local general-purpose governments (Bowler \& Donovan, 2004) and a need to accommodate new development (Porter et. al., 1992).

Today, special districts are created to provide certain services in areas where general-purpose governments lack administrative capacity and financial resources. The functions of most special districts are dealing with water, housing, community development, fire protection or flood control, utilities, highways, irrigation, parks and recreation, soil conservation, health, hospitals, libraries and so on. Furthermore, special districts are differentiated by various districts subtypes according to their functions, size, structure, policy implications and outcomes (Foster, 1997).

Districts are noted for their institutional independence from general-purpose governments. They decide on their administrative and financial issues and are subject to 
little or no oversight from general-purpose governments. Districts are governed by independent boards of supervisors which are either elected or appointed. They collect their revenues from ad-valorem taxes on property and other financial sources such as special assessments, service charges and fees, rates etc. Most special districts can issue bonds which are secured through assessments, fees and charges.

These entities can be classified as dependent and independent. The difference between independent and dependent districts is determined by their autonomy from state or local control. While dependent districts are established and controlled directly by local governments, the independent districts enjoy a higher administrative and financial autonomy. They are governed by an elected board of supervisors and enjoy financial flexibility by determining their budgets, levying taxes, assessments and charges and issuing debt as well as by functioning with little or no oversight from general-purpose governments (Porter et. al., 1992).

Unlike general-purpose local governments, special districts are characterized by geographic flexibility. They can be located on the territory of other special and/or general-purpose government, thus partially or totally overlapping other jurisdictions. Jurisdictional overlap is essential to special-purpose governments: "specialized governments, by their nature, exist in groups, each relying on others as well as on general-purpose governments, to provide essential services” (Berry, 2009, p. 45).

Last but not least, special districts are also known for their low political visibility. Low visibility encourages political abuse (Porter, 1997) because of a lack of oversight from general-purpose governments that may discourage citizen control (Bollens, 1957). By enjoying low political visibility, special districts decisions are rarely subject to public debate. Most of the time citizens do not understand that a service is being provided by a jurisdiction that is politically independent from a general-purpose government. Therefore, it is these four particular characteristics: narrow purpose, administrative and financial 
independence, geographic flexibility and low political visibility that differentiate special from general-purpose governments.

\subsubsection{Special Districts Advantages and Disadvantages}

As entities of government, special districts present both advantages and disadvantages. Among the advantages the author would like to mention the following. First, special districts can provide services in areas where general-purpose governments have limited financial and administrative capacities (Porter, 2008). Unlike generalpurpose governments which provide services regardless of citizen demand, special districts provide services that are tailored toward the community needs.

Second, special districts are considered to be independent from politics because they enjoy administrative and financial autonomy (Porter et. al., 1992). Third, districts are considered more efficient in delivering services due to their narrow scope (Porter, 2008). In comparison to general-purpose governments which handle a variety of functions, special districts focus on one or a few limited functions and, therefore, are expected to perform better than the former.

Fourth, special districts are favored because they finance facilities for new development (Porter, 1997) usually at no direct cost to general-purpose governments. Fifth, these entities shift the cost of improvements to those who directly benefit from them and not to the general public (Porter et.al., 1992). Sixth, the use of special districts allows communities to raise revenues without increasing general taxes. In addition, special districts may be seen as a mechanism for financing infrastructure (Porter, 1997) that spread the payment over 20-30 years due to their ability to issue bonds. Lastly, districts are supposed to be responsive to their constituents (Bartling, 2007) because most special districts are geographically smaller and have fewer residents than counties and cities. 
Not only have special districts been praised but they have also been criticized. Special districts have often been criticized because they encourage governmental fragmentation both geopolitically (jurisdictional fragmentation) and functionally generating coordination issues and administrative inefficiencies (Foster, 1997). The existence of special districts weakens the powers of general-purpose governments by removing specific functions from the latter (Bollens, 1957; Porter, 1997) and by leading to an inequitable distribution of services (Chicoine \& Walzer, 1985).

Special districts are considered uneconomic entities. As a result of their small size and their functional specialization, the services provided by districts tend to be more expensive and less efficient than those of general-purpose governments (Berry, 2009; Bollens, 1961; Foster, 1997). Third, special districts may offer an irresponsible provision of services because they do not coordinate their actions with those of general-purpose local governments (Porter et. al., 1992).

Another criticism of special districts resides in their low political visibility as they have been labeled "shadow governments" (Axelrod, 1992; Eger III, 2006). Special districts may create confusion among residents as to which jurisdiction (a generalpurpose or a special-purpose government) has responsibility for providing certain services (Carr, 2004).

Special districts operate with little or no oversight from state and local generalpurpose governments, fact that may foster opportunities for political abuse (Porter, 1997; Porter et. al., 1992) and may impede citizen control (Bollens, 1957). Finally, special districts have also been criticized because they support mainly the interests of private developers (Burns, 1994; Porter et al., 1992). 


\subsubsection{Summary}

To sum up, special districts have been the fastest growing form of local governments in the last fifty-five years. Their specific characteristics are narrow purpose, specialized function(s), institutional independence, geographic flexibility and low political visibility. It is these features that distinguish them from general-purpose governments.

In theory, special districts have both pluses and minuses. On one hand, they benefit communities through quality service provision in areas where general-purpose governments are unable to provide them, through their efficiency and responsiveness in delivering services, through their capacity to raise revenues without increasing taxes, through their ability to link costs directly to those who benefit from the services provided as well as through their capacity to finance infrastructure improvements.

On the other hand, districts may have some negative implications. They may encourage governmental fragmentation, can facilitate fiscal abuse due to a lack of local general-purpose government oversight, may deliver expensive, inefficient and irresponsible services and they may create confusion among citizens due to their low political visibility.

\subsection{Special Districts in Florida}

This section provides a brief overview about the types, functions and powers of special districts in Florida to place the CDDs within a broader framework. In Florida, special districts were first created in the mid 1800s to solve public transportation needs and to coordinate public functions such as drainage and land management. In the mid 1900s and especially, after World War II, as a response to the Florida land development and its population increase, there was a need for more specialized districts such as 
mosquito control, aviation authorities, beach erosion, hospital, and fire control districts (Florida Special Districts Handbook, on-line). Today, there are approximately 1,628 active special districts in Florida ${ }^{2}$ that cover a diverse array of functions ranging from community development and redevelopment, to water management and control, to educational and health care facilities, to housing and recreation etc.

The comprehensive law for special districts titled The Uniform Special District Accountability Act of 1989 was adopted "to have one centralized location for all legislation governing special districts” (§189.402(2) Fla. Stat., 1989). It contains provisions regarding the creation, operation, financial reporting, taxation, elections, compliance with general law provisions and comprehensive planning of special districts (Florida Special District Handbook, on-line). Chapter 189 Florida Statutes (Fla. Stat.) defines special districts as "local units of special purposes as opposed to general purpose government located within a limited boundary and created by general law, special act, local ordinance or by Rule of the Governor and Cabinet” (\$189.403(1) Fla. Stat., 1989). The law clearly states that the term "special districts" does not include school districts, community college districts, improvement districts, municipal service taxing/benefit unit or entities that provide electrical service.

As mentioned earlier, special districts can be classified as dependent and independent. Chapter 189 Fla. Stat. defines the status of districts as follows. A dependent district is one that meets at least one of the following four criteria: it has a governing body identical to that of a general-purpose government; all board members are appointed by a general-purpose government; the board members can be removed by the generalpurpose government and the district's budget requires approval from the general-purpose government (§189.403 (a-d) Fla. Stat., 1989). An independent district is not a dependent

\footnotetext{
${ }^{2}$ As of September 1, 2010
} 
district as defined above. It is a special district that has administrative and financial independence. The independent special district is governed by an independent body of administrators and has financial control over its operations; it determines its budget, levies taxes and charges, issues debt, elects a board of directors, employs staff and consultants and operates facilities with little or no oversight from general-purpose government. Independent special districts may have appointed or elected governing board members, or a combination of both. In most states, local general-purpose governments must agree to the creation of special districts (Porter et. al., 1992).

As depicted in Table 4.1, in Florida there are more independent than dependent districts: more than $62 \%$ of the special districts are independent.

Table 4.1 The Status of Special Districts in Florida

\begin{tabular}{lccc}
\hline District status & Dependent & Independent & Total \\
\hline Number of districts & 617 & 1011 & 1628 \\
Percentage of districts & $37.9 \%$ & $62.1 \%$ & $100 \%$ \\
\hline
\end{tabular}

Source: www.FloridaSpecialDistricts.org

In Florida there are different types of special districts, each type with its specific powers. The functions of most special districts refer to community development and redevelopment, water, housing, fire protection or flood control. Other purposes of these entities include irrigation, health facilities, libraries, airports, industrial development, parks and recreation, soil conservation, highways, mosquito control and the like.

The functions of dependent districts can be seen in Table 4.2, with the top five functions being community redevelopment (30.69\%), housing authority (10.23\%), subdivision/maintenance (7.94\%), neighborhood improvement (5.04\%) and health facilities $(4.58 \%)$. 
For the independent districts the top five functions are illustrated in Table 4.3: community development (54.58\%), drainage and water control (7.27\%), soil and water conservation (5.57\%), fire control and rescue (5.29\%) and hospital (2.64\%).

\section{Table 4.2 Types of Functions by Dependent Status}

\begin{tabular}{lc}
\hline Function & Percentage \\
\hline Community Redevelopment & $30.69 \%$ \\
Housing Authority & $10.23 \%$ \\
Subdivision/Maintenance & $7.94 \%$ \\
Neighborhood Improvement & $5.04 \%$ \\
Health Facilities & $4.58 \%$ \\
Housing Finance & $4.12 \%$ \\
Industrial Development & $3.66 \%$ \\
Library & $2.75 \%$ \\
Drainage \& Water Control & $2.60 \%$ \\
Airport/Aviation & $2.44 \%$ \\
Water \& Sewer & $2.14 \%$ \\
Downtown Development & $1.83 \%$ \\
Educational Facilities & $1.83 \%$ \\
Municipal Services & $1.83 \%$ \\
Fire Control \& Rescue & $1.68 \%$ \\
Port & $1.37 \%$ \\
Expressways \& Bridges & $1.07 \%$ \\
Recreation/Parks & $1.07 \%$ \\
Other & $13.13 \%$ \\
\hline Total & $100 \%$ \\
\hline Source & \\
\hline
\end{tabular}

Source: www.FloridaSpecialDistricts.org ${ }^{3}$

\footnotetext{
${ }^{3}$ Functions that accounted for $1 \%$ or less are listed under other. A detailed list of all the functions can be found in Appendix 3
} 
Dependent districts enjoy a wider variation than independent districts in terms of functions fulfilled. More than half of the dependent districts perform functions pertaining to community redevelopment, housing and neighborhood maintenance and improvement whereas $54.5 \%$ of the independent districts perform activities solely in the area of community development.

\section{Table 4.3 Types of Functions by Independent Status}

Function

Community Development

Drainage \& Water Control

Soil \& Water Conservation

Fire Control \& Rescue

Hospital

Housing Authority

Recreation/Parks

Mosquito Control

Expressways \& Bridges

Library

Transportation

Water Supply

Water \& Sewer

Airport/Aviation

Other

Total

Source: www.FloridaSpecialDistricts.org

\section{Percentage}

$54.58 \%$

$7.27 \%$

$5.57 \%$

$5.29 \%$

$2.64 \%$

$2.46 \%$

$1.61 \%$

$1.42 \%$

$1.32 \%$

$1.32 \%$

$1.23 \%$

$1.13 \%$

$1.13 \%$

$1.04 \%$

$11.99 \%$

$100 \%$

While special districts can perform almost any function, the most common performed functions by both dependent and independent districts are referring to water management and control, transportation, housing, library and recreation. Within the State of Florida, the status of a district seems to show preference for particular functions: 
dependent districts favor several areas such as community redevelopment, neighborhood improvement, housing finance and educational facilities while independent districts favor mostly the community development function. The preference for supporting the aforementioned functions as well as the high number of special districts is driven both by a rapid population growth that occurred in the State of Florida in the last 60 years as well as a tax aversion sentiment among Floridians. Florida's population grew extensively from 2.77 million people in 1950 (US Census, 1950) to 15.98 million in 2000 (US Census, 2000) and to 18.53 million in 2009 (US Census, 2009).

The Florida comprehensive law on special districts addresses major issues with regard to creation, powers, functions, financing, merger or dissolution and elections of both independent and dependent special districts. It entrusts the Florida Department of Community Affairs to create and keep an official list of all special districts within the State of Florida. The Special District Information Program was thus created within the Florida Department of Community Affairs and, according to the Florida Special District Handbook (on-line, section 1-3) the program is serving three roles. First, it is a clearinghouse by collecting, maintaining and updating information about each special district. Second, it provides technical assistance to special districts. And, third, it monitors special-districts to comply with reporting requirements and helps local generalpurpose governments and state agencies to collect delinquent reports from special districts.

Another intent of the Uniform Special District Accountability Act of 1989 was to promote coordination between special districts and local general-purpose governments in order to develop comprehensive plans subject to the Local Government Comprehensive Planning and Land Development Regulation Act (Fla. Stat. 163, part II, 1985). Therefore, state legislation requires each special district to submit a public facilities report and any annual notice of changes to the containing general-purpose government as well as an 
updated facilities report every five years. The public facilities report should describe the existing facilities and their operating capacities as well as the proposed facilities to be built in the next five years; it should be submitted one year after the district is created. Even though state legislation identifies the need of coordinating special districts' infrastructure with that of local general-purpose governments, it does not enforce such a provision and leaves it to the discretion of local general-purpose governments which "may use and rely upon" public facilities reports (\$189.415(6) Fla. Stat., 1989).

Chapter 189 Fla. Stat. also addresses accountability issues. According to the enabling legislation, special districts have to report to three types of authorities. First, each special district must submit the following reports to state agencies: the annual financial report, the annual financial audit report, bond reports and retirement system reports. Second, each special district must submit other types of reports to the local general-purpose government in which it is located such as public facilities reports, designation of registered office and agent and regular public meeting schedule. Third, each special district must file the following documents with the Special District Information Program: creation documents and amendments, a written statement about the basis for its independent or dependent status and a map of the district. In cases when special districts do not comply with the reporting requirements the Florida Department of Community Affairs provides technical assistance and may initiate enforcement.

In conclusion, in Florida special districts are subject to the legislative regulations of the Chapter 189 Fla. Stat. The state law contains provisions about the special districts' creation, powers, operation, financing, compliance with state laws and comprehensive planning.

According to the Florida Department of Community Affairs as of September 1, 2010 there were a total of 1616 active special districts in the State of Florida. Districts perform a variety of functions ranging from community development and redevelopment, 
water, housing, fire protection, flood control, irrigation, health facilities, libraries, airports, industrial development, parks and recreation, soil conservation, highways, mosquito control and the like. Out of all these functions, community development occupies the first place, with more than one third of special districts performing it.

\subsection{Community Development Districts}

This part of the chapter aims at offering background information about CDDs. It first describes the historical and financial contexts within which CDDs were created. Then, an overview of the creation, proliferation, activity and finances of CDDs is provided. This exploratory analysis draws on document analysis (Florida State legislation, Florida Special Districts Handbook) as well as secondary data from the Florida Department of Community Affairs, Florida Department of Financial Services and US Census Bureau.

\subsubsection{Historical Context of Community Development Districts}

Community Development Districts (CDDs) are multi-purpose, independent special districts, empowered to plan, manage, finance and construct infrastructure services that accommodate new development. The CDDs are authorized to issue taxexempt government bonds, typically backed up by special assessments, ad-valorem taxes and charges on homebuyers. The State of Florida enabled the creation of this type of special districts through the Chapter 190 Florida Statute (Fla. Stat.), entitled The Uniform Community Development Districts Act of 1980, as a response to the inability of local general-purpose governments to provide adequate infrastructure to service growth.

As a result of the population growth experienced by the State of Florida during the 1950s and 1960s, local governments faced the burden of inadequate infrastructure services. According to US Census (1960) Florida's population almost doubled from 2.77 
million in 1950 to 4.95 million in 1960 and local governments had to find solutions to provide the necessary infrastructure aimed at accommodating new development.

Chapter 190 Fla. Stat. should be understood as a solution to the Florida legislature to adhere to a uniform method for establishing CDDs, thus overcoming the timeconsuming procedures of creating various special districts. In 1972 the Florida Environmental Land and Management Study (ELMS) Committee was established to manage the unplanned growth within the state of Florida. One of the ELMS committee recommendations was to create special districts that provide basic infrastructure services such as water, sewer, drainage and roads in large scale developments which had to be approved as Developments of Regional Impact (DRI). As a consequence of the ELMS recommendation, the New Community Districts Act was adopted in 1975. The Act of 1975 gave landowners the opportunity of creating special districts to fund the needed infrastructure for new communities but the act "tied the districts approval to development orders" (Florida Atlantic University/Florida International University Joint Center for Environmental and Urban Problems, 1995, p. 1). Since the process of establishing DRI's was extremely tedious and expensive no districts were established under this law. Chapter 190 Fla. Stat. was adopted five years later and, unlike its predecessor, it encouraged landowners to create districts for infrastructure services by separating district approval process from the development approval (Florida Atlantic University/Florida International University Joint Center for Environmental and Urban Problems, 1995, p. 5).

One predecessor of CDDs is Reedy Creek Improvement District which was established as "a catch-all municipal authority for governing development on Disney's land" (Bartling, 2007, p. 3). The establishment of the Reedy Creek Improvement District paved the way for special districts as providers of infrastructure services (Bartling, 2007). The passage of Chapter 190 Fla. Stat. provided for a uniform method for establishing CDDs and it has been considered "an attempt to offset past special district abuses and to 
curtail the proliferation of special acts" (Florida Atlantic University/Florida International University Joint Center for Environmental and Urban Problems, 1995, p. i).

\subsubsection{Financial Context}

The creation of CDDs, in particular, and special districts, in general, should also be related to the fiscal environment of tax and expenditure limitations imposed by states on municipalities. In the United States capital projects have been the responsibility of local governments rather than the national level since the $19^{\text {th }}$ century. At the turn of the $20^{\text {th }}$ century local governments (especially cities) have become major service providers in the areas of infrastructure provision and economic development. "Municipal governments carried out huge capital projects (...) city governments provided the most extensive, most advanced public services" (Sbragia, 1996, p. 65). Because of the magnitude of their capital projects cities have become "visible borrowers" (Sbragia, 1996) and states had to impose debt limits on municipalities through constitutional amendments and statutory laws. The limits referred to applying a specific percentage of the assessed property value and to the requirement of electorate's bond issues approval. At the same time, the citizens' dissatisfaction with the high level of government spending, dissatisfaction manifested through the tax revolt of the 1970s led to the imposition of tax and expenditure limitations (TELs).

In Florida TELs are mainly concerned with ad-valorem taxes. There are several categories of limitations on the ability of local governments to levy ad-valorem taxes. First, there are limitations on the rate of taxes expressed through caps on property mills. In 1980, the Florida legislature passed the "Truth in Millage" Act which "establishes the statutory requirements that all taxing authorities levying a millage must follow all notices

and budget hearing requirements" (Florida Department of Revenues, on-line). These requirements were supplemented in 2007 to provide for maximum tax levies for counties, 
municipalities and independent special districts. Ad-valorem taxes may be increased above the maximum specified rate only with supermajority and unanimous votes. There are also referendum requirements for issuing general obligation debt.

The Florida Constitution authorizes a tax exemption on homestead property for the first $\$ 25,000$ of assessed value of homestead property to be exempted from taxation. (Art.VII, §6(a) Fla. Const.). In 2008, voters approved the increase in exemption up to $\$ 50,000$ (Art.VII, §6(b) Fla. Const.). Beginning in 1995 the Florida "Save our Homes" constitutional amendment limited the annual increase in the assessed value of homesteaded properties to the lower limit of either 3\% or the National Consumer Price Index (§193.155(1) Fla. Stat., on-line). Finally, in 2009 a 10\% cap on increases in assessed value of non-homestead properties was adopted (Art.VII, § 4(g) Fla. Const.).

As a response to state limitations, local governments developed means of circumventing them. Among the most famous mechanisms for escaping tax and debt limits were federal tax exemption on municipal bonds, the adoption of revenue bonds and the creation of new governmental units such as special districts, public authorities, public corporations and the like. The municipal revenue bond was an important financial mechanism since 1930s (Vogt, 2004) and by mid 20 th century there was an extensive increase in the number of special-purpose governments such as special districts and public authorities (Pagano \& Perry, 2008). In 1980s special-purpose governments were considered to have taken over significantly the responsibility for local capital investment (Sbragia, 1996, p. 191).

In order to finance capital projects and economic development local governments used the strategy of circumventing the state limits placed on municipal spending and tax limits. The mechanisms of circumvention referred to use of revenue bonds, federal tax exemption on municipal bonds and the creation of special-purpose governments such as special districts and public authorities. 


\subsubsection{Growth Management Context}

The context within which CDDs were created should be related to the concurrency requirement of the Florida growth management legislation. The CDDs have proliferated once the 1985 Florida Growth Management Act was adopted. Concurrency required that adequate public facilities be available or fiscally accounted for prior to or concurrent with new development but the state legislation did not address how the infrastructure development was going to be funded. Therefore, local governments had to identify financial sources for infrastructure development and special purposegovernments, in general, and CDDs, in particular, represented one of those sources. From this perspective CDDs can be useful financial mechanisms for infrastructure improvements which may fulfill the concurrency requirement for development, ensuring that adequate public facilities are in place in a timely manner. Thus, districts can coordinate infrastructure provision with new development and fund the "unfunded mandate of concurrency."

\subsubsection{CDD Creation and Establishment}

The justification for the creation of CDDs is considered as "a way for development to pay for itself" (Bartling, 2007; Nicholas \& Chapin, 2007) by providing basic infrastructure improvements and ensuring its long-term maintenance. Even though any entity or person can submit a petition for CDD formation, including a county or a city, their formation is, generally, initiated by landowners/developers who petition their surrounding local general-purpose government to create a CDD.

Each petition should include the following: name of the district, a description of the CDD external boundaries, a written consent to establishment of all landowners who own property within the district, initial designated board of supervisors, a map of the district which should contain existing utilities if any, proposed timetable and estimated 
costs for construction, a designation of the future public and private uses of land for the area and a statement of estimated regulatory costs (§190.005(a) Fla. Stat., 1980). After conducting a public hearing, the Florida Land and Water Adjudicatory Commission or local general-purpose governments can determine whether to grant or deny a petition for the district's establishment according to six factors set forth in $§ 190.005(\mathrm{e})$ Fla. Stat.

The Law distinguishes the CDD process of establishment according to their size ( $\$ 190.005$ Fla. Stat.). Therefore, a CDD containing 1,000 acres or more is established through the Rule of the Florida Land and Water Adjudicatory Commission (consisting of the Governor and the Cabinet) while a CDD with less than 1,000 acres in size is established by an ordinance adopted by the board of county commissioners, (with the approval of the municipality that contains the CDD) or through an ordinance adopted by a municipality.

Figure 4.1 CDD Method of Establishment

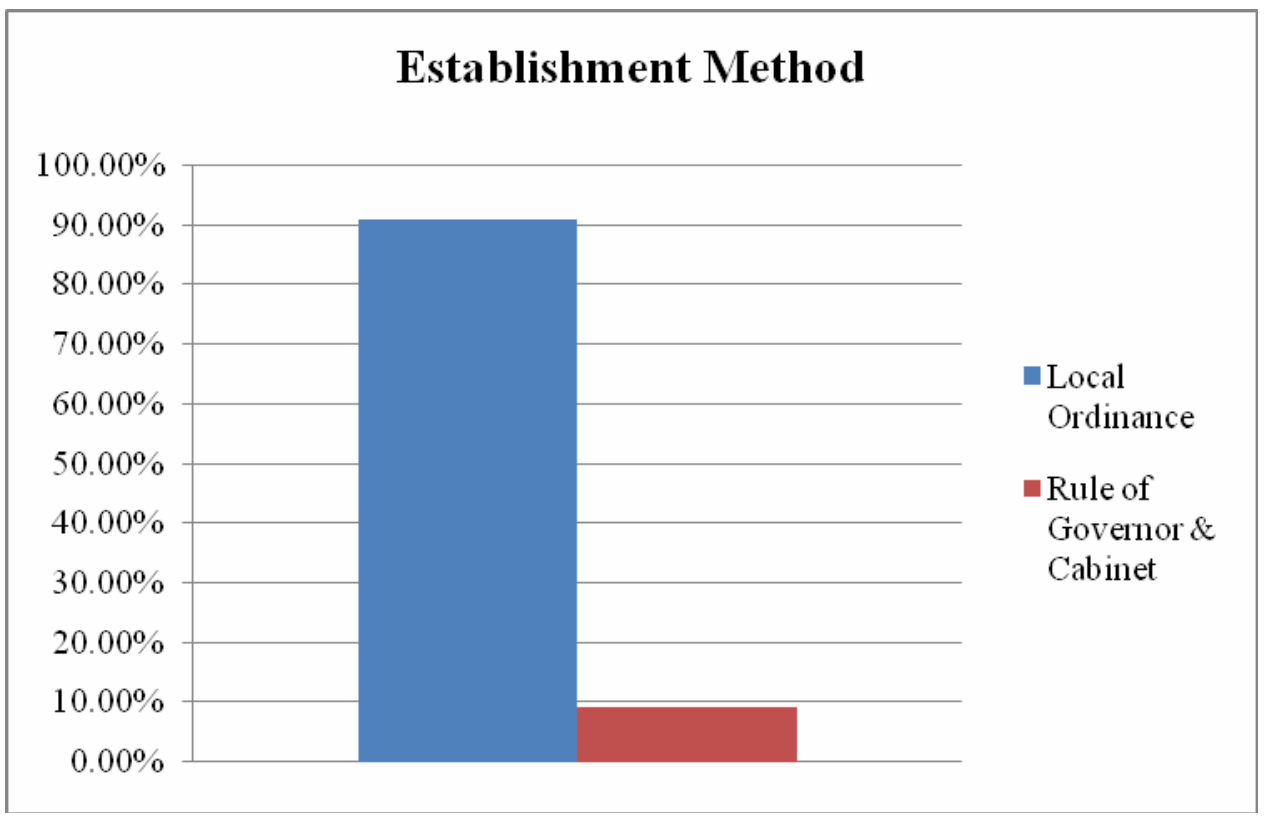

Source: www.FloridaSpecialDistricts.org 
According to Figure 4.1 generated from the Florida Department of Community Affairs' data, $90.9 \%$ of the CDDs were less than 1000 acres in size while $9.1 \%$ were more than 1000 acres in size. These figures show that the majority of CDDs were established by local general-purpose governments. Out of these, Florida counties established $64.2 \%$ while cities $35.8 \%$ of CDDs.

\subsubsection{Proliferation of CDDs}

Even though the first CDD was created in 1982 in Hillsborough County, districts proliferation increased significantly during the 1990's. The increase in CDDs was facilitated by the adoption of the 1985 Florida Growth Management Act which required the infrastructure to be in place and funding be available to new development (BenZadok, 2007; Nicholas \& Chapin, 2007). Other factors that facilitated the increase in the number of CDDs are related to the nature of these districts: CDD ability to offer developers access to financial resources and a competitive advantage through the reduced project costs (Bartling, 2007).

According to the Florida Department of Community Affairs, as of September 1st, 2010 there were 579 active CDDs in the State of Florida. As described in Figure 4.2, five years after the adoption of the Chapter 190 Fla. Stat. only a few of CDDs were created. The creation of CDDs increased steadily after 1990 when local comprehensive plans were adopted. The figures reveal both a drastic increase in the creation of CDDs after 2000, with a peak in 2006 when more than 100 CDDs were created as well as a dramatic decrease after 2007 with only one CDD being created in 2009. When looking at CDD proliferation by decade it is worth noting that the majority of CDDs $(82.3 \%)$ were created in the $2000-2009$ decade, $15.5 \%$ in the $1990 \mathrm{~s}$ and the rest of the $2.2 \%$ in the $1980 \mathrm{~s}$. The CDD number seems to be fueled by the housing market within the State of Florida: they boomed from 2000 until 2006 and then, declined considerably. 
Figure 4.2 Creation of CDDs by Year

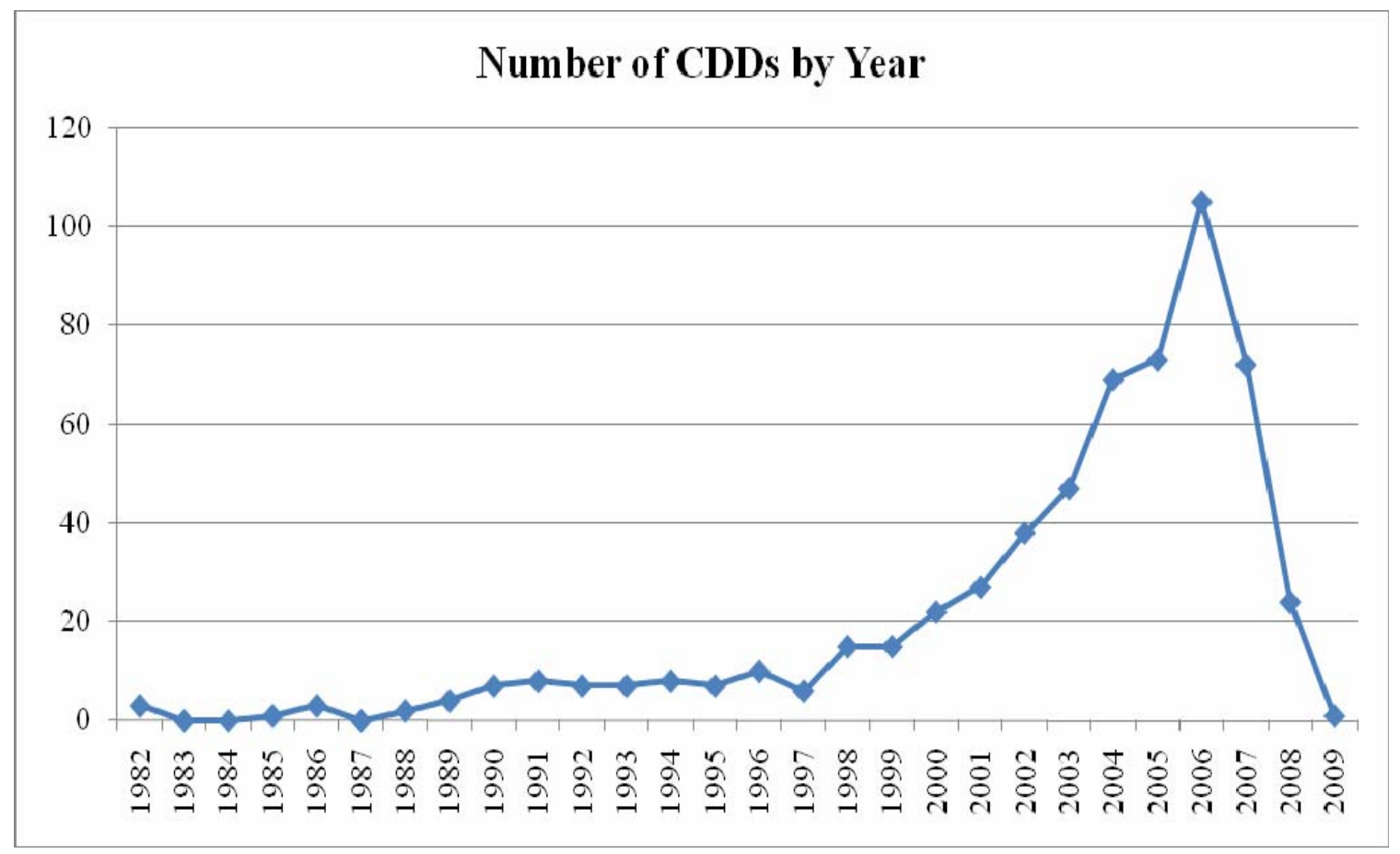

Source: www.FloridaSpecialDistricts.org

With regard to CDD geographical distribution (depicted in Figure 4.3), 38 out of the 67 counties in Florida have at least one CDD. Approximately $50 \%$ (50.4\%) of the CDDs are located within six counties in Florida, as follows: Hillsborough (66), MiamiDade (58), Lee (51), Pasco (40), Manatee (38) and St. Lucie (40). At the other extreme there are counties that contain only one district (Alachua, Desoto, Franklin, Martin and Seminole). The CDDs seem to be mostly concentrated in counties located in the South and Central Florida. They are mainly predominant in larger counties with almost one third of the CDDs located in Miami-Dade, Broward, Palm Beach, Duval and Hillsborough counties. It is also worth noting that there are counties which experienced rapid growth but they either did not rely or they barely used CDDs as infrastructure providers. This is the case of counties such as Pinellas, Martin and Seminole. 


\section{Figure 4.3 CDD Geographic Distribution}

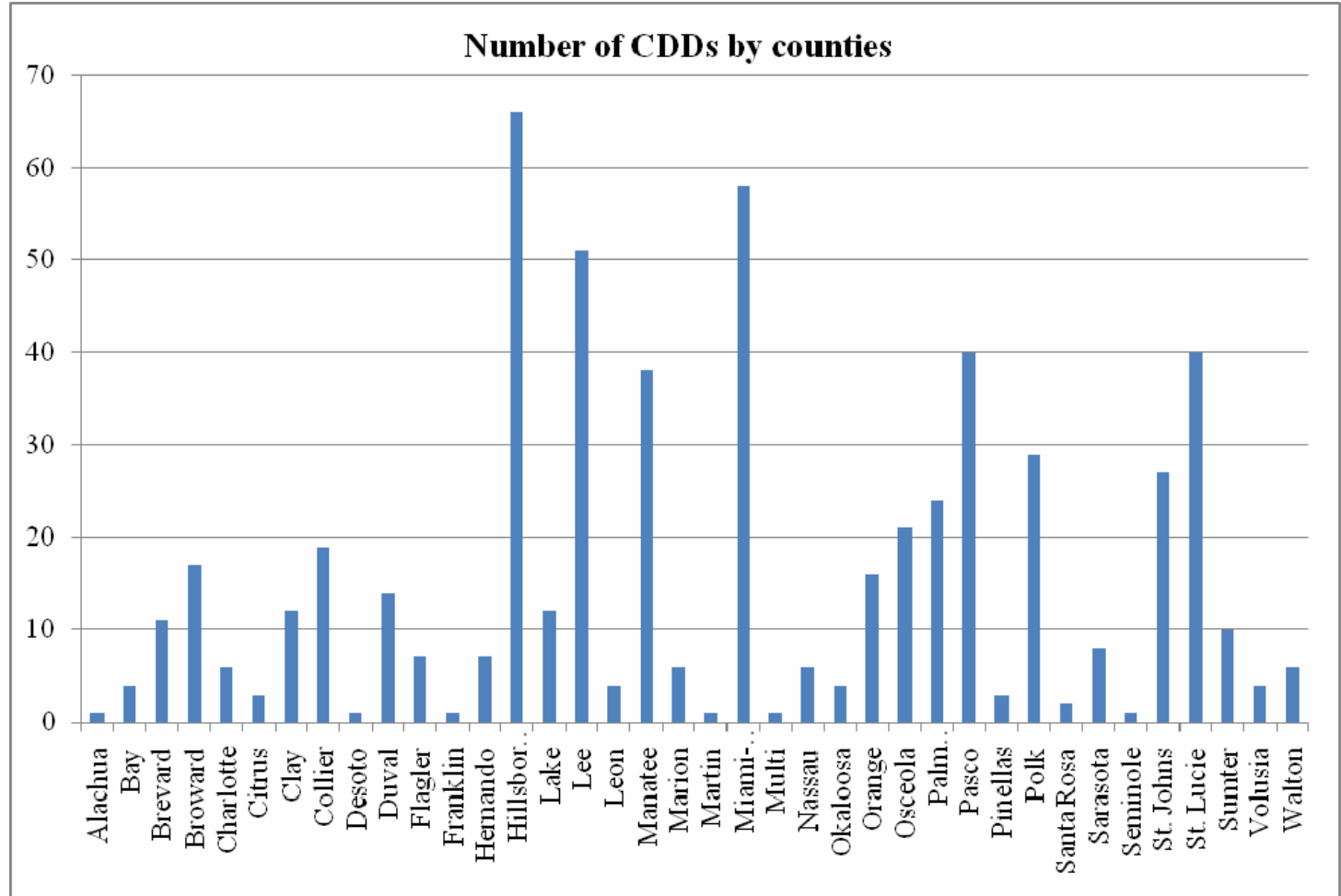

Source: www.FloridaSpecialDistricts.org

\subsubsection{Governance Issues}

Initially, a CDD is governed by a five-member board of supervisors elected by the landowners in the district within 90 days of the official establishment of the CDD. The district's governing board is first elected under a one-acre/one-vote system - a system where landowners have one vote for each acre of land they own in the district. As the CDD grows and reaches a certain number of residents, the board of supervisors is elected by the residents for a four year period. Therefore, for districts with less than 5,000 acres where there are at least 250 qualified electors, the residents take over the earliest six years after the initial appointment of the original board; for the districts of more than 5,000 acres the time frame is ten years and there needs to be at least 500 qualified electors (\$190.006 Fla. Stat., 1980). 


\subsubsection{Functions}

Chapter 190 Fla. Stat. grants three broad categories of powers to CDDs. First, CDDs are granted general powers such as: to sue and be sued, to acquire and to dispose of property, to make and execute contracts, to adopt rules and orders, to borrow money and issue bonds, to assess and impose ad valorem taxes, special assessments, user charges and fees, to lease any project that the CDD is authorized to undertake, to exercise within the district the power of eminent domain relating only to water, sewer, district roads and water management; to cooperate with, or contract with, other governmental agencies and consultants (§190.011 Fla. Stat., 1980).

Second, CDDs enjoy the following special powers: to plan, establish, construct, operate and maintain water management and control, water supply, sewer and wastewater management, bridges and culverts, district roads and projects for concurrency under certain conditions ( $\$ 190.012$ Fla. Stat., 1980).

Last but not least, CDDs may exercise other special powers with the consent of the local general-purpose government. They may plan, establish, construct, operate and maintain systems and facilities such as: parks and recreational, cultural and educational facilities, fire prevention and control, school buildings and related structures, security including guardhouses, fences and gates, electronic intrusion-detection systems and patrol cars, mosquito control, waste collection and disposal and the like (§190.012(2) Fla. Stat., 1980).

\subsubsection{Accountability Issues}

In addition to complying with all the reporting requirements stated in Chapter 189 Fla. Stat. for special districts in general (see section on special districts within the present chapter), CDDs are subject to Government-in-the-Sunshine and public records laws, public bidding and competitive negotiation (§190.033 Fla. Stat., 1980). 
State law requires that the CDDs' existence and taxing power be disclosed in property records $(\$ 190.009$ Fla. Stat., 1980) and in capital bold letters right before the signature block of a home sales contract $(\$ 190.048$ Fla. Stat., 1980) to all existing and future residents of the district.

For the initial purchasers Chapter 190 Fla. Stat. states that every sales contract should contain a disclosure language in bold letters right before the signature block regarding the existence of the CDD and its right to assess the property within the district to pay for improvements and for operation of the district. Then, for the subsequent purchasers, the tax bill for the property to be purchased indicates that there is a CDD assessment. Districts are also supposed to submit their proposed annual budgets for disclosure and information only to local general-purpose governments that have jurisdiction over the districts’ area (§190.008 (b) Fla. Stat., 1980).

\subsubsection{Financial Aspects}

Special-purpose districts, in general, and CDDs, in particular, are considered financial mechanisms because of their ability to generate revenues from those who directly benefit from services as well as due to their ability to issue bonds (Porter et. al., 1992). The types of revenue sources that CDDs are entitled to collect may be classified as lienable and non-lienable. The lienable revenues are represented by ad-valorem taxes and special assessments. Ad valorem taxes (§190.021(1) Fla. Stat., 1980) are assessed, levied,

and collected in the same manner as county taxes. Special assessments $(\S 190.021$ Fla. Stat., 1980) are assessed on the benefits received from land instead of the property value and they are classified in two categories: benefit (back up bond issues) and maintenance (cover operating costs) assessments. The category of non-lienable revenues is comprised by fees, rentals, and charges ( $\$ 190.035$ Fla. Stat., 1980). 
In addition to raising revenues from those who directly benefit, CDDs have the authority to issue tax-exempt bonds for financing infrastructure in the form of capital projects. The most widely used bonds are revenue bonds (\$190.016(8) Fla. Stat., 1980) which are secured by special assessments, user charges and/or fees. The district may also issue general obligation bonds (§190.016(9) Fla. Stat., 1980) which are secured by CDDs' ad-valorem taxes to finance or refinance capital projects or to refund outstanding debt only through voter referendum. Other types of borrowing mechanisms that are available to CDDs are: special assessment bonds (§190.022 Fla. Stat., 1980), bond anticipation notes $(\S 190.014$ Fla. Stat., 1980) and negotiable notes or warrants $(\S 190.015$ Fla. Stat., 1980).

In order to determine the importance of CDD finances, the ways in which the amount of CDD finances compare and relate to the finances of local general-purpose governments are described. In fulfilling this scope, data from Florida Department of Financial Services (DFS) from 1998 to 2007 are being used. ${ }^{4}$ The choice for choosing this time frame is determined by the fact that no available data on CDD debt prior to 1998 could be collected.

According to the Florida DFS' data, between 1998 and 2007 CDDs had raised more than 14.57 billion dollars and had spent around 13.31 billion dollars, carrying an outstanding debt in the amount of 7.14 billion dollars. The CDD revenues and expenditures more than quadrupled over a ten year period whereas the finances of

${ }^{4}$ The number of CDDs included in the present analysis differs from the number of active CDDs. Florida Department of Financial Services reports only the data for both general and special-purpose governments that complied with the reporting requirements. The table below depicts both the total number of CDDs and the number of reporting CDDs for every year since 1998 until 2007.

\begin{tabular}{l|r|r|r|r|r|r|r|r|r|r}
\hline Year & $\mathbf{1 9 9 8}$ & $\mathbf{1 9 9 9}$ & $\mathbf{2 0 0 0}$ & $\mathbf{2 0 0 1}$ & $\mathbf{2 0 0 2}$ & $\mathbf{2 0 0 3}$ & $\mathbf{2 0 0 4}$ & $\mathbf{2 0 0 5}$ & $\mathbf{2 0 0 6}$ & $\mathbf{2 0 0 7}$ \\
\hline Total \# CDDs & 88 & 103 & 125 & 151 & 189 & 237 & 308 & 382 & 489 & 560 \\
\hline Reporting \# CDDs & 84 & 90 & 112 & 139 & 162 & 192 & 262 & 316 & 409 & 548 \\
\hline
\end{tabular}


counties and cities increased with more than $50 \%$ and $60 \%$ respectively. Community Development Districts appear to be the fastest growing local jurisdiction in terms of financial resources among the three types of local governments for 1998-2007. ${ }^{5}$

Figure 4.4 shows a comparison among the percent of revenues raised by Florida counties, cities and CDDs. The CDDs proved to raise a modest part of the total revenues of local governments in the State of Florida, showing a somewhat steady trend from $1.07 \%$ in 1998 to $3.36 \%$ in 2007 with a peak of $4 \%$ in 2006 .

Figure 4.4 Percent of Revenues by Type of Local Government

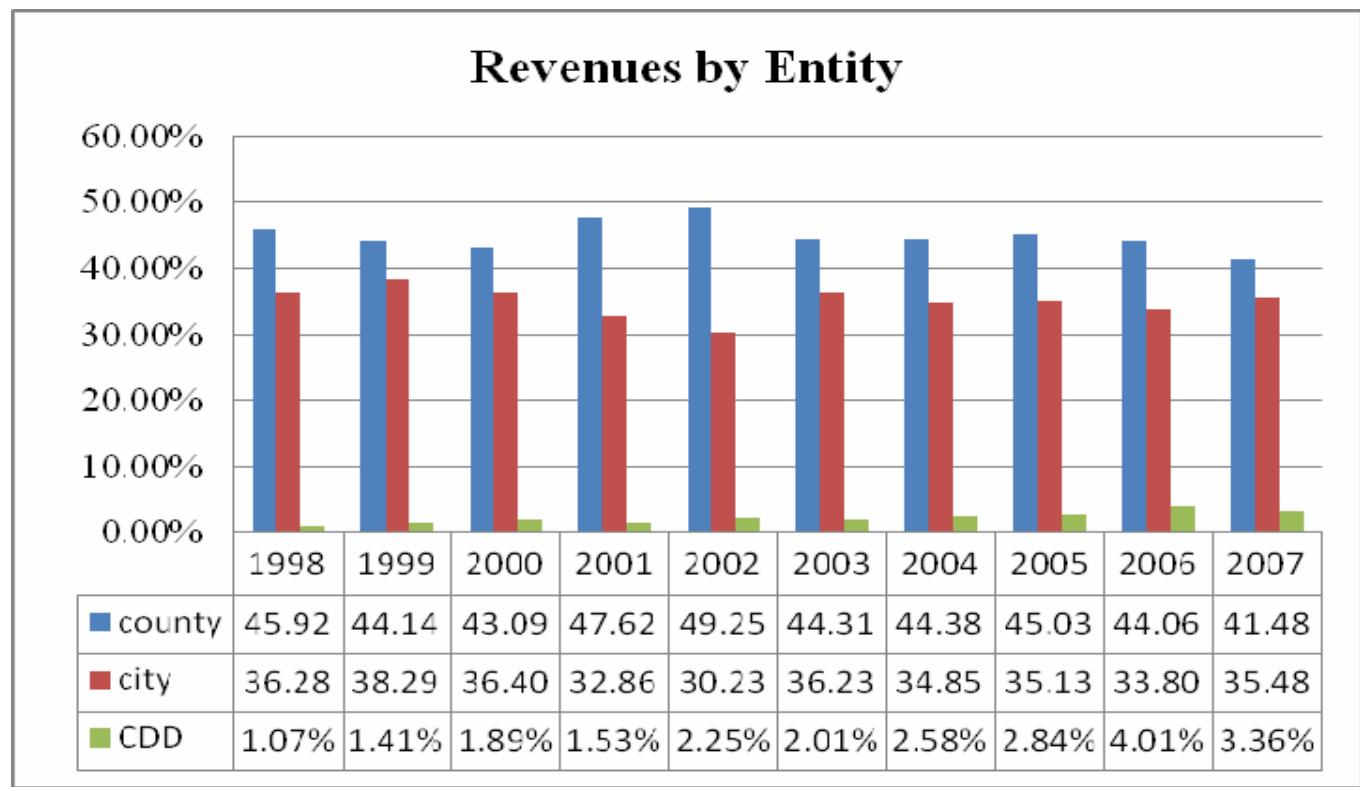

Source: Florida Department of Financial Services

These figures demonstrate that over a ten year period CDDs were used as a steady though modest source of generating revenues while counties and cities showed a decrease in generating revenues of $4.44 \%$ and $.8 \%$ respectively. Even though the amount of CDD

\footnotetext{
${ }^{5}$ The financial data were adapted to inflation using Consumer Price Index - all urban consumers - 1982$84=100$ for the current year (2007)
} 
revenues increased over the years, they comprised a small fraction in comparison to cities and counties.

Figure 4.5 Percent of Expenditures by Type of Local Government

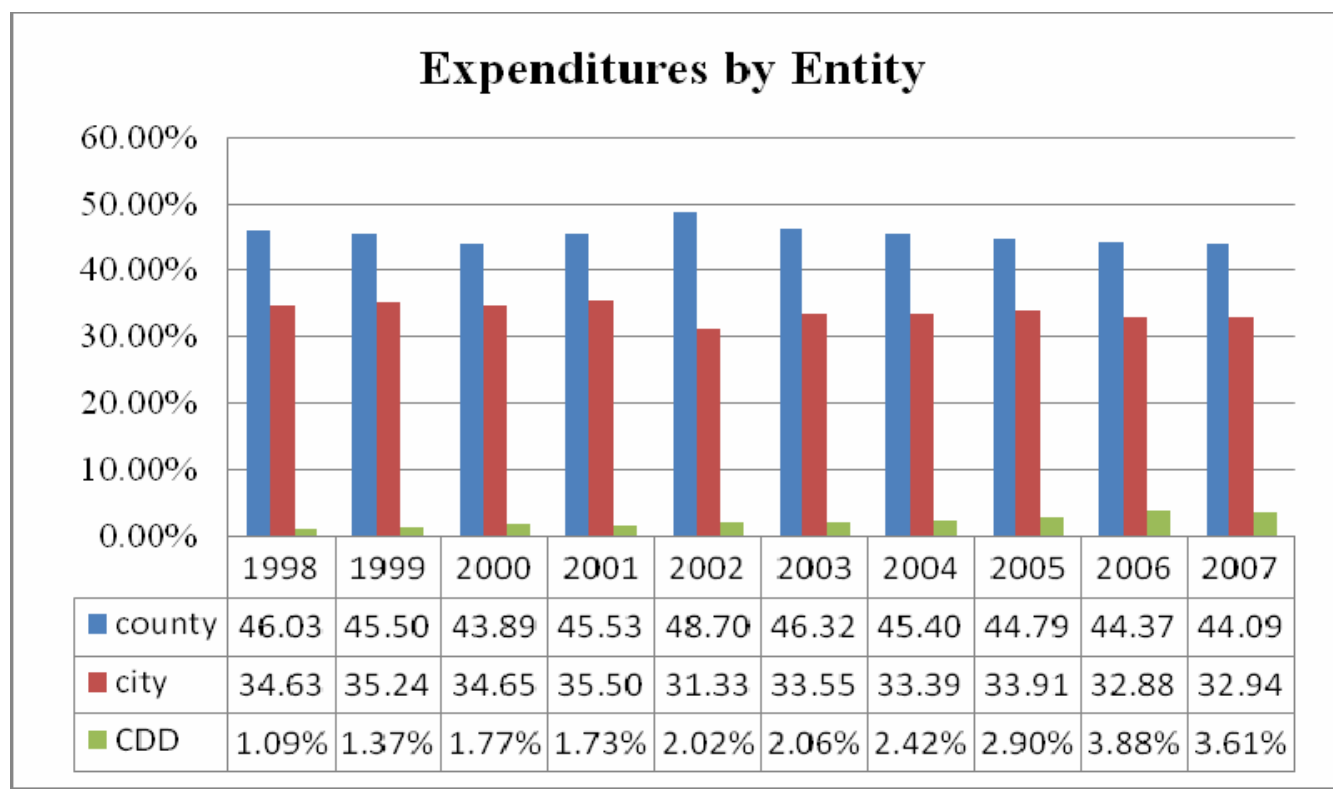

Source: Florida Department of Financial Services

In the case of expenditures (Figure 4.5), the analysis shows a similar trend to the situation of revenues. Counties are the local governmental entities with the highest rate of spending, decreasing $2 \%$ in ten years from $46.03 \%$ in 1998 to 44.09 in 2007 , followed by cities with a decreasing trend in expenditures from $34.63 \%$ in 1998 to $32.94 \%$ in 2007 and CDDs whose spending pattern increased from $1.09 \%$ to 3.6 over the ten year span.

While CDD revenues and expenditures grew extensively, it is the amount of debt they issued that is the most significant. The CDDs managed to raise debt four times more than in 1998 whereas counties had a small increase of $9 \%$, followed by cities with $34 \%$. In 2007 the amount of CDD outstanding debt represented roughly a third of the debt of Florida counties compared to $1 / 20$ ten years before. Even if the amount of debt issued by 
CDDs had increased considerably over time, it represents a small base when compared to that of general-purpose governments.

When analyzing the entities by the amount of outstanding debt (see Figure 4.6) there was a descending trend for general purpose governments with a decrease of $9.48 \%$ for counties and $2.23 \%$ for cities. On the other hand, CDDs showed an ascending pattern of $6.05 \%$. The number of CDDs with outstanding debt increased almost five times from 78 CDDs in 1998 to 356 in $2007 .^{6}$ Those CDDs that did not report any outstanding debt were either in their early stages and did not issue any bonds or were older districts that had already paid off their bonds.

\section{Figure 4.6 Percentage of Debt by Local Government}

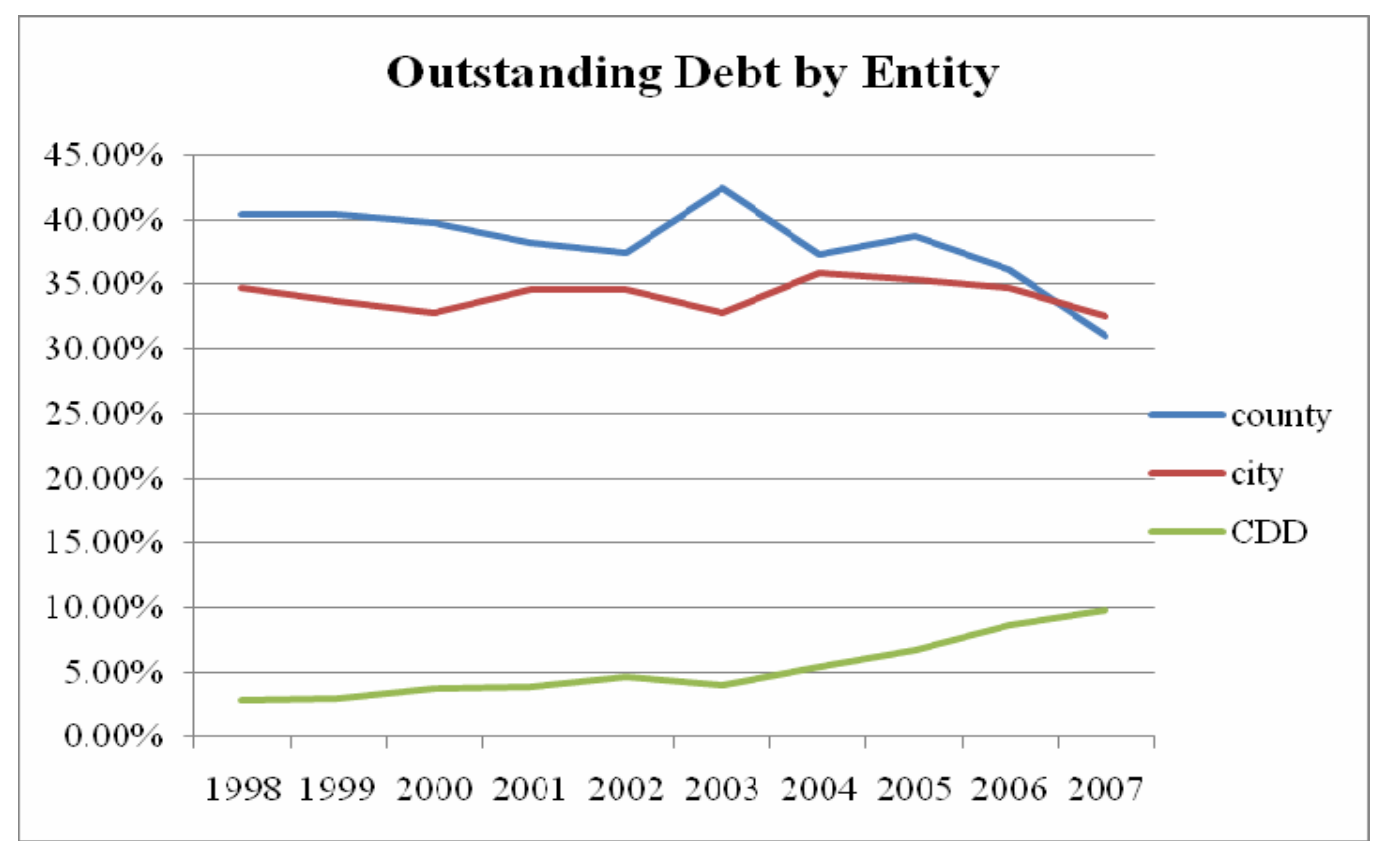

Source: Florida Department of Financial Services

\footnotetext{
${ }^{6}$ According to the Florida Department of Financial Services
} 
To sum up, the analysis of the financial data provided by the Florida DFS shows that CDDs are an increasingly important finance tool. As a result of comparing the rate of change for the finances of the three forms of local government over ten years (19982007), CDDs proved to be the fastest growing local governmental entity in terms of generating revenues and issuing debt. According to the above analysis CDDs borrowing capacity represents a competitive financial advantage in delivering public infrastructure services.

\subsubsection{Expansion, Contraction or Dissolving CDDs}

The CDD board of supervisors may petition the authority that established the CDD to expand or contract the boundaries of a district. The state law stipulates different standards for expansion and contraction limits. Therefore, when districts were established by administrative rule, boundary amendments should not exceed $10 \%$ and no more than 250 acres of the land in the initial district. In the case the districts were established by county or city ordinance, the limitation refers to $50 \%$ and not to exceed more than 500 acres of land from the initial district (\$190.046 (5)(f) Fla. Stat., 1980).

A CDD may be dissolved when there is no development permit within five years of the date the district was established. Additionally, a district may be declared inactive when it did not elect a governing body within four years of existence or when it did not operate within two years of existence (§190.046 (6-8) Fla. Stat., 1980; §189.4044 Fla. Stat., 1989).

Upon request, a CDD may petition the entity which established it for dissolution when it has no outstanding financial obligations (\$190.046(9) Fla. Stat., 1980). According to the Florida Department of Community Affairs, as of September $1^{\text {st }}, 2010$ there were 36 dissolved CDDs in the State of Florida, out of which 15 were dissolved 
between 2008 and 2010. This was the case mainly for CDDs that were recently established and could not begin their activity due to economic hardship.

\subsubsection{Incorporation and Annexation of CDDs}

Districts may incorporate as municipalities when they obtain some standards for population or they may be annexed to an existing municipality. According to $\$ 190.047$ Fla. Stat. corroborated with $\$ 165.061$ Fla. Stat. a CDD may incorporate into a municipality after a referendum is held and the following conditions are met: there should be at least 1,500 residents for counties with less than 50,000 inhabitants and at least 5,000 residents for counties with more than 50,000 inhabitants. However, the ultimate incorporation decision is made by the CDD board of supervisors.

\subsubsection{Summary}

Community Development Districts are a category of special districts that were created through a Florida State Charter for the purposes of providing a limited number of infrastructure improvements. The creation of CDDs in Florida should be viewed within the historical context of special districts creation, the fiscal environment of tax rebellion that led to state imposition of tax and expenditure constraints on municipal governments as well as the Florida growth management legislation.

The CDDs are established through two different approval procedures according to their size. Districts larger than 1000 acres are established by the Rule of the Florida Land and Water Adjudicatory Commission while those smaller than 1000 acres are established by local ordinances of counties and cities. The majority of the CDDs in Florida are established by local general-purpose governments. Up to the moment of the writing of this manuscript, CDD creation has been initiated by developers although any person or entity can initiate their establishment. 
Districts began to be used in 1982 but it was not until the late 1990s that they started to show a significant proliferation. Their growth shows that they have developed according to the fluctuating housing market in Florida, which boomed in the late 1990s until mid 2000s and then declined after 2006. The CDDs are mainly concentrated in Central and South Florida, being predominant in the larger counties, with approximately half of the CDDs being located within six counties: Hillsborough, Lee, Manatee, MiamiDade, Pasco and St. Lucie counties.

The CDDs are governed by an elected board of supervisors which, initially, is made up of landowner's representatives according to the one acre/one vote system. After, districts reach a certain number of residents their representatives are elected among residents within the district. Therefore, CDD major decisions are controlled by the developers in the initial years of district's existence. Districts are authorized to undertake fundamental infrastructure improvements such as water management and control, water supply, sewer and wastewater management, roads and bridges as well as a wide variety of optional improvements such as parks and recreational facilities, cultural and educational facilities, fire prevention and control, security and so on.

Districts may levy ad-valorem taxes, impose special assessments, fees and charges and issue tax-exempt bonds to finance infrastructure improvements and cover the district's operating expenses. Under Chapter 190 Fla. Stat. developers have to disclose to future purchasers the existence of CDD and its right to impose assessments and issue debt.

From 1998 to 2007 CDDs managed to steadily increase their revenues, being the fastest growing local government when compared to Florida cities and counties. However districts' financial resources represented a low tax base as opposed to that of local general-purpose governments. The amount of debt that CDDs raised in ten years increased four times since 1998 to 2007 compared to the debt of general-purpose 
governments which showed only a modest increase for the same time period. Thus, CDD borrowing capacity gives them a competitive advantage in providing infrastructure services.

If necessary, CDDs may be expanded or contracted according to the way the development proceeds. By their nature, districts are perpetual entities but they may be dissolved especially in cases of inactivity. Furthermore, in theory, districts can be incorporated or annexed to the existing municipalities but, in practice, such instances are

rare. In conclusion, CDDs are perpetual institutional mechanisms for infrastructure provision which enjoy governmental powers and protections.

\subsection{Chapter Summary}

Special districts occupy an important place in the American governing structure. They differentiate themselves from local governmental entities of general-purpose (such as counties and cities) through their specific characteristics: narrow specialization, administrative and financial independence, geographic flexibility and low political visibility. In Florida there are over 1600 special districts which fulfill a variety of functions among which are community development and redevelopment, water, housing, fire protection, flood control, irrigation, health facilities, libraries, airports, industrial development, parks and recreation and so on.

Community Development Districts are a subtype of independent special districts which are created through a state charter. They represent an efficient and unique way of managing and financing infrastructure facilities and services that accommodate new development. These entities enjoy administrative, political and financial autonomy.

The CDD governing structure differs significantly from other special districts in Florida. They are independent special-purpose units of local government whose 
establishment is, in practice, initiated by developers or landowners as opposed to generalpurpose governments. They are governed by a board elected by landowners that is independent from the local general-purpose government. The CDD infrastructure is offbudget of the containing general-purpose governments. The latter may use and rely on the reports that CDDs are supposed to submit with no enforcement power.

Unlike the majority of special districts that have one or very limited functions, CDDs are authorized to manage, fund and construct basic infrastructure facilities and services such as water management and control, water supply, water and wastewater, bridges and culverts, district roads and certain projects for concurrency as well as parks and recreation facilities, security, fire prevention, education-related facilities and the like.

The CDDs are attractive because of their financial capacity and their recent growth. When comparing the finances of CDDs with those of counties and cities in Florida the former were the fastest growing local governmental entity in terms of rate of revenue increase, expenditure increase and debt issuance.

The use of CDD to provide public infrastructure services implies both praise and criticism. On the one hand, CDDs are praised because they deliver efficient services that are managed and financed primarily through special assessments, allow communities to raise revenues without increasing general taxes, provide communities with high quality infrastructure services and facilities that are completed in a timely manner and create new communities or improve the existing ones through their ability to incorporate into new municipalities or to be annexed into the existing ones.

On the other hand, CDDs may be open to criticism because they encourage governmental fragmentation. They are perceived as seeking mainly the interests of developers and ignore those of residents and they can abuse their powers because of a lack of local general-purpose government oversight. 


\section{CHAPTER V}

\section{THE ROLE OF COMMUNITY DEVELOPMENT DISTRICTS IN GROWTH MANAGEMENT}

\subsection{Introduction}

This chapter analyzes the implications of CDDs to the growth management in Florida by focusing on districts located within six Florida counties: Hillsborough, Lee, Manatee, Miami-Dade, Pasco and St. Lucie. This aspect is important since CDDs are perceived as being creatures of the Florida growth management legislation that was enacted in 1975 in order to manage unplanned growth. In considering the issue of how to coordinate urban development with infrastructure provision the author is interested in answering the following question: Which are the contributions of CDDs to growth management in Florida?

Growth suggests that CDDs are capable of being adequate managerial and financial mechanisms for infrastructure provision and maintenance. While there is no doubt that CDDs can provide and maintain infrastructure facilities and services for new development, thus funding the "unfunded mandate of concurrency", it is districts" location, type and pattern of development that may have unintended consequences for the way growth occurs.

This chapter proceeds with a brief description of the growth management policy in Florida with particular emphasis on its concurrency requirement; then, it provides a description of CDDs' profile and their implications for growth management by discussing district location, size and the type of development they support as well as 
infrastructure coordination issues; finally, the chapter concludes with a summary and a discussion about the way CDDs influence growth.

\subsection{Growth Management Legislation}

The context within which CDDs were created should be related to the Florida growth management legislation. Growth management can be defined as "the regulation of the amount, timing, location and character of development" (Levy, 2006, p. 229). Downs (2004) refers to growth management as a set of specific regulatory policies which intend to influence future growth to occur in a rational manner. Growth management programs aim to achieve many goals. Some of the most important goals include the following: limit urban sprawl, improve transportation options, create more compact development, coordinate urban development with infrastructure capacity and provide affordable housing.

Growth management programs were adopted in response to environmental concerns and to the way growth was occurring in the 1960s and 1970s. The first statewide growth management system was adopted in Hawaii in early 1960s, followed by Oregon which enacted its growth management law in 1973 and became the model for several other states. In Florida, because of a drastic increase in the population that could not be accommodated by environmentally sensitive areas, the state legislature adopted its first growth management-related legislation in 1972. The Environmental Land and Water Management Act provided that state had ultimate decision in "areas of critical state concern" and on "development of regional impact". In 1975 the State Legislature enacted the Local Government Comprehensive Planning Act (LGCPA) which laid the foundation for the Growth Management Act of 1985. Even though the LGCPA provided that every 
local government adopt a comprehensive plan in accordance with state requirements it failed because there were no state enforcement provisions.

In 1985 the Growth Management Act (GMA) was passed. Florida's growth management program was considered to be the most comprehensive of all the states (Pelham, 2007). Unlike its predecessor, the GMA provided for approval of local plans by the state land planning agency as well as for financial sanctions for the non-compliant local governments.

There are three main policies that are stipulated in the Florida GMA: consistency, concurrency and compact development. Consistency requires that local and regional plans be consistent with the state policies. Concurrency requires that adequate public facilities be available or fiscally accounted for prior to or concurrent with new development. Compact development intends to direct growth towards urban areas with high densities and away from natural resources and agricultural lands.

Of particular relevance to this study is the concurrency requirement. The GMA provides that "development shall be directed to those areas which have in place, or have agreements to provide, the land and water resource, fiscal abilities, and service capacity to accommodate growth in an environmentally acceptable manner" (§187.201(16)(a) Fla. Stat., 1985).

Through its requirements, concurrency was intended to control growth and to foster economic development (Ben-Zadok, 2007). The GMA requires every local government to adopt a capital improvement program for public facilities and to establish minimum level-of-service standards for certain public facilities to accommodate projected growth. There are seven public facilities subject to the concurrency requirement. These are sanitary sewer, solid waste, drainage, potable water (R. 9J-5.011 Fla. Admin. Code), parks and recreation (R. 9J-5.014 Fla. Admin. Code), roads and public transit (R. 9J-5.019 Fla. Admin. Code) and public schools facilities (R. 9J-5.025 
Fla. Admin. Code). Local governments were given flexibility in choosing their own level-of-service standards for all but one public facility - transportation which is subject to state minimum level-of-service standards.

In Florida the concurrency requirement has been both lauded and criticized. In a positive vein, concurrency can control growth through timing, location, type and pattern of development (Ben-Zadok \& Gale, 2001) as well as through denying permits for inadequate public facilities (Ben-Zadok, 2007). Concurrency has also been praised for being a tool for local governments to link development approvals to infrastructure (Connerly, Chapin \& Higgins, 2007). Two big achievements of concurrency requirement were connecting planning with development (Ben-Zadok \& Gale, 2001) and funding capital infrastructure through developers instead of general-purpose governments. The GMA created a "pay as you grow" system where developers had to pay their share to obtain development permits (Pelham, 2007) thus, encouraging unabated growth.

Concurrency has often been criticized for contributing to sprawl by directing growth to less populated areas (Turner, 1990). Probably the biggest criticism of the growth management legislation was the lack of state commitment to fund concurrency requirement - the so-called "unfunded mandate of concurrency" (Ben-Zadok \& Gale, 2001; Connerly et. al., 2007; Pelham, 2001). Instead of providing direct revenue sources for public infrastructure, the Florida legislature adopted a state growth approach with local implementation (Chapin, 2007; Turner, 1990) where growth pays its own way (Nicholas \& Chapin, 2007).

The GMA and its subsequent amendments are considered to have failed because they did not help implementing the concurrency and compact development policies (Pelham, 2007). Some authors (Nicholas \& Chapin, 2007) explained clearly why the concurrency requirement did not succeed. There was a disconnect between the "fiscal theory" and "fiscal reality." When GMA was adopted an estimate of two thirds of 
revenues was supposed to come from the state in the form of a services tax and an increase in motor fuel taxes and one third of revenues were expected from local governments. But the services tax was not approved and local governments had to generate their own funding sources for infrastructure provision such as local optional taxes, impact fees, charges and other fees as well as the creation of special taxing districts.

Therefore, CDDs can be considered tools that fund infrastructure facilities and services while fulfilling the concurrency requirement for development, ensuring thus that public facilities are in place and funded prior to or concurrent with new development. In discussing the implications of CDDs for growth management, this chapter considered the location and size of CDDs within six Florida counties as well as the type and pattern of development districts supported.

\subsection{CDD Profile and Growth Management Implications}

Community Development Districts provide infrastructure services that are geared toward new development. In doing so, districts make choices about location, type and pattern of development. This section describes the CDD profile within the six Florida counties by pinpointing the districts' implications for growth management policies. It discusses districts location, size, financial characteristics, type of development they support and infrastructure coordination issues with their containing general-purpose governments. While there is no doubt that CDDs role to adequately provide infrastructure improvements for new development benefits growth management, it is the other aspects of location, type and pattern of development that pose issues for the way growth occurs.

Most of the CDDs provide public facilities and services mainly for unincorporated areas. $70.4 \%$ of districts are located in unincorporated areas of the six 
counties while the rest are to be found in the inner city areas. Table 5.1 depicts the distribution of CDDs by their location status for each of the six counties. These figures clearly demonstrate that CDDs are mainly located in unincorporated areas and, therefore, operate in areas where counties do not or could not provide infrastructure services.

There are three trends that could be identified. First, there are instances in which the majority of CDDs are located in unincorporated areas (Pasco, Manatee and Hillsborough counties). Second, there are situations in which more than half of the CDDs are located in unincorporated areas (Miami-Dade and Lee counties). Finally, there is St. Lucie County that has two thirds of the CDDs located in incorporated areas. The CDDs location choices demonstrate that, even though, overall, CDDs operate in areas where counties do not or cannot provide infrastructure services, districts may very well be used in municipalities.

Even though districts do not have planning and zoning powers, they still have a significant influence on the way growth occurs through their location preferences. The choice of creating CDDs in unincorporated vs. incorporated areas is related to the type of development districts support Districts supporting mainly single-family residential development are located on the fringe of cities, thus contributing to sprawl patterns. Districts located within the boundaries of municipalities focus more on multi-family residential and mixed-use development, contributing to denser development patterns. There are also instances in which CDDs that are located within the boundaries of municipalities are used for redeveloping inner-city areas or for providing more expensive improvements such as roadways.

Therefore, on one hand, CDDs supporting residential communities with singlefamily houses tend to encourage development that is located on the fringe and, indirectly, contribute to sprawl. On the other hand, districts that support multi-family and mixedused developments might contribute to denser development patterns. 
Table 5.1 CDDs Characteristics by County

\begin{tabular}{|c|c|c|c|c|c|c|c|c|c|}
\hline \multirow[b]{2}{*}{ County } & \multicolumn{3}{|c|}{ CDD location } & \multicolumn{3}{|c|}{ CDD size (acres) } & \multicolumn{2}{|c|}{ Property development } & \multirow[t]{2}{*}{$\mathrm{N}$} \\
\hline & Unincorporated & Incorporated & Total & Mean & Min. & Max. & Dwellings & $\begin{array}{c}\text { Commercial/ } \\
\text { Industrial } \\
\text { (sq.feet) }\end{array}$ & \\
\hline Hillsborough & $83.3 \%$ & $16.7 \%$ & $100 \%$ & 390.2 & 9.4 & 1097 & 47,019 & $4,133,643$ & 54 \\
\hline Miami-Dade & $60.3 \%$ & $39.7 \%$ & $100 \%$ & 110.8 & 9.9 & 516.5 & 44,733 & $9,690,326$ & 58 \\
\hline Lee & $60.0 \%$ & $40.0 \%$ & $100 \%$ & 333.9 & 16.9 & 972 & 22,189 & $1,805,064$ & 40 \\
\hline Pasco & $94.6 \%$ & $5.4 \%$ & $100 \%$ & 544.1 & 135 & 999 & 37,227 & $4,061,000$ & 37 \\
\hline St. Lucie & $33.3 \%$ & $66.7 \%$ & $100 \%$ & 441.7 & 35.7 & 998.9 & 30,797 & $1,245,673$ & 33 \\
\hline Manatee & $88.6 \%$ & $11.4 \%$ & $100 \%$ & 372.2 & 27.6 & 980.8 & 19,834 & $1,620,400$ & 35 \\
\hline All & $70.4 \%$ & $29.6 \%$ & $100 \%$ & 343.9 & 9.4 & 1097 & 201,799 & $22,556,106$ & 257 \\
\hline
\end{tabular}

Note: the figures about property development are estimates provided by developers based on the petition data 
The CDDs size is spread on a continuum ranging from districts as small as 9 or 10 acres to extremely large CDDs which are over $1000 \mathrm{acres}^{7}$ in size. Table 5.1 depicts descriptive statistics for CDD size. The average size for CDDs by county reveals that, with the exception of districts in Miami-Dade County which have a mean size of 111 acres, the districts located in the other five counties have an average that ranges from 334 to 544 acres. When looking at the minimum and maximum for CDD size, there are three trends that stand out. All the counties under analysis but Miami-Dade have CDDs that are in the vicinity of 1000 acres. Two counties (Hillsborough and Miami-Dade) have CDDs as small as 9 and 10 acres. And Pasco County has the highest minimum value for CDD size (135 acres). The analysis suggests that districts located in Pasco County are the largest in size while those in Miami-Dade are the smallest.

The size of CDDs seems to be associated with their age. Larger CDDs were created in the 1980s and 1990s and it was not until recently that one could document CDDs as small as 10 acres. Thus, the vision of the Florida State legislation of creating large enough and feasible CDDs seems to have changed. The existence of small CDDs has most often been criticized for not being compact and big enough to justify the creation of another form of local government. To be viable, the desired CDD average size should be between 300 and 500 acres: "we're always dealing with 300 acres, 400 acres, 500 acres and when it gets down to 14 acres, does it really make sense to make another whole layer of government for such a small piece of property?" (Planning Department, Manatee County).

The legislation does not provide for any minimum or maximum limits about CDD size, it rather states that this issue will be decided upon on a petition-by-petition basis

\footnotetext{
${ }^{7}$ Some CDDs exceed 1000 acres due to subsequent extensions of their boundaries
} 
after considering the factors stipulated in $\$ 190.005(1)(e)$ Fla. Stat. The factors refer to the following:

- whether the establishment of the district is consistent with all the elements of the state and local comprehensive plans,

- whether the area for the proposed district is of sufficient size, compactness and is sufficiently contiguous to be developable as one community,

- whether the district is the best alternative available for delivering community development services and facilities,

- whether the facilities of the district are compatible with the capacity and uses of the existing services and facilities and

- whether the district area is amenable as a separate special-district government.

Therefore, the state legislation leaves the decision about CDD size with the establishing authorities rather than stipulating for a CDD minimum and maximum since the establishing authorities are considered to better judge the appropriateness of district size for specific development projects.

Table 5.2 displays CDD financial characteristics. The estimated infrastructure costs summed a total of $\$ 6,405,179,626^{8}$ and, as of 2007 , the amount of CDD outstanding debt accumulated $\$ 2,314,662,280$. When looking at each county the financial data show some interesting facts. On one hand, the counties with the highest estimated infrastructure costs are Hillsborough, Pasco and St. Lucie. On the other hand, the top leading counties in raising revenues and allocating expenditures are Hillsborough and Miami-Dade counties. Also, Miami-Dade County has raised the highest amount of debt among the six counties.

\footnotetext{
${ }^{8}$ This amount represents the sum of all the CDD estimated infrastructure costs that have been transformed in real dollar values using the current CPI index for 2008
} 
Table 5.2 CDDs Financial Characteristics

\begin{tabular}{l|lr|r|r|r|r}
\hline & $\begin{array}{l}\text { Estimated } \\
\text { infrastructure } \\
\text { costs* }\end{array}$ & $\mathrm{N}$ & Revenues** & Expenditures** & $\begin{array}{l}\text { Outstanding } \\
\text { Debt** }\end{array}$ & $\mathrm{N}$ \\
\hline Hillsborough & $\$ 1,671,576,381$ & 50 & $\$ 129,270,285$ & $\$ 130,110,247$ & $\$ 560,639,288$ & 51 \\
Miami-Dade & $\$ 888,670,560$ & 57 & $\$ 93,172,741$ & $\$ 129,915,648$ & $\$ 809,112,723$ & 57 \\
Lee & $\$ 792,168,419$ & 33 & $\$ 43,906,234$ & $\$ 61,409,469$ & $\$ 269,511,535$ & 37 \\
Pasco & $\$ 1,115,980,455$ & 36 & $\$ 62,616,976$ & $\$ 82,596,741$ & $\$ 221,076,565$ & 31 \\
St. Lucie & $\$ 1,069,027,017$ & 29 & $\$ 16,223,927$ & $\$ 46,512,373$ & $\$ 135,315,000$ & 33 \\
Manatee & $\$ 867,756,793$ & 32 & $\$ 65,387,090$ & $\$ 82,041,490$ & $\$ 319,007,169$ & 34 \\
\hline All & $\$ 6,405,179,626$ & 237 & $\$ 410,577,253$ & $\$ 532,585,968$ & $\$ 2,314,662,280$ & 243 \\
\hline
\end{tabular}

Note: * CDD petitions data; ** 2007 Florida Department of Financial Services data 
These figures show that CDDs in Miami-Dade County are newcomers compared to the districts in the other five counties where a big chunk of the debt might have already been repaid. Also, these numbers may indicate that developers in the other five counties might have contributed more than the ones in Miami-Dade County towards the initial infrastructure costs and, therefore, have less outstanding debt.

The next step of this section analyzes the main types of development that are supported by CDDs as well as the factors that determine the preference for a particular type of development. This aspect of the research is important because type of development is closely related to the type of infrastructure that CDDs build.

The type of development is approved by general-purpose government when developmental permits are issued. The type of development that CDDs support is found to be related to the land-use of the respective area, to the preference of developers and to the needs of a community.

When looking at the type of development by county, it is clear that residential development is the main type of development that CDDs support. Figure 5.1 describes the type of development for each of the six counties. Within the six Florida counties CDDs support mainly residential and mixed-use development. Manatee and Miami-Dade counties have CDDs that are predominantly residential (over 80\%). In Hillsborough, Lee and Pasco counties, residential development represents approximately $70 \%$ of all types of development. St. Lucie is a stand-alone county where residential development represents $40 \%$, commercial $50 \%$ and mixed-use $10 \%$. The type of development trends corroborated with the CDD location status (unincorporated vs. incorporated) demonstrate that CDDs located in unincorporated areas focus more on residential development while those located within the city boundaries are more likely to focus on commercial and mixed-use developments. 


\section{Figure 5.1 Type of Development by County}

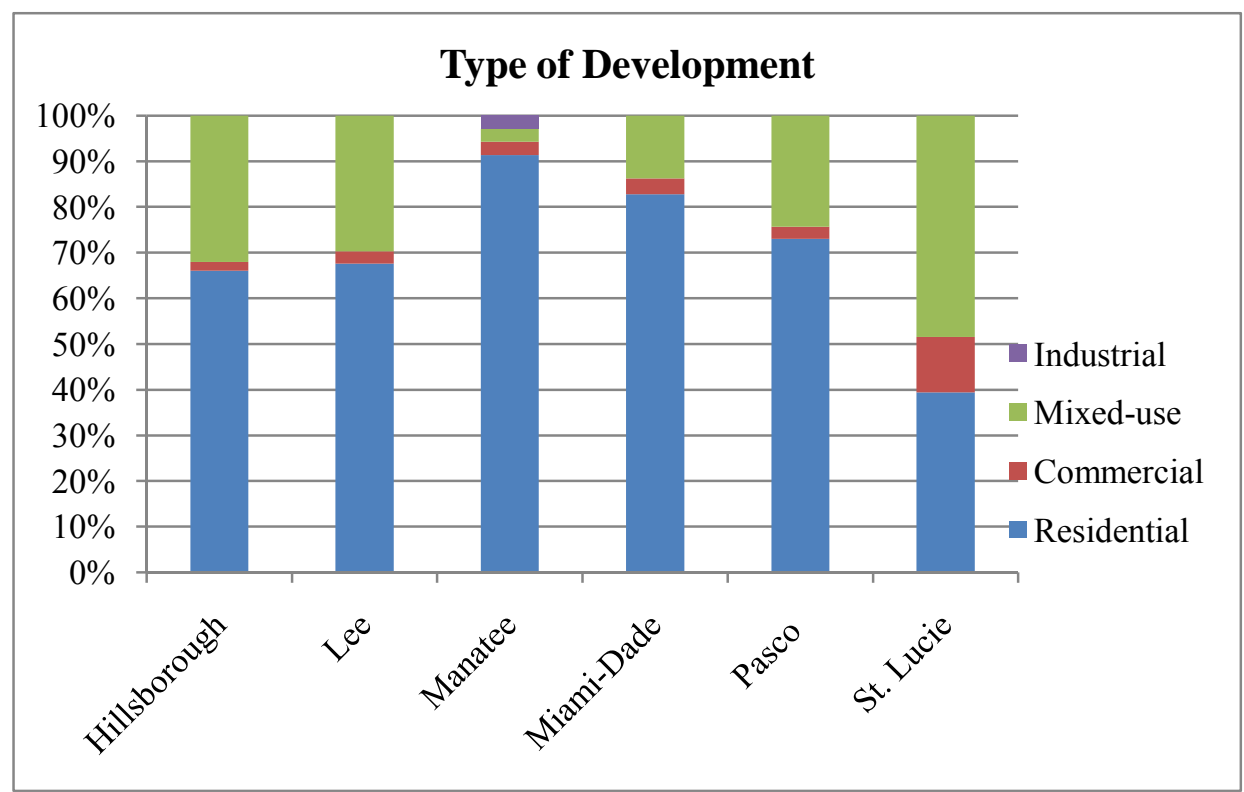

According to Table 5.1 CDDs in Hillsborough and Miami-Dade County are the top two leaders in building housing units. For commercial and industrial property the top leader is, by far, Miami-Dade County. The fact that the CDDs in Miami-Dade County are ranked second in supporting housing units and first in supporting commercial and/or industrial development may be explained by these districts' focus on multifamily housing and mixed-used development as opposed to the districts in the other five counties under analysis.

The preference for residential development is attributable to two main factors. First, CDDs fulfill the need for an increasing population within the State of Florida: "residential is the favorite function because this was the major engine of growth for the state" (CDD representative 2). Second, districts are an opportunity to generate profit for developers: "CDDs focus mostly on residential development because developers prefer to sell instead of leasing and thus make profits without keeping any of the responsibilities of 
paying taxes on commercial or industrial properties" (Division of Special Taxing Districts, Miami-Dade County).

The residential communities that CDDs create could be classified according to the types of improvements they offer. Through the amenities they provide the development that CDDs support ranges from high-end to affordable communities:

We've had some CDDs that do pretty much exclusively high end development, million dollars homes, but we've also had some that have done more of the middle range product - carriage homes and town houses and things like that (...) and we've even had a CDD which is a big community that's considered an affordable area (Planning Division, Lee County).

Starting off as residential planned communities, today CDDs experience a shift towards mixed-use and commercial development: "We're shifting more to the institutional and commercial uses than, probably, would have been anticipated twenty years ago" (Planning Division, Lee County). These two types of developments might fuel the number of CDDs in the future especially given the recent slump in the demand for residential development.

The analysis identified another type of development that CDDs may be useful for, institutional development. Examples of institutional development consist of: educational facilities such as schools and research facilities, public buildings, civic buildings, fire stations, health care facilities and offices. The CDDs should be used more as a vehicle for institutional development as opposed to residential development, especially in today's market where the demand for residential development has dramatically decreased.

There is a changing role of CDDs vis-à-vis development when considering what the legislature intended and what is actually happening. Today CDDs' primary focus is on infrastructure development for residential communities even though the legislature made them more flexible: "there was a contaminated soil clean up, redevelopment, 
blinded area, street lighting, simple things (...) rather than go to the state with every single special interest" (Financial Management Department, Manatee County). Therefore, in practice, CDDs' area of interest evolved from what Chapter 190 Fla. Stat. stated they can do and became adapted to other uses than they were originally intended to.

Finally, the analysis identified a lack of coordination between the infrastructure provided by CDDs and that provided by local general-purpose governments. Even though CDDs must comply with the planning and zoning requirements of local general-purpose governments, the infrastructure districts provide is not included in the capital improvement plan of their surrounding general-purpose governments: "the development that comes out of CDDs is not coordinated with the comprehensive plan of a county; it's consistent but not coordinated" (Planning Division, Lee County). General-purpose governments do not include CDD infrastructure in their capital improvement plan because they cannot control it and because they are not required to do so.

From this perspective CDDs are not believed to fulfill concurrency requirements because most of the improvements that districts support are not subject to levels of service standards as defined by the Florida Growth Management Act.

We look at concurrency through the most part like transportation concurrency. We're looking at our collector and arterial system and where your project first impacts that system. We're looking at a particular link or road and determine whether or not there is capacity, sufficient capacity so, I don't think that the districts are really contributing to provide capacity in that fashion (Planning Division, Lee County).

Concurrency compliance is, therefore, an optional preference of CDDs since the state legislation does not require local general-purpose governments to include districts infrastructure into their programs or CDDs to adopt capital improvement plans. The only thing that CDDs are required to do is to submit public facilities reports to their 
surrounding general-purpose governments. However, these reports are for information purposes only.

Those CDDs who enter into inter-local agreements with general-purpose governments to build major infrastructure projects such as highways, roadways, parks, fire stations, education facilities etc. coordinate their activity with counties but only for those specific projects. Therefore, coordination issues between CDDs and their surrounding general-purpose governments might be addressed through inter-local agreements between the two entities.

In sum, CDDs are specialized governmental entities which provide infrastructure services mainly in unincorporated areas, thus contributing to sprawl patterns. In theory, to make economic sense, the optimum CDD size should be between 300 and 500 acres but, in reality, their size vary from as small as 9.4 acres to as high as 1097 acres. Even though CDDs may be used for any type of development within the six Florida counties districts supported public facilities and services mainly for residential and, secondarily, for mixeduse developments. In determining the role CDDs play vis-à-vis concurrency requirements this chapter found that districts manage to coordinate infrastructure provision with new development but they raise important issues about how location, the type of development they support as well as the lack of coordination with their surrounding general-purpose governments impact growth management.

\subsection{Summary}

The CDDs are considered complements to other public or private forms of infrastructure provision. Most of the public improvements that are supported by districts focus on unincorporated areas, thus encouraging development to be located on the fringe 
of municipalities. Districts are used mainly for residential development and unless CDD size does not average between 300 and 500 acres, they are not economically viable.

Even though CDDs were authorized to provide infrastructure for any type of landuse, they focused mainly on residential development. The future of CDDs might be geared toward mixed-use and commercial developments since the potential of CDDs has not been fully taken advantage in Florida. The districts' usefulness could move beyond providing infrastructure for residential developments, to institutional uses such as educational and health care facilities, to contaminated soil clean up, redevelopment etc.

The findings of this chapter clearly showed that CDDs are believed to partially fulfill the concurrency requirement by linking new development with the needed infrastructure through the availability of funding and the timing of infrastructure. Through their financial capacity districts can build infrastructure improvements in a timely manner.

However, results also indicated that CDDs are not subject to the levels of services standards set forth in the capital improvement plans of general-purpose governments for the following infrastructure services: water and sewer, solid waste, drainage, parks and recreation and roads. In other words, the development that districts support does not comply with the capacity standards for each of the aforementioned infrastructure improvements. From this perspective, CDDs no not seem to fulfill the concurrency requirement since the infrastructure they provide is not included in the capital improvement plans of general-purpose governments and, therefore, not subject to the latter's levels of services.

In sum, CDDs do not seem to foster growth management in Florida. Rather, through their decisions about the location, type and pattern of development CDDs encourage sprawl patterns. Even if districts coordinate infrastructure provision with new 
development they do not coordinate their infrastructure improvements with those of general-purpose governments.

These findings raise two important questions. First, do CDDs influence the way growth occurs? They certainly do. On one hand, CDDs influence growth patterns because they are located primarily in unincorporated areas, thus encouraging sprawl. On the other hand, CDDs have to comply with the planning requirements of general-purpose governments. So, in places where there is plenty of space, CDDs offer "islands of luxury" with single-family houses, golf courses and a lot of open space. In cases where there are more stringent rules that control growth, CDDs encourage denser communities with multi-family housing and mixed-use development.

Second, why have CDDs been used mainly for residential development and have not supported facilities for educational, research or health care purposes? It appears that developers have used this institutional mechanism for generating profits. In Florida we probably will not see CDDs supporting educational or health-care facilities until other entities or individuals than developers (such as public authorities and non-profit organizations) - which are not necessarily profit-maximizers - will start utilizing these multi-purpose districts. 


\section{CHAPTER VI}

\section{THE ROLE OF COMMUNITY DEVELOPMENT DISTRICTS FOR INFRASTRUCTURE DEVELOPMENT}

\subsection{Introduction}

This chapter assesses the contribution of CDDs to the infrastructure development in Florida by analyzing CDDs' profile within six Florida counties: Hillsborough, Lee, Manatee, Miami-Dade, Pasco and St. Lucie. It is divided in two main parts: one that describes the role CDDs play in infrastructure provision and maintenance and another one that identifies indicators of infrastructure variation among CDDs. The chapter proceeds with a brief description of the financing options available for infrastructure development; then, the type of infrastructure improvements provided by CDDs is described; further, the role CDDs play in the provision and maintenance of infrastructure services is being discussed; finally, drivers of infrastructure variation are being identified. Drawing on semi-structured interviews with public officials and CDD representatives as well as on secondary data about CDD activity, findings point to the significant contributions CDDs have made for infrastructure development within the State of Florida.

\subsection{Infrastructure Development}

Infrastructure development is considered to be an important part of the growth management programs for local governments (Porter, 2008). There are several methods for funding public infrastructure. First, the most common way for local general-purpose 
governments to finance public infrastructure is through general revenues such as property taxes, bond issues, increments in sales and excise taxes, fees and charges. Second, local general-purpose governments may require developers to contribute towards public infrastructure provision. Oftentimes developers are required to build and dedicate to local general-purpose governments basic infrastructure and to fund off-site improvements such as roadways or utility extensions. Third, local general-purpose governments impose impact fees (assessments levied on new development to help pay for the construction of infrastructure) on developers when building permits are issued. Last but not least, special districts are an alternative means for funding public infrastructure. This is the case particularly for the special districts with taxing powers that can levy taxes, assessments and issue bonds to cover the costs of infrastructure.

Even though there are a variety of sources to fund public infrastructure, infrastructure provision should be related to infrastructure management when deciding upon the best alternative for infrastructure development, especially because managing public infrastructure is a challenging process (Porter, 2008). Porter (2008) suggests that local general-purpose governments should consider the following aspects when choosing appropriate means for managing and financing infrastructure needs: importance and size of the facility, efficiency in delivering services when specific needs are to be met, ability to link the costs directly to service users, location, quality and timing of public infrastructure construction as well as linking infrastructure development to its capacity.

In Florida, infrastructure management and financing represent a difficult issue for policy-makers. While local general-purpose governments funded an important portion of new development, the rapid increase in population could not keep pace with the demand for growth. Because of the tax-averse sentiment of the Florida's population, state-wide taxes to fund infrastructure could not be adopted and local general-purpose governments 
were authorized to add optional motor fuels taxes, increase their sales taxes and encouraged to impose impact fees and special assessments.

While local taxes such as increases in local sales taxes and local gas taxes as well as impact fees and charges constituted a temporary solution for the infrastructure funding problem, researchers argued that independent special districts, in general, and community development districts, in particular, can fund infrastructure improvements (Bartling, 2007; Porter, 2008; Porter et. al., 1992).

In trying to answer the following question: Which are the contributions of CDDs to infrastructure development in Florida? This chapter analyzes the type and amount of infrastructure supported by CDDs, their role in providing and maintaining infrastructure for new development as well as drivers of infrastructure variation within six Florida counties: Hillsborough, Lee, Manatee, Miami-Dade, Pasco and St. Lucie.

\subsection{Types of Infrastructure Provided by CDDs}

Community Development Districts are local governmental entities that carry out management and financing functions to fulfill their purposes of providing and maintaining infrastructure. Through their financial powers districts borrow money and fund infrastructure improvements, thus "helping developers build the infrastructure they want to build" (Financial Management Department, Manatee County). The CDDs can be considered self-help tools for infrastructure development since they are considered "a way for development to pay for itself' (CDD representative 3).

The infrastructure CDDs provide can be classified according to its location in onsite and off-site improvements. On-site improvements are those types of infrastructure supported by CDDs that are internal to the project while off-site improvements are infrastructure improvements that are external to the CDD project and which usually 
require the presence of an inter-local agreement between a general-purpose government and a district.

On-site improvements constitute the majority of the infrastructure that CDDs build: "most of the money is spent inside the subdivision, developing basic infrastructure within the subdivision" (Financial Management Department, Manatee County). Following the infrastructure categorization proposed in Chapter 190 Fla. Stat. (basic infrastructure and optional special improvements) the author classified on-site improvements in public facilities and public amenities. The difference is relevant since all CDDs provide at least one type of basic infrastructure but only some of the districts choose to add optional special improvements when the petition for CDD creation is submitted for review to local general-purpose governments.

The most common public facilities supported by CDDs refer to basic infrastructure such as storm water management and drainage system, water and sewer system, waste water system, irrigation water system, internal roads, conservation land, sidewalks and street lights. Public amenities may range from recreational facilities such as golf courses, clubhouses, pools, parks, tennis courts, playgrounds, walking or biking trails to enhanced landscape with diverse entry features, security gates and water fountains to security powers, to parking structures and traffic control devices within communities such as speed humps and internal street signage. Within the six Florida counties under analysis all CDDs provide at least a public facility from the basic infrastructure category whereas less than two thirds of the districts $(62.55 \%)$ choose to provide public amenities.

Once the facilities and amenities are built, they have to be open to the general public. CDDs should not be gated communities and there has to be public access to the facilities and amenities they provide: 
When they build this infrastructure, especially roads, if they're using CDD money, that's tax exempt bond money and that can only be used for public facilities (...) technically, those roads, even if they're gated they can't keep the public out (CDD representative 4).

The Uniform Community Development Districts Act stipulates that off-site improvements fall into the category of basic infrastructure. Unlike on-site improvements which are provided by all CDD within the six Florida counties, the present analysis suggests that off-site improvements are provided roughly by less than half of the districts (48.8\%). The majority of off-site improvements are transportation-related and they refer to off-site major roadway, turn lanes, arterial or collector roads that access the community, interchange improvements, traffic lights and bus shelters. There are also offsite improvements related to public utilities that connect services to the existing ones, which may be some distance away, such as improvements that bring water and sewer lines to a specific property.

The CDDs located in incorporated areas are typically focusing on roadway improvements and less on utility extensions when compared to the districts located in unincorporated areas. This can be explained by the fact that cities already have utility systems in place and need help in upgrading their streets: "(In cities) it's more common to have CDDs for roads, not as common for water and sewer because we provide that (...) and roads are so expensive!" (Planning Division, City of Ft. Myers).

The reasons behind the option of providing certain types of off-site improvements are related to the following. First, the location of the new development requires access which may not be supported by the existing infrastructure: "in order for the community to get developed (...) the roads in front of the community have to be upgraded" (Planning Division, City of Ft. Myers). Second, there are transportation or development order requirements that need to be met: "in order for developments to meet certain 
requirements, the district must improve a major road or major interchange of a highway" (Growth Management Department, Hillsborough County). Finally, general-purpose governments are not willing or not able to extend the water and sewer lines up to where the development supported by CDD begins.

To sum up, CDDs provide both on-site and off-site public improvements which are supposed to be open to the general public due to the fact that CDDs use tax-exempt bonds to finance them. Most of the infrastructure provided by CDDs is internal to their projects and off-site improvements are primarily fostering on-site improvements. The choice of focusing on external infrastructure is the result of several factors such as vicinity to major roads and highways, existence of transportation or development order requirements that need to be met or the inability or unwillingness of local generalpurpose governments to provide them.

\subsection{Infrastructure Provision and Maintenance}

In any given jurisdiction that favors special-purpose governments, public service provision is shared by the public, private and non-profit sectors. Section 6.4 discusses the role CDDs play in infrastructure provision and maintenance by considering two public institutional choices for infrastructure delivery: local general and special-purpose governments. Typically, CDDs provide public services such as storm sewer systems, drainage systems, private roads, storm water ponds, while counties or cities focus on water and sewer utilities, public roads, fire protection and public right-of-way. Oftentimes these services are divided between the two types of local governments (general and special-purpose) from the very beginning while other times CDDs construct the infrastructure and then dedicate it to the county or the city they are located in. 
The analysis revealed that there are two scenarios related to the CDDs role in providing infrastructure improvements. Districts may act as both providers and maintainers of public facilities or they act only as providers but not maintainers of infrastructure improvements. In the former case, examples of public infrastructure that is most likely both provided and maintained by CDDs are: storm water management systems - "I think it works quite well to have the CDD assume the primary responsibility for a storm water maintenance because it has access and the ability to focus and concentrate effort within a defined area" (CDD representative 2) or internal roads - "if roads are going to be private, we (county) will be happy for them (CDDs) to finance and maintain them" (Planning Department, Manatee County).

The latter scenario is most likely the case for water and sewer facilities because most general-purpose governments have already a comprehensive water and sewer system in place. There are even instances when counties and cities would try to discourage CDDs from building public utilities just to make sure districts are not competing with them:

We (county) wouldn't want them to provide water and sewer on their own, we would try to discourage small utility plants because we want to be the service provider. If they're going do that somehow, then we would want that to be turned over to us at some point when we are next to them or adjacent to them (County Attorney Office, St. Lucie County).

Other examples of common public facilities that could be built by CDDs and operated by a city or a county are recreational parks - "one of our CDDs in Dade County did a new park for the new City of Doral. So, the CDD paid for the park improvements and all that and then it handed over to the City of Doral and now it's a city park (CDD manager 2)" or roads - "if the district funded the construction of the roads, sometimes 
they're maintained by the district and sometimes they're turned over to the local government" (CDD manager 1).

The CDDs act as providers but not necessarily as operators of public facilities because of two reasons. First, CDDs can build infrastructure in unincorporated areas where general-purpose governments do not have access or the necessary means to do it. Then, CDDs manage to build infrastructure faster than general-purpose governments, hence the benefit of ultimately getting the infrastructure ready in a timely fashion.

There are exceptions to the rule, though. There are instances in which large districts build and own their own public facilities because they can afford to do so: "the larger the district, the more likely they will have their own utility" (CDD representative 4). The instances in which CDDs provide and operate their own water and sewer utilities are rare because such projects require extensive costs and because general-purpose governments already service most of the areas:

It's kind of cost-prohibitive, you've got to start a huge capital investment and there's not enough room to spread that investment once you take out the areas that are covered by the service areas of the two largest general-purpose governments that operate utilities (CDD representative 2).

In addition to provision, maintenance of public infrastructure is an important function of CDDs. Infrastructure maintenance may be performed by either a special or a general-purpose government. When deciding which level of local government (specialpurpose or general-purpose) is better at handling a particular piece of infrastructure, the analysis demonstrated that there are several factors to be considered. One of the most important factors is represented by local conditions such as the particularity of the project. If it is a large project such as a water and sewer management system it makes more sense for a general-purpose government to operate it since it has the capacity and experience while a drainage system could very well be handled by a CDD. 
Other factors include: efficiency - determining the most efficient way to handle a certain piece of infrastructure regardless of the entity that built it; considering the service provider - sometimes it would be wiser for the entity that provided the service to also maintain it; and the type of land-use - for instance, residential development would need different facilities as compared to agricultural land and integration with the overall surrounding facility system.

The maintenance function may be related to the life-cycle of CDDs. Unlike other entities which disappear after they fulfill their scope, CDDs are not terminated once the facilities get built because they are "perpetual entities."

Just because the bond is paid off doesn't mean that the CDD goes away because there's still the ongoing maintenance. CDD owns the recreational facilities, CDD owns the landscaping, CDD owns and maintains the drainage and the water management system and just to continue to pay vendors to keep up the playground and parks and clean the ponds and so forth. So, there's still the ongoing operation and maintenance assessment that still goes on, that property owners' tax is billed even though the bond repaying the assessment goes away (CDD manager $1)$.

Maintenance should also be understood in the context of board of supervisor's transition from developers to residents. The CDDs can be classified in two categories. One category refers to dormant districts where "all they're doing is maintaining what needs to be done to continue to be in existence as a district and maintaining the infrastructure and pay off the bond" (CDD representative 1). The other category represented by active districts, perform improvements for the community on a continuous basis.

Summing up when supporting infrastructure development, CDDs have different roles. On one hand, CDDs act as both providers and maintainers of public improvements such as storm water management systems and internal roads. On the other hand, CDDs 
act as providers but not as maintainers of public services for infrastructure improvements such as water and sewer systems, internal roads and parks. Besides infrastructure provision, maintenance is perceived as one of the most important functions that CDDs fulfill. Moreover, infrastructure maintenance is perceived as a natural function of the CDDs' perpetual nature.

\subsection{Indicators for Infrastructure Variation}

After analyzing the role of CDDs for the infrastructure provision and maintenance in Florida it is also important to understand why districts choose to provide certain types of infrastructure in detriment of others. Relying on secondary data coming from CDD petitions and Florida Department of Financial Services within the six aforementioned counties this section seeks to analyze how CDDs differ when providing public infrastructure.

Since there are no prior theoretical perspectives but only a few empirical studies (Gross, 2005; Mitchell, 2008) that explain service variation for special-purpose governments, the author's choice for indicators of infrastructure variation is a consequence of the suggestions identified in the semi-structured interviews, the preliminary exploratory analysis about CDD functions and activity and previous literature (Gross, 2005; Mitchell, 2008). General-purpose governments within which districts were located (Mitchell, 2008) and district size (Gross, 2005) were found to explain service provision variation in the case of Business Improvement Districts.

The final choice of indicators that were included in the analysis comprised of the following: the county within which CDDs are located (COUNTY), CDD location status

of unincorporated vs. incorporated (LOC), CDD size (SIZE), CDD year of establishment (YEAR), the type of development CDD support (DEVELOP), whether CDDs have 
optional special powers or not (IF SPECIAL), number of services that were owned and maintained by CDDs (OWN), whether CDDs provide off-site improvements (IF OFFSITE), whether CDDs have outstanding debt or not (IF DEBT) as well as financial characteristics such as CDD revenues (REV), expenditures (EXP), estimated infrastructure costs (INFRCOST) and amount of outstanding debt (DEBT). Infrastructure variation among CDDs was expressed as the number of services provided by CDDs.

\subsubsection{Significant Differences}

In order to assess whether there are differences in the amount of services provided by CDDs, cross-tabulations were first employed. Lambda was chosen to identify significant differences between the number of services provided by CDDs and the following independent variables that were measured at the nominal level: COUNTY, LOC, DEVELOP, IF SPECIAL, IF OFF-SITE and IF DEBT. Out of the six explanatory variables that were measured at the nominal level only three showed significant differences in explaining the variation for CDD provided services, as depicted in Table 6.1. All three variables showed a weak but significant relationship with the number of services provided by CDDs.

\section{Table 6.1 Differences in the Number of Services Provided by CDDs}

\begin{tabular}{lccc}
\hline Independent variable & Lambda & P value & N \\
\hline IF SPECIAL & .201 & .000 & 249 \\
COUNTY & .158 & .001 & 249 \\
DEVELOP & .038 & .018 & 247 \\
\hline
\end{tabular}

First, the variable IF SPECIAL showed a fairly weak association with the number of services provided by CDDs. Overall, CDDs with special powers provided a higher 
number of services than the districts which do not have such powers. $87 \%$ of the CDDs that do not have optional special powers provided between four and five services while $76.4 \%$ of the CDDs that have optional special powers provided between six and eight services. Furthermore, CDDs with no special powers offered a maximum of six services as compared with nine services provided by their counterparts.

Then, the number of CDD provided services differed within the six counties. At one extreme there is Miami-Dade County with the majority of CDDs (86.2\%) providing four and five services while at the other extreme there is Pasco County with $83.7 \%$ of the CDDs providing between seven and nine services. More than half of the CDDs in St. Lucie County $(58.1 \%)$ provided six services. In the other three counties the number of services was distributed as follows. In Lee County more than half of the CDDs $(52.8 \%)$ provided between four and five services, Manatee has less than half of the CDDs $(44.1 \%)$ providing between five and six services and Hillsborough County shows a more even dispersion of services: $77.3 \%$ of CDDs provided between five and seven services with approximately equal distribution in the five, six and seven category of services offered.

The highest number of services for Miami-Dade and St. Lucie counties were seven and six respectively, while Hillsborough and Lee counties had eight services each. The only counties that provided nine services are Manatee (20.6\%) and Pasco (35.1\%). Overall, the results demonstrated that CDDs located on the Florida East coast offered fewer services than those located on the West coast.

Finally, type of development had the weakest contribution towards the number of services districts provided. Most of the CDDs which provided infrastructure for commercial (70\%) and all of the CDDs that provided services for industrial $(100 \%)$ developments offered five services as opposed to $22 \%$ for residential and $18.6 \%$ for mixed-use developments. The CDDs that supported residential development showed a similar trend to those that supported mixed-use development. $69.5 \%$ of the districts 
supporting residential development and $67 \%$ of those supporting mixed-use development provided between four and six services. Overall, the services offered by residential and mixed-used CDDs showed a wider variation ranging from three to nine services for residential and one to eight services for mixed-use as compared to commercial (four to seven services) and industrial ones (five services).

Summing up, the number of services provided by CDDs differed according to whether they had or not special powers, the county within which they were located and the type of development they supported. The CDDs with special optional powers provided a higher number of services than the districts that did not have such powers. Districts in Pasco and Manatee counties provided the highest number of services with nine services each, followed by Hillsborough and Lee counties with eight services each and, finally, Miami-Dade and St. Lucie counties with seven and six services, respectively. Finally, CDDs supporting residential and mixed-use development provided more services (nine and eight services respectively) and showed a wider variation than the CDDs supporting commercial and industrial development (seven and five services respectively).

\subsubsection{Determinant Predictors of CDD Infrastructure Variation}

Since there were no previous studies dealing with the factors that determine variability among CDD infrastructure services the author decided the order of entering the variables into the regression model by conducting partial correlation and controlling for the selected variables. Initially, a number of seven independent variables were retained for the analysis because they had significant correlations with the dependent variable (see prior section).

Multiple linear regression analysis was employed to help determine which of the seven indicators could be used to predict the variation of CDD infrastructure. The seven 
explanatory variables accounted for $72 \%$ of the variance of CDD infrastructure variation $(\mathrm{F}(7,226)=87.404)$. Three predictor variable with the lowest non-significant regression coefficients were removed leaving four independent variables for the final model.

The analysis used stepwise, enter and backward methods to obtain the best fit for the model. Stepwise method was first used because it is adequate for exploratory purposes. The other two methods were used to check whether there were any differences for the regression analysis models. All three methods generated the same four indicators that explained the highest amount of variance in predicting CDD infrastructure variation. Their descriptive statistics are presented in Table 6.2.

\section{Table 6.2 Descriptive Statistics for Variables}

\begin{tabular}{llcl}
\hline Variable & Mean & St. deviation & $\mathrm{N}$ \\
\hline PROVIDE & 5.69 & 1.49 & 249 \\
OWN & 3.23 & 1.57 & 249 \\
IF SPECIAL & 1.37 & .485 & 251 \\
LGINFRCOST & 7.26 & .415 & 233 \\
LOC & 1.30 & .457 & 257 \\
\hline
\end{tabular}

As depicted in the table above, on average, CDDs provide more services than they maintain. The average number of services provided by CDDs supports the CDDs' primary role as service providers but also points at the importance of the management function that the districts fulfill.

Table 6.3 shows the magnitude of correlations between dependent and independent variables as well as correlations between independent variables. First, the number of services provided is highly correlated (.78) with the number of services owned 
and maintained by CDDs. The more services owned and maintained by CDDs, the more services CDDs provide overall.

Table 6.3 Bivariate Correlations between Predictor Variables

\begin{tabular}{lccccc}
\hline Variable & PROVIDE & OWN & IF SPECIAL & LGINFRCOST & LOC \\
\hline OWN & $.78^{*}$ & & & & \\
IF SPECIAL & $-.65^{*}$ & $-.50^{*}$ & & & \\
LGINFRCOST & $.30^{*}$ & $.19^{*}$ & $-.24^{*}$ & & \\
LOC & $-.21^{*}$ & $-.19^{*}$ & .08 & -.02 & \\
\hline P $<.05$ & & & &
\end{tabular}

The second highest correlated indicator with the number of services provided by CDDs is IF SPECIAL (-.65). The CDDs that have optional special powers provide more services than those who do not have special powers. LGINFRCOST showed a moderate correlation (.30) with PROVIDE suggesting that higher infrastructure costs are associated with more services. Finally, CDD location status is weakly associated with PROVIDE, indicating that CDDs located in unincorporated areas provide more services than those located in incorporated areas.

The final model that emerged from the stepwise analysis contained only four explanatory variables. Table 6.4 describes the results of multiple regression analysis. The four predictor model accounted for explaining $74 \%$ of the variance of CDD infrastructure provision. The overall model was significant: $\mathrm{F}(4,228)=162.511, \mathrm{p}<.001$.

The strongest predictor variable of CDD infrastructure variation was $\mathrm{OWN}$ ( $\beta=$ .57). This explanatory variable had a positive relationship with the number of services provided by CDDs suggesting that the number of CDD provided services increases as the number of CDD owned and maintained services increases. Managing their own 
infrastructure utilities, facilities and amenities represents an incentive for CDDs to offer more services.

Table 6.4 Stepwise Multiple Regression Analysis of Factors that Influence the CDD Infrastructure Variation

\begin{tabular}{lcccc}
\hline Variables & $\mathrm{B}$ & Std. error & $\beta$ & $\mathrm{p}$ value \\
\hline Intercept & 1.749 & .936 & & \\
OWN & .537 & .038 & .576 & .001 \\
IF SPECIAL & -1.079 & .126 & -.345 & .001 \\
LGINFRCOST & .370 & .127 & .102 & .005 \\
LOC & -.256 & .111 & -.079 & .05 \\
\hline R
\end{tabular}

$\mathrm{R}$ squared $=.74$

No. observations $=236$

$\mathrm{DV}=$ number of services provided

The second most significant predictor of CDD infrastructure variation was IF SPECIAL $(\beta=-.34)$. The CDDs that have optional special powers provided more services than those without such powers. The argument behind this finding is obvious. The CDDs entitled to perform optional special powers such as recreational facilities, enhanced landscaping, parking structures and traffic control devices in addition to the basic infrastructure services, are expected to provide a larger array of functions than the CDDs which are not granted such powers.

The third significant predictor of infrastructure variation was LGINFRCOST $(\beta=$ .10), suggesting that the higher the cost of infrastructure services, the higher the number of CDD provided services. When compared to general-purpose governments which offer a variety of services that might have very different costs, the specialized nature of the CDD-provided services should not generate extreme different costs. The types of services CDDs offer are rather limited to basic infrastructure services such as water, sewer, drainage, roads, parks and recreation and the like districts are not expected to encounter 
big cost differences. Therefore, higher infrastructure costs were expected to reflect a larger number of services.

Finally the fourth significant predictor of CDD infrastructure variation was LOC $(\beta=-.08)$. It indicated that CDDs located in unincorporated areas provided more services than those located in incorporated areas. The former were expected to provide more service than the latter since the unincorporated parts of the county are underdeveloped and have more infrastructure needs than the inner-city areas.

Summing up, the multivariate regression analysis demonstrated that the CDD number of services is influenced by four explanatory factors: the number of CDD owned and maintained services, whether the districts have optional special powers or not, CDD estimated infrastructure costs and CDD location status (unincorporated vs. incorporated).

\subsection{Summary}

This chapter presented the role CDDs play for public infrastructure development. CDDs main functions are to manage and fund basic infrastructure improvements such as storm water management systems, water and sewer systems, irrigation systems, roads and parks and recreation. They can also provide optional amenities such as recreational facilities, enhanced landscape, security gates, parking structures and traffic control devices and so on.

CDDs provide both on-site and off-site improvements and their contribution to the infrastructure development in Florida has been to support basic capital improvement projects. Districts contributed mainly to providing infrastructure that is internal to the developments they support and, to a lesser extent, in helping local general-purpose governments take the burden of major capital improvement projects (such as major roads, highways or bridges) off their shoulders. These findings should be related to the fact that 
CDD infrastructure is not coordinated with that of general-purpose governments since the former is not being included in the latter's capital improvement plan.

The role of CDDs in offering public facilities and utilities may be different. They are either both providers and maintainers for public facilities such as storm water systems, drainage systems, internal roads and the like, or they are only providers but not maintainers of public utilities such as water and sewer systems or recreational parks. CDDs benefit general-purpose governments when the former builds and dedicates infrastructure at no direct cost to the latter. This is mainly the case for water and sewer systems and off-site improvements to major arterial roads and highways.

One question that these results may raise is which is the best mode for delivering infrastructure-related services: a general or a special-purpose government? The answer is probably both. Context and particularity of each jurisdiction seem to tell part of the story. The present analysis revealed that there are no clear guidelines to determine what works best for each community when deciding which local government (special vs. generalpurpose) should provide and maintain a service. Rather, it is a matter of considering all the parameters involved for each particular situation.

Besides the traditional role of providing infrastructure, maintenance seems to be a long-term function of CDDs. They are local governmental entities with perpetual existence whose ultimate function is to continuously maintain the services provided. Then, what happens with CDDs when build-out? It seems that some districts oversee that the debt is paid off and the maintenance is properly ensured while others act as "minigovernmental entities" and continue to add additional improvements to their communities according to the desire of their residents. In this instance, do all CDDs justify the governmental protections forever or should their life span be limited?

As suggested before, CDDs are more than service providers they are also managers of infrastructure-related services. This fact may have long-term consequences 
on the quality of improvements. Then, why do not CDDs maintain all the services they provide? Is it because general-purpose governments do not consider districts prepared enough to handle certain pieces of infrastructure? Is it because general-purpose governments do not want competition in certain areas? Or is it something else?

This chapter has also identified the factors that influenced the amount of infrastructure that has been provided by CDDs. The present analysis revealed that the number of services provided by CDDs differed according to whether they have special powers, according to the county within which they were located and the type of development they supported. Overall, CDDs that have optional special powers, those located on the Florida's west coast and those supporting residential and mixed-use development offered more services than their counterparts.

Finally, when identifying indicators that could be used to predict CDD infrastructure variation results indicated that there were four explaining factors that predicted the variation in the amount of infrastructure provided by CDDs. These are: the number of CDD owned and maintained services, whether the districts have optional special powers or not, CDD estimated infrastructure costs and CDD location status (unincorporated vs. incorporated). Districts with a higher number of owned and maintained services, those with optional special powers, those that had higher estimated infrastructure costs and those located in unincorporated areas determined an increase in the number of CDD provided services. 


\section{CHAPTER VII}

\section{THE PERCEIVED EFFECTIVENESS AND RESPONSIVENESS OF COMMUNITY DEVELOPMENT DISTRICTS AS SERVICE PROVIDERS}

\subsection{Introduction}

Today governance in the United States is considered to be specialized (Mullin, 2009). The context within which this chapter should be understood is that both general and special-purpose governments are delivering public services to citizens. Whereas general-purpose governments have to provide services that accommodate different needs, CDDs focus on a limited number of services. Thus, the latter are expected to be more effective and responsive to their constituents than the former. In trying to answer the following question: Are CDDs perceived to be an efficient and responsive institutional model for infrastructure delivery? the purpose of this chapter is to determine the role of CDDs for infrastructure delivery by assessing districts pluses and minuses as well as their effectiveness and responsiveness as service providers.

This chapter is comprised of three sections. The first section presents a descriptive analysis about the perceived advantages and disadvantages of CDDs impact on service delivery by employing univariate descriptive statistics and cross-tabulations. The second section presents the findings related to the effectiveness and responsiveness of CDDs for service delivery. It describes the results of exploratory factor analysis as well as the creation of three indexes that represent CDD favorability: cost-effectiveness, managerial responsiveness and institutional flexibility. These indexes measure practitioners' general perceptions about developing and implementing CDDs. They can be useful to decision- 
makers when considering CDDs as a means of financing and managing infrastructure. The final section describes the perceived drawbacks of CDD implementation by focusing on the qualitative analysis of the survey.

\subsection{CDD Perceived Pluses and Minuses}

The first section of the survey results depicts the perceived advantages and disadvantages of CDDs impact on service delivery. It presents a description of the individual characteristics of individuals participating in the survey, differences between the on-line and mail modes of survey, a description of the survey items as well as differences among respondents' perceptions according to their individual characteristics.

\subsubsection{Individual Characteristics of Survey Participants}

The survey participants are differentiated by several demographic and professional characteristics. These are: age, highest level of education completed, the department they belong to, whether they have a professional certification or license, their experience within the current position, whether the present position is a supervisory one or not and whether they have working experience outside the State of Florida. A summary of the frequencies for all these demographic and professional indicators are depicted in Table 7.1. Survey participants fall into different age categories. Two thirds of the respondents are between 46 and 65 years of age while less than $7 \%$ are 35 years of age and less. These figures demonstrate that most respondents have a high degree of seniority. 
Table 7.1 Demographic and Professional Characteristics of Participants

\begin{tabular}{lc}
\hline Variables & Percentage of partic \\
\hline Age & \\
$25-35$ & $6.6 \%$ \\
$36-45$ & $23.1 \%$ \\
$46-55$ & $36.3 \%$ \\
$56-65$ & $31.9 \%$ \\
$66+$ & $2.2 \%$
\end{tabular}

Education

98

Highschool

Associate degree

$4.1 \%$

College degree

$1 \%$

Master's degree

$26.5 \%$

Advanced graduate

$53.1 \%$

$15.3 \%$

Department

93

Growth Management

$19.4 \%$

Planning \& Zoning

$23.7 \%$

Community/Economic Development

$15.1 \%$

County/City Attorney

$10.8 \%$

County/City Administration

$12.9 \%$

Budget \& Financial Management

$5.4 \%$

Public Works \& Building

$9.7 \%$

Other

$3.2 \%$

Professional certification

Yes

$65.3 \%$

No

$34.7 \%$

Years in current position

$$
\begin{aligned}
& 0-5 \\
& 6-10 \\
& 11-15 \\
& 16-20 \\
& 21+
\end{aligned}
$$

$45.7 \%$

$21.3 \%$

$8.5 \%$

$14.9 \%$

$9.6 \%$

Type of current position

99

Supervisory

$88.9 \%$

Non-supervisory

$11.1 \%$

Experience outside Florida

Yes

$44.4 \%$

No

$55.6 \%$

99 
Participants in this survey are extremely well educated with only $5 \%$ having a degree less than college. Furthermore, figures about educational attainment show that more than half (51.5\%) of the participants have a Masters' degree and almost $15 \%$ have an advanced graduate degree beyond Master's, thus demonstrating that the survey respondents are among the elites in terms of educational attainment.

Survey respondents come from different departments/divisions as follows: Planning and Zoning, Growth Management, Community/Economic Development, County City Administration, County City Attorney, Public Works and Building, Budget and Financial Management and other. All these departments are involved, to a certain degree, with reviewing the CDDs' creation and/ or monitoring documentation requirements. It is no surprise that Planning and Zoning, Growth Management and Community/Economic Development represent the top three departments in providing survey participants. Also, the participants from these departments have a planning background and, therefore share similar outlook through training and experience.

The presence of a professional certification or license reveals that almost two thirds of the respondents hold such a certificate and, are, considered, experts in their field of endeavor. Over $45 \%$ of the participants spent five years or less in their current position. The professional certification indicator is not consistent with the trends described for age and education where one would expect that a group comprised of mainly experienced and highly educated participants to also have workplace longevity.

Type of current position describes the supervisory vs. non-supervisory status. An overwhelming majority $(88.9 \%)$ of the survey participants hold a supervisory position. This fact may be explained by both age and education of the respondents. Finally, a bit more than half of the participants do not have experience outside the State of Florida. The author would expect this indicator to reveal significant differences in the bivariate analysis. 
Table 7.2 describes summary measures for central tendency and variability for two individual indicators: age and number of years in current position. While age is almost normally distributed, the distribution for the variable number of years in current position is positively skewed, its mean of 9.5 years exceeding its median of 6 years.

Table 7.2 Descriptive Statistics for Age and Years in Current Position

\begin{tabular}{lcccc}
\hline Variable & Mean & Median & Standard deviation & N \\
\hline Age & 50 & 51 & 10.2 & 91 \\
Years in current position & 9.5 & 6 & 8.5 & 94 \\
\hline
\end{tabular}

In sum, the survey participants represent an elite/ managerial type of group with most members being comprised of experienced and highly educated individuals who hold supervisory positions within their work units and have a strong professional planning background.

\subsubsection{Difference Between On-line and Mail Surveys}

Respondents for the on-line and mail surveys offered fairly similar views about CDD advantages and disadvantages. There were two survey items which yielded different answers between the two groups. Table 7.3 illustrates these differences. Sixty two point two percent of the respondents from the on-line surveys compared to $42.8 \%$ of the respondents from the mail survey disagreed and strongly disagreed with the fact that CDDs relieve property tax burden by levying independently.

The second survey item that showed significant differences between the on-line and mail questionnaires was the item measuring whether CDDs circumvent debt limits of general-purpose governments. Those answering by mail were more supportive of the belief that CDDs circumvent the debt limits of general-purpose governments than on-line respondents. 
Table 7.3 Differences between On-line and Mail Surveys

\begin{tabular}{lccc}
\hline Variable & Gamma & P value & N \\
\hline CDDs relieve property tax burden & -.294 & .046 & 101 \\
CDDs circumvent debt limits of GP governments & -.350 & .016 & 101 \\
\hline
\end{tabular}

For this particular study the survey mode does not affect the way participants responded. The participants in both on-line and mail survey were approximately evenly distributed with no significant differences among their individual attributes. Also, survey participants share a homogenous professional background, that of being public officials. Their workplace provides them with both internet access and e-mail addresses and, therefore, internet is part of their work.

\subsubsection{Survey Items}

In addition to the individual characteristics of participants, the survey consisted of twenty five items. The survey items were classified into five major categories. These are structure flexibility, financial implications, economic development, accountability and general overview. The items in the first four categories were categorized according to a five point Likert scale, ranging from strongly disagree to strongly agree. The items in the general overview section were measured by using a seven point semantic differential scale.

The first step of the analysis described percentage frequencies for each of the survey item. The results in this section are displayed according to the main sections of the survey. When asked about the three different aspects of CDD structure flexibility there was a clear pattern of agreement which was differentiated as follows: $63 \%$ of the participants agreed with the fact that CDDs provide community-tailored services, $50 \%$ of the participants agreed with the survey item "CDDs enjoy little oversight from generalpurpose governments" and 38\% agreed with the fact that CDDs are self-supporting mechanisms over time (Table 7.4). 
Table 7.4 CDD Structure Flexibility

\begin{tabular}{lcccccc}
\hline Variable name & $\begin{array}{c}\text { Strongly } \\
\text { Disagree }\end{array}$ & Disagree & Neutral & Agree & $\begin{array}{c}\text { Strongly } \\
\text { Agree }\end{array}$ & $\mathbf{N}$ \\
\hline $\begin{array}{l}\text { CDDs are self-supporting } \\
\text { mechanisms }\end{array}$ & $5 \%$ & $24 \%$ & $25 \%$ & $\mathbf{3 8 \%}$ & $8 \%$ & 101 \\
\hline $\begin{array}{l}\text { CDDs provide community } \\
\text { tailored services }\end{array}$ & $1 \%$ & $11 \%$ & $13 \%$ & $\mathbf{6 3 \%}$ & $12 \%$ & 100 \\
\hline $\begin{array}{l}\text { CDDs enjoy little oversight } \\
\text { from GP governments }\end{array}$ & $3 \%$ & $15 \%$ & $11 \%$ & $\mathbf{5 0 \%}$ & $21 \%$ & 99 \\
\hline
\end{tabular}

The second section of the survey refers to CDD financial implications related to three main groups of beneficiaries: general-purpose governments, developers and residents. The results are depicted in Table 7.5. Survey participants did not consider CDD financial implications have benefits for general-purpose governments. $41 \%$ of the respondents disagreed with the fact that CDD assessments are more stable than the taxes and fees of general-purpose governments, $38 \%$ of respondents disagreed with the fact that CDDs relieve property tax burden by levying independently and $35 \%$ of respondents disagreed with each of the following statements: "CDDs circumvent debt limits of general-purpose governments" and "CDDs relieve general-purpose governments from capital projects".

Overall survey respondents did not consider that CDDs have any beneficial financial implications for general-purpose governments. The CDDs were perceived of not relieving general-purpose governments from capital infrastructure provision and property tax burden or circumventing their debt limits. Neither were CDDs' assessments considered more reliable than the taxes and fees of general-purpose governments.

When considering the CDD financial implications for developers, respondents' opinions showed an agreement pattern. Forty one percent of the respondents agreed with the fact that CDDs increase short-term profitability for developers and $39 \%$ of them 
agreed that CDDs allow developers to enhance amenities at lower cost. Therefore, survey participants perceived CDDs as having beneficial financial implications for developers.

\section{Table 7.5 CDD Financial Implications}

\begin{tabular}{|c|c|c|c|c|c|c|}
\hline Variable name & $\begin{array}{l}\text { Strongly } \\
\text { Disagree }\end{array}$ & Disagree & Neutral & Agree & $\begin{array}{l}\text { Strongly } \\
\text { Agree }\end{array}$ & $\mathbf{N}$ \\
\hline $\begin{array}{l}\text { CDDs relieve property tax } \\
\text { burden by levying } \\
\text { independently }\end{array}$ & $13 \%$ & $38 \%$ & $23 \%$ & $23 \%$ & $3 \%$ & 101 \\
\hline $\begin{array}{l}\text { CDDs circumvent debt limits } \\
\text { of GP governments }\end{array}$ & $7 \%$ & $35 \%$ & $28 \%$ & $26 \%$ & $3 \%$ & 101 \\
\hline $\begin{array}{l}\text { CDDs' assessments are more } \\
\text { stable than the taxes of GP } \\
\text { governments }\end{array}$ & $13 \%$ & $41 \%$ & $33 \%$ & $12 \%$ & $1 \%$ & 101 \\
\hline $\begin{array}{l}\text { CDDs relieve GP governments } \\
\text { from capital projects }\end{array}$ & $14 \%$ & $35 \%$ & $17 \%$ & $30 \%$ & $4 \%$ & 100 \\
\hline $\begin{array}{l}\text { CDDs increase short-term } \\
\text { profitability for developers }\end{array}$ & $1 \%$ & $5 \%$ & $29 \%$ & $41 \%$ & $24 \%$ & 101 \\
\hline $\begin{array}{l}\text { CDDs allow developers to } \\
\text { enhance amenities at } \\
\text { lower cost }\end{array}$ & $4 \%$ & $15 \%$ & $30 \%$ & $39 \%$ & $12 \%$ & 100 \\
\hline $\begin{array}{l}\text { CDDs' assessments are } \\
\text { commensurate with quality }\end{array}$ & $3 \%$ & $21 \%$ & $43 \%$ & $31 \%$ & $2 \%$ & 101 \\
\hline $\begin{array}{l}\text { CDDs' levies give bigger } \\
\text { "bang for the buck" than } \\
\text { ad-valorem taxes }\end{array}$ & $9 \%$ & $29 \%$ & $37 \%$ & $24 \%$ & $1 \%$ & 101 \\
\hline
\end{tabular}

Finally, the CDD financial implications for residents revealed that the opinions of respondents were mainly neutral. If, on the one hand, $43 \%$ of the respondents neither disagreed nor agreed with the fact that CDD assessments are commensurate with the quality of services, on the other hand, $31 \%$ of them agreed with this statement. While $37 \%$ of them neither disagreed nor agreed with the fact that CDD levies give bigger "bang for the buck" than ad-valorem taxes, $29 \%$ of the respondents disagreed with this item. Results concerning the financial implications for residents are mixed. Survey 
participants agreed with the fact that the quality of CDD services justifies the amount of their assessments but disagreed with the fact that CDDs levies offer a bigger value for the monies spent when compared to the ad-valorem taxes of general-purpose governments.

The results for the third section of the survey, CDD economic development implications, are depicted in Table 7.6. The CDDs economic development implications were described in comparison with general-purpose governments. The results for this section are mixed. When asked about whether CDDs provide infrastructure in areas where general-purpose governments are not able to, respondents provided balanced answers: while $37 \%$ of the respondents disagreed with the statement, $36 \%$ of them agreed to it.

Table 7.6 CDD Economic Development Implications

\begin{tabular}{|c|c|c|c|c|c|c|}
\hline Variable name & $\begin{array}{l}\text { Strongly } \\
\text { Disagree }\end{array}$ & Disagree & Neutral & Agree & $\begin{array}{l}\text { Strongly } \\
\text { Agree }\end{array}$ & $\mathbf{N}$ \\
\hline $\begin{array}{l}\text { CDDs provide infrastructure } \\
\text { in areas where GP } \\
\text { governments are not able to }\end{array}$ & $3 \%$ & $37 \%$ & $22 \%$ & $36 \%$ & $2 \%$ & 101 \\
\hline $\begin{array}{l}\text { CDDs build infrastructure } \\
\text { faster than GP governments }\end{array}$ & $3 \%$ & $19 \%$ & $28 \%$ & $42 \%$ & $8 \%$ & 101 \\
\hline $\begin{array}{l}\text { CDDs provide services cheap } \\
\text { than GP governments }\end{array}$ & $3 \%$ & $40 \%$ & $45 \%$ & $12 \%$ & $0 \%$ & 100 \\
\hline $\begin{array}{l}\text { CDDs impose hidden costs to } \\
\text { the surrounding GP } \\
\text { governments }\end{array}$ & $3 \%$ & $27 \%$ & $33 \%$ & $29 \%$ & $8 \%$ & 101 \\
\hline $\begin{array}{l}\text { CDDs offer residents higher } \\
\text { quality infrastructure than } \\
\text { GP governments }\end{array}$ & $8 \%$ & $39 \%$ & $31 \%$ & $20 \%$ & $2 \%$ & 101 \\
\hline $\begin{array}{l}\text { CDDs better maintain service } \\
\text { than GP governments due to } \\
\text { their narrow purpose }\end{array}$ & $5 \%$ & $33 \%$ & $35 \%$ & $25 \%$ & $2 \%$ & 101 \\
\hline $\begin{array}{l}\text { CDDs better maintain service } \\
\text { than GP governments due to } \\
\text { their smaller size }\end{array}$ & $5 \%$ & $33 \%$ & $31 \%$ & $28 \%$ & $3 \%$ & 101 \\
\hline
\end{tabular}


The same situation applies to the survey item "CDDs impose hidden costs to the surrounding general-purpose governments" where $27 \%$ of the respondents disagreed with the statement and $29 \%$ of them agreed to it. In this instance, the figures support a neutral view where CDDs are not necessarily perceived as being complements of public services for general-purpose governments or as imposing additional costs to the containing general-purpose governments.

Whereas respondents showed a strong agreement (42\%) with the fact that CDDs build infrastructure faster than general-purpose governments, $40 \%$ of them disagreed with the fact that the services provided by CDDs are cheaper than those provided by general-purpose governments. Furthermore, 39\% of the respondents disagreed with the fact that CDDs offer residents higher quality infrastructure than general-purpose governments.

Finally, respondents did not think that CDDs better maintain infrastructure services when compared to general-purpose governments neither because of their narrow purpose or because they cover a smaller geographic area. 33\% of the respondents disagreed with each of the two survey items concerning infrastructure maintenance. These findings are contrary to the public choice theory which states that smaller governmental units are more efficient than the larger ones.

The fourth survey section discussed CDD accountability issues in relation to general-purpose governments. Results in this section are presented in Table 7.7. There is a disagreement sentiment about the coordination of CDD reports and infrastructure with the capital improvement plans of general-purpose governments. Forty five percent of the respondents disagreed with the fact that CDD reports were used and relied upon by general-purpose governments when designing capital improvement plans and $35 \%$ of them disagreed with the item "CDD infrastructure is well coordinated with capital improvement plans of general-purpose governments." Respondents' answers were neutral 
(61\% of them neither disagreed nor agreed) in assessing whether CDDs overstep their powers as a result of limited oversight.

Table 7.7 CDD Accountability Issues

\begin{tabular}{lcccccc}
\hline Variable name & $\begin{array}{c}\text { Strongly } \\
\text { Disagree }\end{array}$ & Disagree & Neutral & $\begin{array}{c}\text { Agree } \\
\text { Agree }\end{array}$ & $\mathbf{N}$ \\
\hline $\begin{array}{l}\text { CDD reports are used and } \\
\text { relied upon by GP } \\
\text { governments }\end{array}$ & $9 \%$ & $\mathbf{4 5 \%}$ & $32 \%$ & $14 \%$ & $0 \%$ & 100 \\
\hline $\begin{array}{l}\text { CDDs infrastructure is well } \\
\text { coordinated with GP } \\
\text { governments }\end{array}$ & $6 \%$ & $35 \%$ & $\mathbf{4 1 \%}$ & $17 \%$ & $1 \%$ & 99 \\
\hline $\begin{array}{l}\text { CDDs overstep their powers } \\
\text { due to limited oversight }\end{array}$ & $1 \%$ & $16 \%$ & $\mathbf{6 1 \%}$ & $20 \%$ & $2 \%$ & 99 \\
\hline
\end{tabular}

Lastly, the results for CDD general overview section are displayed in Figure 7.1. The variables in this section are measured by seven point semantic differential scales where 1 and 7 have opposite values. For the variable growth management 1 means "foster growth management" and 7 means "gut growth management". Respondents had a neutral opinion about the CDDs' implications for growth management. On a scale of 1 to 7, $40 \%$ of the survey participants chose number 4 supporting the neutral view. Furthermore, as suggested in Figure 7.1, all the other answer categories were fairly balanced.

The second survey item in this section, fiscal balance is described as follows: 1 means CDDs encourage fiscal balance and 7 means CDDs add to the fiscal stress of the surrounding entities. The answers of the respondents were geared toward the fact that CDDs add to the fiscal stress of the surrounding communities. On a scale of 1 to $7,29.3 \%$ of the respondents chose $5,10.1 \%$ chose 6 and $4 \%$ of them chose 7 . 


\section{Figure 7.1 CDDs’ General Overview}

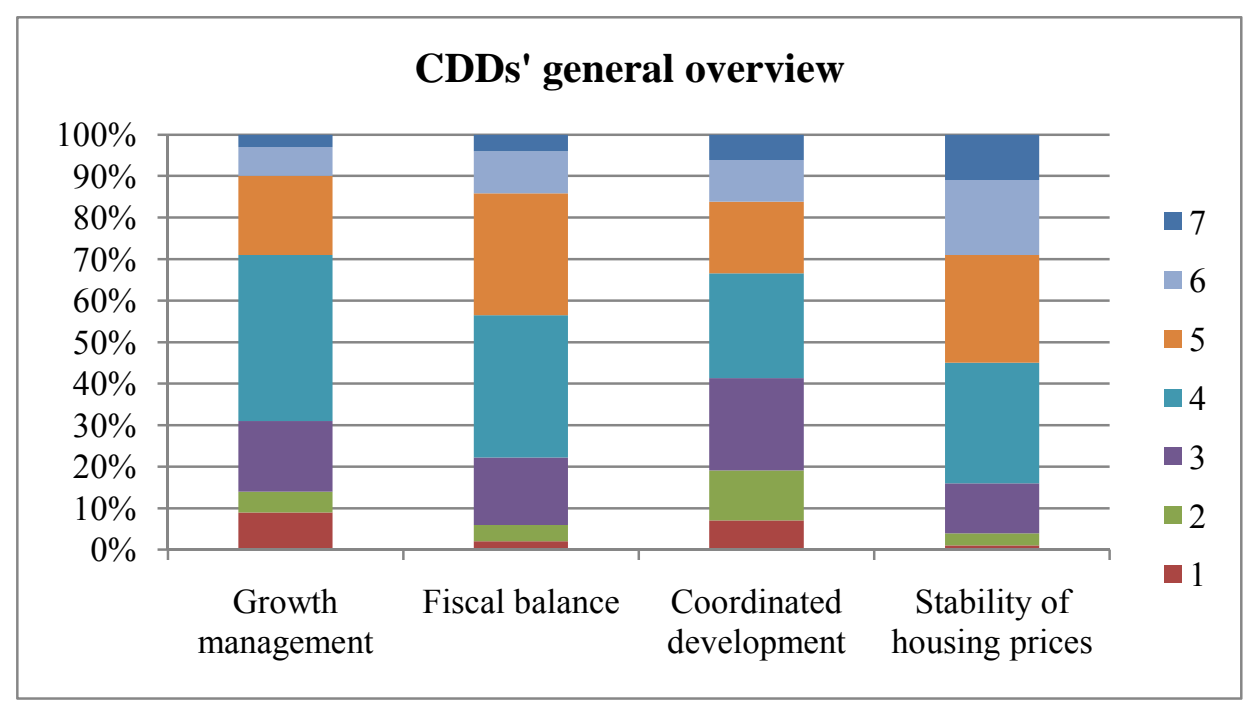

For the third variable, coordinating development, 1 means CDDs encourage coordinated development and 7 means CDDs discourage coordinated development. The opinion of respondents indicated the preference for the fact that CDDs encourage coordinated development. On a scale of 1 to $7,22.2 \%$ of the respondents chose $3,12 \%$ of them chose 2 and $71 \%$ chose 1.

The final variable in this section, stability of housing prices, was measured as follows: 1 means CDDs facilitate stability of housing prices and 7 means CDDs contribute to the "boost an boom" in the housing prices. Respondents considered that CDDs contribute to increases in housing prices. $26 \%$ of them opted for a $5,18 \%$ for a 6 and $11 \%$ for a 7 .

To sum up, respondents perceived CDD pluses and minuses differently. They favored all the aspects of CDD structure flexibility. Therefore, respondents considered that CDDs meet the needs of their communities, they are independent from generalpurpose governments and they are self-supporting institutions. 
Results about CDD financial implications differed according to the three groups of beneficiaries: general-purpose governments, developers and residents. On the one hand, CDDs are not perceived as having any financial benefits for general-purpose governments. Respondents disagreed with the assertion that CDDs relieve the burden of general-purpose governments with capital projects and property tax and the former circumvent the debt limits of the latter. On the other hand, CDDs are viewed as having beneficial financial implications for developers because they generate short-term profits by allowing for improvements to be built at lower costs. The CDD financial implications for residents are mixed, being either beneficial or non-beneficial. Respondents favored the fact that the quality of services offered by CDDs are commensurate with the assessments they impose but they disagreed with the fact that CDD assessments offer better investment returns than ad-valorem taxes.

Results about CDD economic development implications suggest that CDDs are not necessarily better than general-purpose governments in providing and maintaining infrastructure services. Even if CDDs build infrastructure faster than general-purpose governments, the former do not, necessarily, provide infrastructure cheaper or of higher quality than the latter. Furthermore, respondents did not consider CDDs better maintain public services than the general purpose governments when their specialized function and geographic boundaries are considered.

Respondents' views about CDD accountability issues in relation to generalpurpose governments suggested that CDD activity is not coordinated with that of generalpurpose governments. Finally, the results for the CDD general overview section were mixed. While overall, respondents had a neutral perception about the CDD impact on growth management, they considered that CDDs supported coordinated development. Furthermore, CDDs are more likely to contribute to the fiscal stress of the surrounding communities and to increase the housing prices. 


\subsubsection{Differences among Respondents}

The second step of the analysis consisted of cross-tabulations. Contingency tables were constructed to determine whether there is an association between the participants' individual characteristics and the survey items. The statistical technique for measuring association was Gamma since all the explained variables were ordinal and the explanatory variables were categorized as either dichotomous and interval variables. The construct "department type" was transformed into a dichotomous variable by defining its categories as planners and non-planners. The participants from Growth Management, Planning and Zoning and Community/Economic Development departments were combined into the category named "planners" and the participants from the other departments were combined into the "non-planners" category. The decision to classify the participants in the two aforementioned categories resides in the fact that $62 \%$ of the respondents with a professional certificate hold an American Institute of Certified Planners certificate and, therefore, have a planning professional background. The types of licenses that respondents hold are presented in Table 7.8.

\section{Table 7.8 Type of Professional Certification}

Professional certification

American Institute of Certified Planners

BCC\&LG

Professional Engineers

Bar

Other $^{9}$
Percentage respondents

$61.7 \%$

$3.3 \%$

$11.7 \%$

$16.7 \%$

$6.7 \%$

Total number of respondents who hold a professional certification: 60

\footnotetext{
${ }^{9}$ Other refers to the following certifications: Certified Public Accountant, International City/County Management Association certification and State Certified Building Code Administration.
} 
The significant results of the cross-tabulations are depicted in Table 7.9. One out of the seven explanatory variables, "years in current position" did not have any effect on the survey items and it was not reported in the table below.

Table 7.9 Association of Survey Items by Individual Characteristics

\begin{tabular}{lccc}
\hline Independent variable & Gamma & P & N \\
\hline Age & & & \\
CDDs' levies give "bigger bang for the buck" & -.25 & .034 & 91 \\
\hline Education & & & \\
CDDs enjoy little oversight from local GP governments & .36 & .006 & 97 \\
\hline Department type dichotomous & .47 & .007 & 94 \\
CDDs provide community-tailored services & .41 & .008 & 94 \\
CDDs enjoy little oversight from local GP governments & & & \\
\hline If professional certificate & .45 & .004 & 98 \\
CDDs build infrastructure faster than GP governments & .32 & .051 & 98 \\
CDD reports are used and relied upon by GP governments & -.32 & & \\
\hline Type of current position & .58 & .009 & 99 \\
CDDs circumvent debt limits of GP governments & .44 & .058 & 98 \\
CDD reports are used and relied upon by GP governments & .44 & & \\
\hline Experience outside Florida & .37 & .010 & 99 \\
CDDs remain self-supporting institutions over time & & &
\end{tabular}

Age is significant in explaining the fact that CDD levies give "bigger bang for the buck" than ad-valorem taxes. This association is negative (-.25) which means that the younger the respondents the more they favored the statement that CDDs assessments are offering higher benefits for the money spent when compared to the taxes of generalpurpose governments. $50 \%$ of the participants in the $25-35$ years range, $33.3 \%$ for the $36-$ 45 years range to $24.2 \%$ for $46-55$ and $17.2 \%$ for $56-65$ year range. Though significant, the association is weak since the number of younger participants is relatively low compared to the number of the more experienced participants.

Education is moderately associated (.36) with the fact that CDDs enjoy little oversight from local general-purpose governments. This association is a positive 
relationship meaning that the more educated the respondents are, the more they support the fact that there is little oversight on part of general -purpose governments for CDD activity. Sixty four percent of the participants with a college degree, $78.8 \%$ of the participants with a Master's degree and $80 \%$ of the respondents with an advanced graduate degree agreed and strongly agreed with this statement.

Type of department makes a difference in predicting two survey items. First, department type shows a moderate association (.47) with the fact that CDDs provide community-tailored services. Eighty seven percent of the participants who do not have a planning background (non-planners) agreed and strongly agreed with the fact that CDDs provide community tailored services in comparison to $63.5 \%$ of participants with planning background (planners). Second, type of department helped improve the prediction of the survey item "CDDs enjoy little oversight from local general-purpose governments" by $41 \%$. Ninety percent of non-planners in comparison to $52.9 \%$ of planners agreed and strongly agreed with the fact that there is a lack of control on the activity of CDDs.

The fourth explaining variable, the presence of a professional certificate is also associated with two survey items. The presence of a professional certificate is moderately associated (.45) with the fact that CDDs build infrastructure faster than general-purpose governments. Sixty one percent of the participants who have a professional certificate agreed and strongly agreed with the fact that CDDs build infrastructure faster than general-purpose governments in comparison to only $35.3 \%$ of the respondents who do not hold such a certificate. The presence of a professional certificate is negatively associated (-.32) with the fact that CDDs reports are used and relied upon by generalpurpose governments when local comprehensive plans are designed. Seventy-two point five percent of the respondents with a professional license disagreed and strongly 
disagreed with the fact that general-purpose governments use and rely on CDD reports as opposed to only $38.2 \%$ of the respondents who do not hold a professional certificate.

Type of current position is strongly associated (.58) with the survey item "CDDs are a means of circumventing debt limits of general-purpose governments." Supervisors may understand the depth of the problem. Fifty-four point five percent of the participants who do not hold a supervisory position agreed and strongly agreed with the fact that CDDs help circumventing debt limits in comparison to $25 \%$ of the participants who actually hold a supervisory position. Furthermore, $47.8 \%$ of those who have a supervisory position disagreed and strongly disagreed with the fact that CDDs circumvent debt limits when compared to only $9.1 \%$ of those with non-supervisory positions.

Last but not least, working experience outside the State of Florida showed a moderate association (.37) with the fact that CDDs remain self-supporting institutions over time. Sixty-one point four percent of those respondents who have work experience outside Florida agreed or strongly agreed with the fact that CDDs are self-supporting mechanisms over time as opposed to $36.4 \%$ of those respondents who do not have working experience outside the State of Florida.

Summing up, the individual characteristics of respondents showed a significant association relationship with nine out of twenty one survey items. Most of the significant associations were moderate, ranging from .32 to .47 , one was fairly weak (.25) and one was strong (.58). Younger respondents favored the statement "CDD levies give "bigger bang for the buck" than ad-valorem taxes" while the elder ones disagreed with it. Respondents with higher education supported the statement that CDDs enjoy little oversight from local general-purpose governments. Respondents who do not have a planning professional background considered that CDDs provide community tailored services and that CDDs have little oversight from general-purpose governments. 
Respondents with a professional certificate thought that CDDs build infrastructure faster than general-purpose governments. However, they did not support the fact that CDD reports are used and relied upon by general-purpose governments when the capital infrastructure plans are designed. Respondents with non-supervisory positions supported the fact that CDDs help circumventing debt limits of general-purpose governments while respondents with supervisory positions disagreed with this statement. Finally, respondents who had working experience outside the State of Florida considered that CDDs remain self-supporting institutions over time.

\subsection{Factor Analysis and Indexes Creation}

The second main section of the survey results describes the analysis and results of factor analysis (FA) and index creation for the perceived pluses and minuses of CDDs. This study uses exploratory FA to determine the importance of including selected items into indexes of CDD favorability. The option of developing composite measures resides in the fact that indexes are expected to have higher reliability and validity than individual variables (Babbie, 1990; Neuman, 2004; O’Sullivan et. al., 2003). The second section of the survey results describes the principal component analysis and its results as well as the procedures followed to construct three indexes depicting CDD favorability.

\subsubsection{Principal Component Analysis}

Principle components analysis was used because there are no prior theoretical drivers to guide this study. The primary purpose of the analysis is to identify and construct composite measures for the factors underlying the survey items. Principal component was chosen because it is more common in exploratory FA and its usefulness resides in the fact that it generates factors that are used in subsequent analysis (Bryant \& Yarnold, 1995). 
Initially twenty one items were considered for being included in the analysis. There were four problematic items that were eliminated from the analysis because they were cross-loading with several variables and they did not belong to the factor structure. The elimination process was performed during several steps with one item being eliminated at a time and then, re-running the analysis. The item "CDDs impose hidden infrastructure costs to the surrounding general-purpose governments" had cross loadings of -.45 and .43 with two factors. The item "CDD reports are used and relied upon by general-purpose governments when local comprehensive plans are designed" had cross loadings between .4 and .52 with three factors. Furthermore, its presence in the analysis decreased the reliability of its underlying factor. Then the item "CDDs enjoy little oversight from local general-purpose government" did not fit to the structure of the factor measuring CDDs' cost-effectiveness and it was removed from the analysis because of low communalities (.39). Finally, the item "CDDs overstep their powers because of limited oversight from general-purpose governments" was redundant since it was similar to "CDDs enjoy little oversight from local general-purpose government". It was eliminated from the analysis because it decreased the reliability of its underlying factor.

Principal component FA with varimax rotation was conducted to explore the remaining seventeen items of the CDD survey. The initial eigen values showed that the first factor explained $28.55 \%$ of the variance, the second factor $11.18 \%$ of the variance, the third factor explained $10.75 \%$ of the variance, the fourth factor explained $7.63 \%$ of the variance and the fifth factor explained 6.14\%. Four, five and six factor solutions were examined, using varimax rotations of the factor loading matrix since the scree plot showed that six factors could be extracted. The five factor solution, which explained $64.26 \%$ of the variance, was chosen because four factor solutions was too difficult to interpret and the six factor solution ended up with a single item underlying the final factor. The factor loadings matrix is presented in Table 7.10. 
Table 7.10 Factor Loadings and Communalities ( $\mathrm{N}=96)$

Items

Factors

Communality

Cost

Managerial Flexibility Financial Developers'

Effectiveness Responsiveness

Mechanisms Interest

CDDs are self-supporting mechanisms

.73

CDDs provide community-tailored services

.74

CDDs relieve property tax burden

CDDs circumvent debt limits of GP

governments

CDDs' assessments are more stable than the taxes and fees of GP governments

CDDs relieve GP governments from the burden of capital infrastructure funding

CDDs increase short-term profitability for developers

CDDs allow developers enhance amenities at lower cost

CDD assessments are commensurate with quality of improvements

CDD levies give bigger "bang for the buck" than ad-valorem taxes 
Table 7.10 Factor Loadings and Communalities (continued)

\begin{tabular}{l} 
Items \\
\hline CDDs provide infrastructure in areas where \\
GP governments are not able to
\end{tabular}

Factors

Communality

\begin{tabular}{|c|c|c|c|}
\hline $\begin{array}{c}\text { Cost } \\
\text { ffectiveness }\end{array}$ & $\begin{array}{c}\text { Managerial } \\
\text { Responsiveness }\end{array}$ & Flexibility $\begin{array}{c}\text { Financial } \\
\text { Mechanisms }\end{array}$ & $\begin{array}{c}\text { Developers } \\
\text { Interest }\end{array}$ \\
\hline
\end{tabular}

GP governments are not able to

CDDs build infrastructure faster than GP governments

CDDs provide services cheaper than GP governments

CDDs offer residents higher quality infrastructure than GP governments

CDDs better maintain services than GP governments due to their narrow purpose

CDDs better maintain services than GP governments due to their smaller size

CDD infrastructure is well coordinated with GP governments' capital improvement plans

Eigenvalues

ans

.71

Extraction Method: Principal Component Analysis. Rotation Method: Varimax with Kaiser Normalization. Factor loadings less than .4 were suppressed from the table 
The factors were named according to the items that had the highest loadings. The first factor was labeled cost-effectiveness, the second was named managerial responsiveness, the third one institutional flexibility, the fourth one financial mechanisms and the fifth factor was labeled developers' interest. Cronbach's alpha was used to examine the internal consistency of each of the five factors extracted.

With the exception of the last factor, developer's interest (.390 for two items), the values of Cronbach's alpha were good and moderate: .826 for cost-effectiveness factor (four items), .715 for managerial responsiveness (four items), .701 for institutional flexibility (four items) and .605 for financial mechanisms (three items). Overall the principal component analysis indicated that four factors were representative for the public officials' responses and the items of the CDD survey.

The final step of the analysis consisted of constructing composite measures for CDD favorability. Based on the results of FA, three indexes were created. These indexes were related to the first three factors extracted from the FA: CDD cost-effectiveness, CDD managerial responsiveness and CDD institutional flexibility. The composite measures were created by adding the scores of each survey item comprising the first three factors extracted by FA.

The items in each index were given equal values. Index items are supposed to be weighted equally unless there are theoretical or methodological reasons for weighing (Babbie, 1990; Neuman, 2004). The three indexes were validated by conducting reliability analysis. Item analysis was employed to examine the degree to which the composite measure is related to the survey items.

The values of the indexes ranged from 4 to 20 where 4 means respondents strongly disagree with the fact that CDDs are cost-effective, responsive and flexible entities and 20 means respondents strongly agree with the three aforementioned attributes 
of CDDs. Descriptive statistics for all three composite measures are summarized in Table 7.11.

All of the three composite measures have a fairly normal distribution. Skewness and kurtosis coefficients had values within the range of normal distribution and the histograms of indexes showed that the distributions were almost normal (see Appendix 7). According to the values of the mean, CDD cost-effectiveness and institutional flexibility are ranked lower than the CDD managerial responsiveness. Results suggest that the survey respondents considered CDDs are more responsive to their communities than they are flexible or cost-effective. Also, looking at the minimum and maximum values, CDD responsiveness had the widest dispersion, followed by CDD costeffectiveness and institutional flexibility.

\section{Table 7.11 Descriptive Statistics for Indexes}

\begin{tabular}{lccccccc}
\hline Index & No. of items & Mean & St. dev. & Min. & Max. & $\mathrm{N}$ & Alpha \\
\hline Cost-effectiveness & 4 & 11.25 & 3.05 & 4 & 19 & 101 & .82 \\
Managerial responsiveness & 4 & 12.79 & 2.65 & 4 & 20 & 98 & .71 \\
Institutional flexibility & 4 & 11.41 & 2.61 & 4 & 18 & 100 & .70 \\
\hline
\end{tabular}

What do these values mean? The facts behind these numbers reveal the following story. The CDDs are a responsive and flexible institutional choice for infrastructure delivery but not necessarily an effective one. The biggest advantage of the CDD structure resides in its managerial responsiveness. The CDD specialized nature ensures that the community's needs are fulfilled. Through their administrative and financial independence from general-purpose governments CDDs' self-supporting feature supports the provision of services that are tailored to community's needs. Districts' perpetual existence and narrow focus explain their managerial responsiveness. Responsiveness is also perceived as a quality/cost ratio. Respondents considered the CDD assessments are commensurate 
with the quality of the services provided. The CDDs support infrastructure services according to the wishes of their communities: some may entail high-end amenities while others may be very modest and extremely affordable communities.

Flexibility is the second most important factor perceived by respondents when assessing CDDs. Districts are mainly favored as flexible institutions because they manage to build infrastructure faster than general-purpose governments and because they provide services in places where general-purpose governments are not able to. Not only are CDDs fast in building infrastructure but they are also addressing a type of public or private market failure. However, respondents did not view flexibility through the lenses of lowercost services. CDDs tend to supply services that are the same value or higher with/than other public or private infrastructure providers. Flexibility also resides in the fact that CDD assessments are not as stable as the taxes of general-purpose governments. The flexibility of districts' assessment may pose significant burdens to residents since districts may increase the amount of assessments as they see fit.

CDD effectiveness shows the least favorability on part of public officials. CDDs are considered as being less effective than general-purpose governments when providing and maintaining infrastructure services. Respondents are neutral in assessing whether CDD services are of higher quality than those of general-purpose governments. Districts are perceived as providing about the same quality of services with the surrounding governmental entities. This fact is supported by the perception that CDD levies are not necessarily better spent than the taxes of general-purpose governments. The CDDs are also perceived as not being more effective than general-purpose governments when maintaining infrastructure services. Therefore, the assumption that smaller units of governments performing specialized functions better handle public services is not supported by the findings of this study. 
To sum up, in order to assess CDD favorability an exploratory FA of seventeen survey items was conducted. Five major factors were identified. These are: CDD costeffectiveness, managerial responsiveness, institutional flexibility, financial mechanisms and developers' interests. Three of them were useful in developing indexes measuring CDD favorability. The favorability indexes were labeled the same as the factors extracted: CDD cost-effectiveness, managerial responsiveness and institutional flexibility. This analysis demonstrated that CDDs are a responsive and flexible institutional choice for infrastructure delivery but not as effective as anticipated. These indexes of favorability are expected to serve as guideline for decision-makers when assessing the effects of CDDs.

\subsection{Qualitative Analysis of Survey}

The survey also contained an open-ended question about the things respondents would change in CDD implementation. The aim of this survey question was to reveal the perceived drawbacks of CDD implementation. When asked about what things they would change, respondents provided various explanations. They focused on six main common issues. First, they recommended for better disclosure requirements about CDDs and their financial obligations to prospective residents. Second, respondents suggested more administrative and fiscal local and state oversight. Third, survey participants recommended better intergovernmental coordination between CDDs and local generalpurpose governments. Fourth, respondents had opposite views on the authority that should establish CDDs. Two respondents suggested that all CDDs should be established by local general-purpose governments vs. one respondent who stated that the state should deal with CDD establishment and granting of additional special powers. Fifth, respondents recommended that CDD life span should be limited. Once they build the 
infrastructure and they pay off the debt, they should cease to exist. Finally, respondents recommended that CDDs should be allowed only in areas where infrastructure is unlikely to be built such as infill and economically distressed areas.

In addition to the aforementioned common themes, respondents identified other things that they might change in the implementation of CDDs. Some recommendations were related to $\mathrm{CDD}$ functions. These are: CDDs should be responsible for basic infrastructure services, CDDs should be used to finance new infrastructure improvements rather than reimbursing developers for infrastructure that is already in place as well as CDDs should adhere to the building and maintenance requirements of local generalpurpose governments. Other recommendations referred to limiting the numbers of CDDs within a development, allowing residents to decide the changes to their assessments rates, requiring developers to demonstrate long-term stability before being able to file a petition for $\mathrm{CDD}$ creation, requiring the commitments in the petitions to be binding and addressing the issue of what ultimately happens to the infrastructure in case CDDs cease to exist. Respondents stressed the fact that all these changes could only be ensured through amendments to Chapter 190 Fla. Stat.

\subsection{Summary}

The analysis of the survey data provided some significant findings that will assist in the further understanding of the role of CDDs in providing and maintaining infrastructure improvements and services. The descriptive analysis of the survey items revealed several important findings. First, structure flexibility is viewed as an advantage

of CDDs. Survey participants prioritized CDD structure flexibility as follows: fulfilling the needs of the community, being independent from general-purpose government and being self-supporting entities. 
Second, CDD financial implications varied according to the type of beneficiaries. On one hand, CDDs were not perceived as having beneficial financial implications for general-purpose governments because they do not relieve general-purpose governments from the burden of capital infrastructure or the property tax and because they do not circumvent the debt limits of general-purpose governments. On the other hand, CDDs have beneficial financial implications for developers and residents. Districts are thought of benefiting developers because the former generate short-term profits for the latter and allow enhancement of amenities at lower costs. The CDDs also benefit residents because district assessments are commensurate with the quality of services that are provided.

Third, CDDs are not necessarily better than general-purpose governments in providing and maintaining infrastructure services. Whereas CDDs build infrastructure faster than general-purpose governments, the former do not provide infrastructure cheaper or of higher quality than the latter. Furthermore, districts are not viewed as better maintaining public services than general-purpose governments when their specialized function and geographic boundaries were considered.

Fourth, CDD activity was not found to be coordinated with the capital improvement plans of general-purpose governments. If respondents had a neutral opinion about the CDD impact on growth management, they supported the fact that CDDs encourage coordinated development. CDDs were also perceived to contribute to the fiscal stress of the surrounding communities and to increases in the housing prices.

The analysis also suggested that there were some important differences in the way respondents perceived CDD pluses and minuses. The results revealed significant differences for nine out of the twenty one survey items analyzed according to the individual and professional characteristics of respondents. There is a clear distinction between the preferences of those who are more experienced, higher educated, with a supervisory position, planning background and working experience outside the State of 
Florida vs. those who are younger, less educated, with no supervisory position, without a planning background and with working experience in Florida. The first category of respondents are more critical than the second one when assessing CDD pluses and minuses.

The results of the principal component FA showed that respondents perceived CDD according to five common factors: cost-effectiveness, managerial responsiveness, institutional flexibility, financial mechanisms and developer's interest. However, only three out of five extracted factors were useful in creating indexes of CDD favorability. CDD favorability indexes were named as follows: CDD cost-effectiveness, managerial responsiveness and institutional flexibility. Districts were perceived as being responsive and flexible mechanisms for service delivery. Their narrow focus and perpetual existence make them provide services that are tailored towards the needs of the communities they support. The CDD institutional flexibility allows them to build infrastructure in a timely manner and in areas where other entities cannot. However, their effectiveness in providing and maintaining services is not as high as predicted. In fact, districts are less effective than general-purpose governments in delivering infrastructure-related services.

Finally, the qualitative analysis of the survey revealed that there are six main issues that should be changed with regards to CDD implementation. These are: better disclosure requirements about CDDs and their financial obligations to prospective residents, more administrative and fiscal local and state oversight, better intergovernmental coordination between CDDs and local general-purpose governments, designating local general-purpose governments as solely establishing authorities for CDDs, limiting the CDD's life span and allowing CDDs to be established only in areas where infrastructure is unlikely to be built. The qualitative analysis suggested that CDDs are too independent in fulfilling their functions and there should be better oversight on their powers and activity. 
In conclusion, CDDs have both advantages and disadvantages. Overall, the results of this analysis suggest that CDDs are desirable institutional choices among public officials because of their managerial responsiveness and institutional flexibility. The CDD responsiveness makes them closer to community's needs than any other public or private mechanisms which provide infrastructure services. The CDD flexibility gives them a competitive advantage of building infrastructure faster and in remote areas but may also have negative implications for residents. However, districts are not as favorable for their effectiveness in providing and maintaining infrastructure services. Furthermore, CDDs are not perceived as helping general-purpose governments to overcome their debt limits, to maintain or decrease the level of their taxes or to take the big ticket infrastructure items off their shoulders. CDDs are considered a developers' tool that facilitates the latter's access to financial mechanisms such as tax-exempt municipal revenue bonds. Planners and respondents who do not have working experience outside the State of Florida are less favorable of CDDs. They consider districts as a sprawl stimulation that favors a build-out rather than a growth management tool. 


\section{CHAPTER VIII}

\section{DISCUSSION AND CONCLUSIONS}

\subsection{Introduction}

Community Development Districts (CDDs) are a particular type of multi-purpose, independent special districts created by a state charter, whose main purpose is to manage and finance infrastructure services that accommodate new development within the State of Florida. They have important implications for both growth management policies and public service delivery. Districts influence the way growth occurs by coordinating the infrastructure provision with development as well as by guiding the location, rate and type of development through their decisions. The CDDs also have important implications for service delivery due to their flexible institutional structure which may allow for efficient and responsive infrastructure services provision.

Even though CDDs are similar to local governments of general purpose such as counties and cities there are a few features that differentiate the former from the latter. These are: districts' specialized function of providing and maintaining specific infrastructure services, districts' institutional independence from other governmental entities through administrative, financial and political autonomy, districts' ability to overlap the territory of other jurisdictions and districts' low political visibility as they have often been characterized as "shadow governments".

As infrastructure management and financing have become extremely important for policy makers, special-purpose governments are seen as a solution for dealing with its development in an era of fiscal stringency (Porter, 2008; Porter et al., 1992). The CDDs are authorized to cover a fairly broad spectrum of infrastructure facilities and services 
such as water management and control, water supply, water and wastewater, bridges and culverts, district roads and certain projects for concurrency as well as amenities such as parks and recreation facilities, security, fire prevention, education-related facilities and the like.

The context within which CDDs were created should be related to the planning and fiscal realities in Florida in the 1980s and 1990s. Districts have proliferated in response to the concurrency requirement of the 1985 Florida Growth Management Act. The Florida growth management legislation requires that adequate public facilities be available or fiscally accounted for prior to or concurrent with new development but it does not address how the infrastructure development is going to be funded. Therefore, local governments are responsible for identifying financial sources to support infrastructure development and special purpose-governments represented one of these sources.

The CDD formation should also be understood in the context of creation and proliferation of special-purpose governments in general as well as tax and debt constraints that were adopted by states to impose limitations on local general-purpose governments. In Florida such constraints started in 1980 with the adoption of millage caps on property tax, followed in the 1990s by referendum requirements for issuing general obligation bonds and adoption of limits on the annual increase in the assessed values of homestead properties. These fiscal realities corroborated with a tax-averse population facilitated the proliferation of CDDs within the State of Florida.

By examining the role of CDDs on growth management and service delivery in Florida, this study focused on the following research purposes: providing an overview of CDD functions and activity, analyzing the contribution of CDDs for growth management and infrastructure development, identifying drivers of CDD infrastructure variation as 
well as determining the role of CDDs for infrastructure service provision by assessing districts advantages and disadvantages as service providers.

The study contributes significantly to the scholarly literature. It fills an important gap in the academic literature by providing a comprehensive analysis of a subtype of multi-purpose districts. It assesses the effectiveness and responsiveness of CDDs in delivering infrastructure services through the perceptions of public officials and CDD representatives. The study also addresses methodological issues identified in the extant literature by relying on state-level secondary data and primary data about CDD impacts.

The CDD study used a mixed methods research approach, drawing on secondary data about CDD features and activity, interviews with CDD representatives and public officials as well as on a survey of public officials within the counties and cities that have established CDDs. The findings of the study demonstrated that the CDD institutional model is both a policy and a service delivery tool for responsive infrastructure provision that can be adopted by states across the United States. However, the Florida experience showed that the CDD model should be used with caution.

The rest of the chapter is organized as follows: it summarizes and discusses each finding according to the research questions; it discusses implications for future research; it connects the results of this study to the theory behind it; it acknowledges the limitations of this study and concludes with an overall summary.

\subsection{Discussion of Results}

\subsubsection{An Overview of the CDD Model}

Community Development Districts are the most commonly used type of independent special districts in Florida. They are perpetual institutional mechanisms for infrastructure delivery which enjoy governmental powers and protections. The CDDs are 
uniformly created by a state charter and they have been established, according to their size, by either local general-purpose governments or the Florida Land and water Adjudicatory Commission. Although, virtually anyone can petition an establishing authority to create a CDD (even a county or a city), in Florida, CDDs have only been initiated by developers.

Their utilization reflects the need for new services driven by a rapid population growth that has taken place within the last six decades. The legislation that created CDDs was passed in 1980, but it was not until late 1980s - early 1990s when districts showed a steady increase. They flourished from late 1990s until the mid 2000s and dramatically decreased after 2006. The CDD proliferation was driven by the adoption of local comprehensive plans by local governments as well by the boom of the Florida real estate market. Districts are primarily located in larger counties in Florida concentrating in the southern and central parts of the state. District location pattern shows that CDDs proliferated within the counties and cities that experienced higher population increases.

Community Development Districts enjoy administrative and financial autonomy. They are governed by an elected board of supervisors which is initially elected from among landowners' representatives and, subsequently, it transitions to a board comprised of residents. Districts may pose democratic accountability issues to their residents because of the one-acre/ one-vote system where landowners vote for each acre of land they own in the district until a certain quorum of electors is achieved. The one-acre/onevote system does not allow residents to be democratically represented for at least the first six to ten years of CDD existence. A probable a solution to this would be the institution of a situation similar to condominiums where residents should be allowed to participate in CDD decisions once the majority of housing units are owner-occupied.

Districts can be considered self-supporting entities since the development they generate pays for itself. CDDs have significant financial implications especially with 
regard to the amount of outstanding debt they issued. From 1998 to 2007 the amount of debt that CDDs have issued increased four times while the debt of general-purpose governments stagnated. The comparison between the amount of debt issued by CDDs and local general-purpose governments demonstrated that CDD borrowing capacity gives them a competitive advantage in providing infrastructure services when compared to other local governmental entities. Even if CDDs are considered independent in raising their revenues, they are truly subsidized by the federal government through the nature of the tax-exempt bonds they float for funding.

\subsubsection{The Implications of CDDs to Growth Management}

In discussing the implications of CDDs for growth management, the study considered the location and size of CDDs within six Florida counties as well as the type and pattern of development districts supported. Overall, more than two thirds of the CDDs (70.4\%) provided infrastructure services for unincorporated areas. The choice of creating CDDs in unincorporated vs. incorporated areas is related to the type of development CDDs support. Districts that support residential development are mainly located on the fringe of municipalities, fulfilling the preferences of citizens for the suburbs. As expected, mixed-use and commercial development is predominant for the CDDs located within the boundaries of municipalities. Therefore, on one hand, CDDs supporting residential communities with single-family houses tend to encourage development that is located on the fringe and, indirectly, they contribute to sprawl. On the other hand, districts that support multi-family and mixed-used developments might contribute to denser development patterns. There are also instances in which CDDs that are located within the boundaries of municipalities are used for redeveloping inner-city areas or for providing more expensive improvements such as roadways. Ultimately, the decision about the way a jurisdiction develops belongs to general-purpose governments 
since they are the ones which have planning and zoning powers. Districts have to comply with these requirements.

The CDD size ranges from as small as 9.4 acres to as high as 1097 acres, with an average size of approximately 344 acres. With the exception of Miami-Dade County where the CDD average is 111 acres, all the other five counties have a mean size between 334 and 544 acres. These figures confirmed the suggestions of public officials who recommended that CDD should be between 300 and 500 acres in size to be economically feasible. The small CDD size in Miami-Dade County might be explained by the fact that CDDs in this county favored more residential development in the form of multi-family and condominiums and less single-family housing or that the development community is dominant. Furthermore, CDDs in Miami-Dade County focused more on providing basic infrastructure services and less on supporting optional amenities. It can, therefore, be argued that CDD size influences the quality and quantity of infrastructure improvements. Larger CDDs, especially those located on the Florida's west coast have more open space and nicer amenities such as lakes, golf courses and the like.

The state legislation does not mention any minimum or maximum size for CDDs, leaving the decision about CDD size with the establishing authority. The question should not necessarily be about the minimum or maximum size for a CDD but rather consider the adequacy of CDD size so that future residents have the opportunity of being democratically represented. The CDDs supporting residential and mixed-use development should be comprised of at least 500 housing units to give residents the opportunity of being democratically represented and to avoid developers' control once the units are owner-occupied. As documented by the petitions' data there were plenty of instances in which CDDs had less than 500 proposed housing units even if they had reached their ideal size. The establishing local general-purpose governments should pay more attention to this issue when deciding the appropriateness of the CDD size. 
Within the six Florida counties districts supported public facilities and services mainly for residential development. The CDD focus on residential development may be explained by the existence of a demand for residential development due to the rapid population increase and to the housing boom in the 2000s. Once the demand for housing has decreased, CDDs ceased to be attractive to developers (fact reflected by the dramatic decrease in the CDD number after 2006).

The Florida legislature made CDDs a vehicle for any person or entity to provide infrastructure but only developers have taken advantage of this institutional choice of infrastructure provision. The idea of CDD as an institutional choice for infrastructure provision was initiated by developers' interests in South Florida (Broward, Collier and Hillsborough counties (communication with Kenza van Assenderp - one of the lawyers who drafted Chapter 190 Fla. Stat. - on March 11, 2009) but the legislature made it applicable to virtually anyone who wants to build basic infrastructure services in Florida. However, it remains unclear why other individuals, groups or entities have not used it so far.

The CDDs drastic decline in the last five years may suggest that CDDs might be "creatures of a dead era." Only time will tell whether young CDDs (those that have issued debt but did not complete construction or sold their housing units) will survive the current housing crisis. However, as a result of a recent proposition concerning the empowerment of the Florida residents to decide on the adoption and amendments of future land-use plans (Amendment 4 to Florida Constitution), CDDs could remain a useful tool for developers to continue building in remote areas since the infrastructure provided by CDDs is not included in the capital improvement plans of local generalpurpose governments.

In the future the CDD applicability could seek the interests of public institutions, local governments, non-profit organizations or any other interested party in building 
facilities and improvements for institutional uses such as educational, research, healthcare institutions and the like. The future of CDDs might be geared toward mixed-use and commercial developments since the number of new CDDs dropped dramatically after 2006. As stated before, their usefulness could move beyond providing infrastructure for residential developments, to institutional uses such as educational and health care facilities, to contaminated soil clean up, redevelopment etc.

Depending on the preference of developers, CDD may support both exclusive and affordable communities. Developers' preference for high-end amenities encourages the development of exclusive communities while those who do not value such amenities develop more affordable communities. Probably the intent of the state legislation was not to make CDD a driver for providing "islands of luxury" as these hi-end communities have often been described. Rather, CDDs were intended to provide the needed fundamental infrastructure. Thus, CDD tax exempt powers should be applied towards funding basic infrastructure while the enhanced amenities might be taxed.

What seems to be missing in a scenario where oversight from general-purpose governments does not exist is a lack of coordination and cooperation between the general and the special-purpose governments. The CDD infrastructure is not coordinated with that of general-purpose governments since the former is not being included in the latter's capital improvement plan. This disconnect happens because general-purpose governments do not have any enforcement powers on CDDs and, therefore, keep all the reports they receive from districts for information purposes only. The issue of infrastructure coordination might be partially addressed by stimulating local governmental entities to enter into intergovernmental agreements when delivering infrastructure services. As suggested by Mullin (2010) coordination issues might be addressed through collaboration. A solution for solving the lack of coordination might be 
the presence of inter-local agreements between CDDs and their surrounding generalpurpose governments.

According to Ben-Zadock and Gale (2001) concurrency requirement can manage growth through timing, location, type and pattern of development. Concurrency is described in terms of available land and water resources, available financial resources, level of service standards and timing. The findings of this study clearly showed that CDDs are believed to partially fulfill concurrency by linking new development with the needed infrastructure through the availability of funding and the timing of infrastructure. Through their financial capacity districts can build infrastructure improvements in a timely manner.

Concurrency also requires local general-purpose governments to adopt capital improvements programs with minimum levels of service for the following infrastructure services: water and sewer, solid waste, drainage, parks and recreation and roads. In other words, there has to be enough capacity for each of the aforementioned infrastructure improvements for the development to go through. From this perspective, CDDs no not seem to fulfill the concurrency requirement since the infrastructure they provide is not included in the capital improvement plans of general-purpose governments and, therefore, not subject to the latter's levels of services. From this perspective, the concurrency compliance ultimately depends on the decisions of CDDs.

In sum, CDDs do not seem to foster growth management in Florida. Even if districts coordinate infrastructure provision with new development their decisions about location, type and pattern of development have the unintended consequences of encouraging sprawl. This finding is consistent with Turner (1990) who stated that concurrency may lead to sprawl. 


\subsubsection{The Contribution of CDDs to the Infrastructure Development in Florida}

Community Development Districts are perceived as being an alternative to other public or private means of providing infrastructure. They either cover some type of public or private market failure by providing services and improvements where other entities cannot or do not want to, or they fulfill the desire of a community to provide certain services. The contribution of the CDDs to the infrastructure development in Florida has been multifold. In discussing the CDD profile within six Florida counties, this study indicated some important findings.

The CDDs provide both on-site and off-site improvements and their role to the infrastructure development in Florida has been to support basic capital improvement projects such as stormwater management and drainage systems, water and sewer facilities, waste water systems, roads, sidewalks and streetlights, recreational facilities etc. Districts contributed mainly to providing infrastructure that is internal to the developments they supported and, to a lesser extent, in helping local general-purpose governments take the burden of major capital improvement projects (such as major roads, highways and bridges) off their shoulders. Off-site improvements are primarily fostering on-site improvements and they are either transportation-related or refer to extension of utility lines to the development site.

Once built CDD facilities are supposed to be open to the general public because of the fact that CDDs use tax-exempt bonds to finance them. In reality, CDD improvements rarely benefit the general public but rather those who pay for the services, enjoy them. Oftentimes districts are viewed as gated communities due to their impressive security features.

The role of CDDs in offering public facilities and utilities may be different. They are either both providers and maintainers for public facilities such as storm water systems, drainage systems, internal roads and the like, or they are only providers but not 
maintainers of public utilities such as water and sewer systems or recreational parks. There are no clear guidelines when deciding which local governments (special vs. general-purpose) should provide and maintain a service. Rather, it is a matter of considering all the parameters involved for each particular situation.

The CDDs have also contributed to the infrastructure development in Florida by building and dedicating infrastructure to general-purpose governments at no direct cost to the latter (mainly water and sewer systems and off-site improvements to major arterial roads and highways). This way, CDDs are attractive for general-purpose governments because the latter have the infrastructure in place without having to pay for it.

The CDDs are more than funding mechanisms; they are also management tools for infrastructure services. Once CDDs build the infrastructure they are supposed to, their role is to act as managers of the newly created communities. Unlike other entities which disappear after they fulfill their scope, CDDs are perpetual entities. Some districts act in a manner similar to homeowners' associations by maintaining the infrastructure and paying off the bond while others continue to perform improvements for the community. This way districts could be a real solution to managing public infrastructure (Porter, 2008).

While CDDs are clearly a real solution for providing infrastructure improvements it is a question of deciding which entity (general-purpose or special-purpose) should maintain the services provided by CDDs. This decision is dependent on several factors among which are: the nature of the service, the size of the project, service efficiency, the entity that is the service provider, the type of land-use as well as linking the infrastructure capacity with development (Porter, 2008). In addition to these reasons, the author would like to add the fact that a general-purpose government will ultimately make this decision by suggesting CDDs to undertake or not the maintenance of certain services. When developers petition a general-purpose government to establish a CDD they have to include a statement of estimated regulatory costs which contains a table estimating the 
entities that provide and/or maintain infrastructure improvements for the new development. General-purpose governments may approve or disapprove the proposed providers and maintainers of services and suggest further changes when they consider districts are not suitable to maintain specific services. Other times general-purpose governments may not want competition or duplication of services. Because of the fact that the majority of CDDs are located in unincorporated areas of the counties, they seem to complement rather than compete with the services provided by general-purpose governments at least in the short-term.

CDDs are perceived as alternative mechanisms for infrastructure provision. This fact reinforces the view of Van Assenderp (n.d.) who stated that besides CDDs, there are other alternatives for the provision and maintenance of infrastructure which are classified in relation to their efficiency and accountability. These are either public alternatives such as general-purpose governments, dependent districts such as municipal service tax units and municipal service benefit units or private alternatives which include private developers and/or companies who get bank loans to provide the necessary infrastructure as well as homeowners' associations. In Van Assenderp's (n.d.) view CDDs are a public alternative for infrastructure provision which is more efficient and less accountable than general-purpose governments and more efficient and more accountable than homeowners' associations.

\subsubsection{CDD Infrastructure Variation}

When identifying drivers of infrastructure variation the present analysis revealed that the number of services provided by CDDs differed according to whether districts have optional special powers, the county within which they are located and the type of development they support. Overall, CDDs that have optional special powers, those located on the Florida's west coast and those supporting residential and mixed-use 
development provided more services than their counterparts. The CDDs located within the counties on the Florida's west coast differed from those located on the east coast through the fact that the former had more optional special powers and served larger communities when compared to the latter. Moreover, CDDs on the west coast enjoyed a lot of open space and provided amenities such as lakes and golf courses, favored residential development that focused on single-family housing as opposed to condominiums and multi-family housing which were predominant in the CDDs located on the east coast. The infrastructure variation between the west and east coast can be explained by the facts that CDDs within Miami-Dade County are the smallest in size and St. Lucie County has two thirds of its CDDs located within the boundaries of municipalities.

Residential and mixed-use development attracts, through their nature, more amenities than commercial and industrial developments. In order for developers to be competitive on the housing market, they aim at making communities more attractive for prospective buyers by offering enhanced amenities. It is these optional amenities that make a difference among the number of services provided by CDDs because, overall, all CDDs provide basic infrastructure, offering, more or less, the same type of fundamental infrastructure services.

This study also suggested that there were four indicators that predicted the amount of infrastructure provided by CDDs. An increase in the number of CDD provided services was associated with an increase in the number of CDD owned and maintained services, with districts that had optional special powers, with an increase in the amount of the CDD estimated infrastructure costs and with districts located in unincorporated areas.

When a petitioner wants to initiate the establishment of a CDD one has to specify both the entity which is responsible for the construction and the owner of district facilities and services. The CDDs that are proposed to be both owners and maintainers of district 
facilities are more likely to build more services. Being the managers of specific infrastructure facilities and services proved to be a strong incentive for CDDs to build more services. Since infrastructure facilities such as water and sewer and internal roads are mainly just financed through CDDs and then, turned over for maintenance to generalpurpose governments, it is the other infrastructure items that influence the infrastructure variation. Therefore, CDDs are, indeed, more than funding mechanisms, they are management tools.

Higher infrastructure costs influenced the provision of more services. Compared to general-purpose governments which handle a variety of services CDDs focus on specific infrastructure services. Thus, CDD infrastructure services are not expected to show a significant price difference. Districts that provide high end amenities are expected to spend more than those which provide only basic infrastructure. The more money is spent, the higher the number of services provided. It can be argued that optional amenities play an important role in predicting the amount of infrastructure services provided by CDDs.

Finally, as anticipated, CDDs located in unincorporated areas provide more services than those located within city boundaries. This is explained by the fact that unincorporated areas have more infrastructure needs than municipalities. The latter might need just to upgrade the existing facilities while the former need to build everything from scratch.

\subsubsection{The Perceived Effectiveness and Responsiveness of CDDs as Service Providers}

In order to determine the role districts play in service delivery this study assessed CDD pluses and minuses as well as their effectiveness and responsiveness in delivering services. The CDDs were perceived as being favorable for developers and residents and not so favorable for general-purpose governments. Their favorability resides in the 
following. First, structure flexibility was seen as an advantage of CDDs because it fulfills the needs of the community, allowing districts to be independent from general-purpose government and be self-supporting entities. CDDs are considered to benefit developers because they generate short-term profits for the latter by allowing them to build enhanced amenities at lower costs. Through their tax-exempt powers districts represent an incentive for developers as long as they generate profit. CDDs are also perceived to benefit residents because their assessments are commensurate with the quality of services offered. Moreover, CDDs are considered favorable because they build infrastructure faster than general-purpose governments. Therefore, the needed infrastructure might be in place in a timely manner. Even though residents are those who ultimately bear the costs, they have the infrastructure in place when they need it.

Finally, CDDs are desirable because they encourage coordinated development. CDDs might aid the growth management in Florida by ensuring the presence of infrastructure. As long as development orders are consistent with the land-use of an area, it can be argued that CDDs encourage coordinated development. But the infrastructure that CDDs provide is not coordinated with the capital improvement plans of generalpurpose governments, a fact that may lead to sprawling development patterns.

Community Development Districts were not considered as beneficial for generalpurpose governments. They were perceived of not relieving general-purpose governments from the burden of capital infrastructure or the property tax, neither of circumventing the debt limits placed on general-purpose governments by states. These findings disconfirm the view expressed in the scholarly literature that special-purpose governments are established to avoid increases in property taxes or to circumvent tax and expenditure limitations placed on general-purpose governments by states (Bowler \& Donovan, 2004; Carr, 2006; Foster, 1997; McCabe, 2000). Rather, the results of this study revealed that CDDs were created to serve the interests of developers (Burns, 1994; Porter et. al., 1992) 
and to facilitate their access to tax-exempt bonds. Contrary to the opinion of survey participants, secondary data about CDD financial activity point to the fact that districts have taken advantage of their borrowing powers and increased their debt considerably.

Results also indicated that CDDs were not necessarily better than general-purpose governments in maintaining infrastructure services. Districts did not provide a less expensive or higher quality infrastructure when compared to general-purpose governments. Furthermore, survey participants considered that CDDs were more likely to contribute to the fiscal stress of the surrounding communities and to increases in the housing prices.

Instead of relieving their surrounding governments from the burden of their taxes, CDDs were perceived as contributing to the fiscal stress of general-purpose governments by overburdening taxpayers. Even though CDDs were not perceived as having financial benefits for general-purpose governments, they contributed significantly to the infrastructure development in Florida. Their contribution focused mainly on providing infrastructure for CDD developments and, to a lesser extent, on building highway or major roadway improvements.

However, CDDs built fundamental infrastructure facilities such as water and sewer utilities, stormwater systems, drainage systems and internal roads. And some of these facilities were turned over to general-purpose governments, fact that represents a great relief for the latter. The present study suggested that general-purpose governments preferred that certain pieces of infrastructure such as water and sewer systems be turned over to them once built due to local governments' capacity to manage big utility systems and due to their desire to avoid duplication of services. It appears that CDDs, similar to other special districts, provide services that are complementary rather than competitive with those of general-purpose governments (Carr, 2004b). 
The study indicated there were some important differences in the way respondents perceived CDD pluses and minuses. The opinions of survey respondents were divided between two camps. Respondents with planning background, those with more experience, those with higher education and working experience outside of Florida were more critical about CDD structure flexibility, financial and economic development implications as well as issues of coordination with general-purpose governments when compared to their counterparts. In other words, overall, the minority favored CDDs while the majority did not. The majority of respondents expressed critical views about CDDs in most of the studied areas. They considered that CDDs did not provide infrastructure according to a community's needs but according to the willingness of developers.

The contribution of CDDs to the service delivery showed that specialized governance is more responsive and more flexible but less effective than general-purpose governance. The biggest advantage of CDDs resides in their managerial responsiveness. The CDD specialized nature ensures that the community's needs are fulfilled. Through their administrative and financial independence from general-purpose governments CDDs support the provision of services that are tailored toward their residents. The CDDs' perpetual existence and narrow specialization also explain their managerial responsiveness. Finally, respondents perceived responsiveness through the fact that CDD assessments are commensurate with the quality of the services provided.

Districts are mainly favored as being flexible institutions because they manage to build infrastructure faster than general-purpose governments and because they provide services in places where general-purpose governments are not able to. Not only are CDDs fast in building infrastructure but they are also addressing a type of public or private market failure.

Community Development Districts are considered as being less effective than general-purpose governments when providing and maintaining infrastructure services. 
Respondents were neutral in assessing whether districts' services are of higher quality than those of general-purpose governments. The CDDs were, therefore, perceived as providing about the same quality of services with their surrounding governmental entities. Districts were also perceived as not being more effective than general-purpose governments when maintaining infrastructure services.

Unlike public choice theorists who argued that special-purpose governments improve the efficiency and effectiveness in local service delivery (Bish \& Ostrom, 1973; Ostrom, 1999) the results of this study confirm the findings from the empirical literature that special-purpose governments are less efficient than the general-purpose ones (Berry, 2009; Foster, 1997; Mullin, 2009). Then, the question that comes to mind is why does specialized governance continue to be on the rise in Florida? In the case of CDDs, developers' interest played a significant role in initiating their creation and fueling their proliferation. The findings of this study are consistent with previous scholars (Bollens, 1957; Burns, 1994) who argued that it is the desire of interests groups to provide certain functions that leads to the formation and proliferation of special-purpose governments.

Finally, the qualitative analysis of the survey revealed that there are six main issues that should be changed with regard to CDD implementation. These are: better disclosure requirements about CDDs and their financial obligations to prospective residents, more administrative and fiscal local and state oversight, better intergovernmental coordination between CDDs and local general-purpose governments, designating local general-purpose governments as solely establishing authorities for CDDs, limiting the CDD life span and allowing CDDs to be established only in areas where infrastructure is unlikely to be built.

Future home purchasers need to be educated about what CDDs are and what powers they have. Prospective buyers do not seem to pay enough attention to the available disclosure mechanisms when they purchase a property within a CDD or to the 
fact that $\mathrm{CDD}$ assessments cannot be claimed on their income tax returns. Disclosure mechanisms about the nature of CDDs are in place for both initial and subsequent purchasers. For initial purchasers Chapter 190 Fla. Stat. stipulates that there should be a disclosure language, in bold letters, right before the signature block about the existence of $\mathrm{CDD}$ and its right to assess the property within the district to pay for infrastructure improvements and operation of the district ( $\$ 190.040$ Fla. Stat., 1980). For subsequent purchasers there are disclosure mechanisms such as a previous tax bills for the property to be purchased or notices of establishment to issue bonds - which will show the property is subject to a CDD assessment. In some instances, additional disclosure requirements have been required by the CDD establishing authority. For example, Miami-Dade County requires CDD petitioners to provide a declaration of restrictive covenants which contains estimated infrastructure costs and the assessments' fixed amount for the first three years. Therefore, disclosure mechanisms about CDDs are in place and future purchasers need to do their homework before buying a property.

As previously asserted (Florida Atlantic University/Florida International University Joint Center for Environmental and Urban Problems, 1995), CDDs are too independent and their establishing authorities should play a more active role in overseeing a district's activity. As per Chapter 190 Fla. Stat. The CDDs are perpetual mechanisms which enjoy governmental powers and protections. But what happens with the districts after they build the infrastructure they are supposed to and pay off their debt? Does the maintenance function justify the need to keep CDDs in place or should their life span be limited? As suggested by the experience of other independent special districts, only time will tell if CDDs will truly justify the governmental protections they enjoy. 


\subsection{Implications for Further Research}

While the findings of this study have answered the existing research questions they, certainly, have raised others. This study provided a comprehensive view about CDD role and implications for infrastructure growth and service delivery in Florida. It is a starting point since CDDs' impacts have not been systematically researched. Therefore, there are plenty of research directions toward which this study may lead. Further research might focus on the following:

- accountability issues between CDDs and their residents,

- the implications for infrastructure delivery when inter-local agreements between CDDs and general-purpose governments are considered,

- the impact of CDDs on housing values,

- the influence of the overlapping jurisdiction arrangement on the debt burden of general-purpose governments when CDDs are considered,

- assessing the efficiency of CDDs in comparison to general-purpose governments by using different performance indicators,

- assessing CDD contribution to the infrastructure financing by comparing the magnitude of CDD financial impacts with those of impact fees and capital spending of general-purpose governments;

- identifying the usefulness of CDDs for other states by documenting and comparing CDDs with similar districts in other states and

- assessing the impacts of sociological factors such as migration patterns by performing a comparative analysis between CDDs located on the Florida's west vs. east coast. 
The present study has considered only the views of public officials and CDD representatives. To provide a complete picture of CDDs, the voice of other stakeholders such as developers and residents should be heard.

\subsection{Relationship of Results to Theory}

The conceptual framework for this study was New Public Management (NPM), a public management reform movement that is on the rise since 1970s. Within the NPM framework, CDDs represent one of the "hollowed-out" alternatives for delivering public infrastructure services. The findings of this study demonstrated that CDDs are a flexible institutional mechanism which was employed as a solution to a lack of state and local funding as well as to direct service provision.

The theory of NPM suggests that CDDs, as specialized local governments, are expected to provide more responsive and efficient services than general-purpose governments. Since CDDs are smaller in size than general-purpose governments, they are expected to better consider the needs of communities. Districts' functional specialization is supposed to offer higher quality services thus, making them more efficient than general-purpose governments. In practice, districts proved to be responsive but not necessarily efficient in delivering infrastructure-related services. Unlike public choice theorists that argued that special-purpose governments improve the efficiency and effectiveness in local service delivery (Bish \& Ostrom, 1973; Ostrom, 1999) the results of this study confirm the findings from the empirical literature that special-purpose governments are less efficient than the general-purpose ones (Berry, 2009; Foster, 1997; Mullin, 2009).

Consistent with the criticism addressed to NPM, findings of the present study also suggest that CDDs raise accountability issues for their residents and the surrounding 
general-purpose governments and there is a disconnection between specialization and coordination (Pollitt \& Bouckaert, 2000). Supporting the view of metropolitan reformers, the activity of CDDs was found not to be coordinated with that of general-purpose governments. Moreover, districts were perceived to support mainly the interests of private developers (Burns, 1994; Porter et. al., 1992).

The results of this study are consistent with most of the values of NPM but one. The contribution of CDDs to the service delivery showed that specialized governance is more responsive and more flexible but possibly less effective than general-purpose governance.

\subsection{Limitations of the Study}

Although the author made every effort to ensure reliability and validity of the findings there are some limitations that need to be acknowledged. One of the limitations resides in the fact that the secondary data used in the hapter five of this study represent estimations of petitioners at the time when CDDs were established rather than actual facts about CDD activity. Since no publicly released data about CDD activity were available, the author had to compromise and use estimated data.

Another limitation of this study refers to the non-involvement of developers and residents. This may bias the research findings towards the views of public officials and CDD representatives. Initially developers were considered for inclusion in the study but the author could not get access to them and decided to exclude them from this analysis.

The findings in chapters five and six are not necessarily generalizable to other parts of Florida. Even though approximately half of the CDDs are concentrated within six Florida counties, the selection of CDDs to be included in the analysis was not random. Also, the findings of the entire study have low validity and may not be directly 
generalizable to other states although the CDD model has certainly the potential to be adopted in other states.

Finally, the author acknowledges the fact that both the interviewees and the respondents to the survey might not offer honest and complete answers. The survey results represent part of the story.

\subsection{Summary}

This study tried to shed light on CDD impacts contributing to a better understanding of special districts in general. The CDDs are perpetual institutional mechanisms for infrastructure delivery which enjoy governmental powers and protections. The present study showed that districts are both policy and service delivery tools. Districts have important implications for growth management by coordinating the timing and financing of infrastructure provision with development as well as by making choices about location, type and pattern of development. The CDDs have also significant implications for public service delivery since they are flexible institutional choices for responsive infrastructure service provision.

Community Development Districts were perceived as being an alternative to other public or private means of providing infrastructure. Districts either cover some type of public or private market failure by providing services and improvements where other

entities cannot or do not want to provide, or they fulfill the desire of a community to provide specific services.

When discussing the CDDs role for growth management this study found that CDDs manage to coordinate the timing and financing of infrastructure provision with new development but they raise important issues about how location, the type of development they support as well as the lack of coordination with their surrounding 
general-purpose governments impact growth management. Through their decisions to locate mainly in unincorporated areas and focus on residential development, districts encourage sprawl patterns. Moreover, the infrastructure that CDDs provide is not subject to the levels of services standards set forth in the capital improvement plans of generalpurpose governments. The practical applicability of the CDD institutional model should be extended beyond supporting mainly residential development, to institutional uses such as educational and health care facilities, to contaminated soil clean-up, redevelopment of distressed areas and the like.

When infrastructure variation was assessed localized conditions played an important role. The amount of infrastructure CDD provided was predicted by the amount of infrastructure service owned and maintained by districts, by whether districts had or not optional special powers, by the districts estimated infrastructure costs and by the district location status in unincorporated vs. incorporated areas.

The contribution of the CDDs to the infrastructure development in Florida has been to support basic capital improvement projects such as stormwater management, drainage systems, water and sewer systems, waste water management, roads, sidewalks and streetlights. Districts contributed mainly to providing infrastructure that is internal to the developments they supported and, to a lesser extent, to helping local general-purpose governments take the burden of major capital improvement projects such as major roads, highways or bridges off their shoulders. However, districts have helped general-purpose governments by building and dedicating public improvements to the latter.

This study demonstrated that CDDs are more than funding mechanisms; they are management tools for infrastructure services. Once CDDs build the infrastructure they had to, their role is to act as managers of the newly created communities. Unlike other entities which disappear after they fulfill their scope, CDDs are perpetual entities which could solve the issue of managing public infrastructure (Porter, 2008). 
The contribution of CDDs to the service delivery showed that specialized governance is more responsive and more flexible but less effective than general-purpose governance. The CDDs are desirable institutional choices for infrastructure delivery because of their managerial responsiveness and institutional flexibility. Districts' responsiveness makes them closer to the needs of their communities than any other public or private mechanisms which provide infrastructure services. The CDD flexibility gives them a competitive advantage of building infrastructure faster and in remote areas but may also have negative implications for residents. However, districts are not as favorable as the theory suggests for their effectiveness in providing and maintaining infrastructure services. Furthermore, CDDs are not perceived as helping general-purpose governments to overcome their debt limits, to maintain or decrease the level of their taxes or to take the big ticket infrastructure items off their shoulders. The CDDs are considered a developers' tool that facilitates the latter's access to financial incentives such as taxexempt municipal revenue bonds.

Overall, the findings of this study are consistent with the views expressed in the scholarly literature that specialized governance is a flexible and responsive institutional design that meets local services demands (Mullin, 2009) but not as efficient as anticipated (Berry, 2009; Foster, 1997). According to the Florida's experience CDDs have proven to be an entrepreneurial institutional mechanism for infrastructure delivery. However, the decision of using this institutional choice for service delivery should be used with caution, especially considering its unintended consequences for the way growth occurs. Decision-makers should balance districts institutional flexibility with their unintended consequences for growth management when they make policy choices about infrastructure provision. The CDD institutional model is not necessarily the ideal model but an alternative means of managing and funding infrastructure. Ultimately, as Foster (1997) points out the way in which services are delivered depends on policy choices. In 
Florida, the decision to use CDDs may be a mixed blessing in terms of benefits and costs to the surrounding general-purpose governments. 


\section{BIBLIOGRAPHY}

Aiken, L.S., West, S.G. \& Pitts, S.C. (2003). Multiple Linear Regression. In J.A. Schinka, W.F. Velicer \& I.B.Weiner (Eds), Handbook of Psychology: Research methods in Psychology (volume 2), (pp. 483-507). Hoboken, NJ: John Wiley \& Sons.

Allison, P. D. (1999). Multiple regression: A primer. Thousand Oaks, Calif.: Pine Forge Press.

Axelrod, D. (1992). Shadow government: The hidden world of public authorities and how they control over $\$ 1$ trillion of your money. New York: Wiley.

Axinn, W. G., \& Pearce, L. D. (2006). Mixed method data collection strategies. Cambridge; New York: Cambridge University Press.

Babbie, E. R. (1990). Survey research methods (2nd ed.). Belmont, Calif.: Wadsworth Pub. Co.

Baer, S. E., \& Feiock, R. C. (2005). Private governments in urban areas. The American Review of Public Administration, 35(1), 42-56. doi: 10.1177/0275074004271717

Barnes, J., Cote, J., Cudeck, R., \& Malthouse, E. (2001). Checking assumptions of normality before conducting factor analyses. Journal of Consumer Psychology, 10(1/2, Methodological and Statistical Concerns of the Experimental Behavioral Researcher), pp. 79-81.

Bartling, H. (2007). Private governance, public subsidies: The political ecology of exurban sprawl in Florida. Paper presented at the 2007 4th International Conference of the Research Network Private Urban Governance \& Gated Communities: Private Urban Governance : Production of Urban Spaces, Interactions of Public and Private Actors, Sustainability of Cities, Paris, Université Paris 1 Panthéon-Sorbonne. $\begin{array}{llll}\text { Retrieved on } & \text { August } & 2910 & \text { from }\end{array}$ http://www.staff.unimainz.de/glasze/Abstracts_Papers_Paris_2007/Bartling.pdf

Becker, C.J. (2010). Self-determination, accountability mechanisms and quasigovernmental status of Business Improvement Districts in the United States. Public Performance and Management Review, 33(3), 413-435.

Ben-Zadok, E., \& Gale, D. E. (2001). Innovation and reform, intentional inaction, and tactical breakdown: The implementation record of the Florida concurrency policy. Urban Affairs Review, 36(6), 836-871. 
Ben-Zadok, E. (2007). Consistency, concurrency and compact development: Three faces of growth management implementation in Florida. In T. Chapin, C. Connerly \& H. Higgins (Eds.), Growth management in Florida: Planning for paradise (pp. 21-50). London: Ashgate

Bernard, H. R. (2000). Social research methods: Qualitative and quantitative approaches. Thousand Oaks, Calif.: Sage Publications.

Berry, C. R. (2009). Imperfect union: Representation and taxation in multilevel governments. New York: Cambridge University Press.

Billings, S. B., \& Leland, S. (2009). Examining the logic behind the self-help, self-taxing movement: Business improvement district formation. Public Budgeting \& Finance, 29(4), 108-124. doi:10.1111/j.1540-5850.2009.00945.x

Bish, R. L. \& Ostrom, V. (1973). Understanding urban government; metropolitan reform reconsidered. Washington: American Enterprise Institute for Public Policy Research.

Blair, G.S. (1986). Government at the grassroots. Pacific Palisades, CA: Palisades Publishers.

Bollens, J. C. (1957). Special district governments in the United States: Foreword. Berkeley: University of California Press.

Bourdeaux, C. (2005). A question of genesis: An analysis of the determinants of public authorities. Journal of Public Administration Research and Theory, 15(3), 441-462.

Bourdeaux, C. (2007). Reexamining the claim of public authority efficacy. Administration \& Society, 39(1), 77-106.

Bowler, S., \& Donovan, T. (2004). Evolution in state governance structures: Unintended consequences of state tax and expenditure limitations. Political Research Quarterly, 57(2), pp. 189-196.

Bryant, F.B. \& Yarnold, P.R. (1995). Principal component analysis and exploratory and confirmatory factor analysis. In L.G. Grimm \& P.R. Yarnold (Eds), Reading and understanding multivariate statistics (1st ed.), (pp. 99-136). Washington, DC: American Psychological Association.

Bunch, B. S. (1991). The effect of constitutional debt limits on state governments' use of public authorities. Public Choice (1986-1998), 68(1-3), 57-70.

Burns, N. (1994). The formation of American local governments: Private values in public institutions. New York: Oxford University Press. 
Business Week. (1986, March 3). Special report: The hollow corporation, pp. 56-85.

Carr, J. B. (2004a). Perspectives on city-county consolidation and its alternatives. In J.B. Carr \& R.C. Feiock (Eds.), City-county consolidation and its alternatives: Reshaping the local government landscape (pp. 3-24). Armonk, N.Y.: M.E. Sharpe.

Carr, J. B. (2004b). Whose game do we play? Local government boundary change and metropolitan governance. In R.C. Feiock (Eds.), Metropolitan governance: Conflict, competition, and cooperation (pp. 212-239). Washington, D.C.: Georgetown University Press

Carr, J. B. (2006). Local government autonomy and state reliance on special district governments: A reassessment. Political Research Quarterly, 59(3), 481-492.

Chapin, T. S., Connerly, C. E., \& Higgins, H. T. (2007). Growth management in Florida: Planning for paradise. Aldershot, England ; Burlington, VT: Ashgate.

Chapin, T. (2007). Local governments as policy entrepreneurs: Evaluating Florida's 'concurrency experiment'. Urban Affairs Review 42(4), 505-532

Chicoine, D. L., \& Walzer, N. (1985). Governmental structure and local public finance. Boston, Mass.: Oelgeschlager, Gunn \& Hain.

Comrey, A. L., \& Lee, H. B. (1992). A first course in factor analysis (2nd ed.). Hillsdale, N.J.: L. Erlbaum Associates.

Costello, A. B., \& Osborne, J. (2005). Best practices in exploratory factor analysis: four recommendations for getting the most from your analysis. Practical Assessment Research \& Evaluation, 10(7).

Creswell, J. W. (2003). Research design: Qualitative, quantitative, and mixed methods approaches (2nd ed.). Thousand Oaks, Calif.: Sage Publications.

Cudeck, R., \& MacCallum, R. C. (2007). Factor analysis at 100: Historical developments and future directions. Mahwah, N.J.: Lawrence Erlbaum Associates.

Denhardt, J. V., \& Denhardt, R. B. (2007). The new public service: Serving, not steering (ed.). Armonk, N.Y.: M.E. Sharpe.

Dooley, D. (2001). Social research methods (4th ed.). Upper Saddle River, N.J.: Prentice Hall.

Downs, A. (2004). Growth management and affordable housing: do they conflict? (ed.). Washington, D.C.: The Brookings Institution. 
Eger, Robert J.,III. (2006). Casting light on shadow government: A typological approach. Journal of Public Administration Research and Theory, 16(1), 125-137

Florida Administrative Code (n.d.). Rule 9J-5. Minimum criteria for review of local government comprehensive plans and plan amendments, evaluation and appraisal reports, land development regulations and determinations of compliance. Retrieved on September $3^{\text {rd }}, 2010$ from https://www.flrules.org/gateway/ChapterHome.asp?Chapter=9J-5

Florida Atlantic University/Florida International University Joint Center for Environmental and Urban Problems. (1995). Community Development Districts: A Florida profile. Boca Raton: Author.

Florida Constitution (1968). Retrieved on September $3^{\text {rd }}, 2010$ from http://www.leg.state.fl.us/Statutes/index.cfm?Mode=Constitution \&Submenu=3\&Tab $=$ statutes $\&$ CFID $=166050717 \&$ CFTOKEN $=28512338$

Florida Department of Community Affairs. (n.d.). Florida Special Districts Handbook. Retrieved on September $3^{\text {rd }}, 2010$ from http://www.floridaspecialdistricts.org/handbook

Florida Department of Revenue. (n.d.). History and facts about truth in millage. Retrieved on September $3^{\text {rd }}, 2010$ from http://dor.myflorida.com/dor/property/trim/

Florida Statutes (Chapter 163, Part II). (1985). The Florida Growth Management Act. Tallahassee: State of Florida.

Florida Statutes (Chapter 165). (n.d.). Formation of Local Governments. Retrieved on September $3^{\text {rd }}, 2010$ from http://www.leg.state.fl.us/Statutes/index.cfm?App_mode=Display_Statute\&URL=01 $\underline{00-0199 / 0165 / 0165 . h t m l}$

Florida Statutes (Chapter 187). (1985). State comprehensive plan. Tallahassee: State of Florida.

Florida Statutes (Chapter 189). (1989). The uniform special district accountability act of 1989. Tallahassee: State of Florida.

Florida Statutes (Chapter 190). 1980. The uniform Community Development District act of 1980. Tallahassee: State of Florida.

Florida Statutes (Chapter 193). (n.d.). Assessments. Part I: General provisions. Retrieved on September $3^{\text {rd }}, 2010$ from http://www.leg.state.fl.us/statutes/index.cfm?App_mode=Display_Statute\&URL=Ch $\underline{0193 / \mathrm{ch} 0193 . \mathrm{htm}}$ 
Foster, K. A. (1997). The political economy of special-purpose government. Washington, D.C.: Georgetown University Press.

Frank, H.A., Christian, P., \& Scutelnicu, G. (2009). Generating the public financial management knowledge base: Analyzing method and direction as a sub-discipline of public administration. Journal of Public Budgeting, Accounting \& Financial Management, 21(2), 223-246.

Frankfort-Nachmias, C., \& Leon-Guerrero, A. (2006). Social statistics for a diverse society (4th ed.). Thousand Oaks, Calif.: Pine Forge Press.

Frant, H. (1997). Reconsidering the determinants of public authority use. Journal of Public Administration Research and Theory, 7(4), 571-590.

Fredericksen, P., \& London, R. (2000). Disconnect in the hollow state: The pivotal role of organizational capacity in community-based development organizations. Public Administration Review 60(3), 230-239.

Frederickson, H. G., \& Smith, K. B. (2003). The public administration theory primer. Boulder, Colo.: Westview Press.

Green, S. B., \& Salkind, N. J. (2005). Using SPSS for Windows and Macintosh: Analyzing and understanding data (4th ed.). Upper Saddle River, NJ: Pearson/Prentice Hall.

Gross, J. (2005). Business Improvement Districts in New York City's low-income and high-income neighborhoods. Economic Development Quarterly, 19(2), 174-189.

Hatcher, L. (1994). A step-by-step approach to using the SAS system for factor analysis and structural equation modeling. Cary, NC: SAS Institute.

Haynes, P. (2003). Managing complexity in the public services. Maidenhead: Open University Press.

Ho, R. (2006). Handbook of univariate and multivariate data analysis and interpretation with SPSS. Boca Raton, FL: Chapman \& Hall/CRC.

Kettl, D. F. (1988). Government by proxy: (mis?)managing federal programs. Washington, D.C.: CQ Press.

Kettl, D. F. (1993). Sharing power: Public governance and private markets. Washington, D.C.: The Brookings Institution.

Kettl, D. F. (2000). The global public management revolution: A report on the transformation of governance. Washington, D.C.: Brookings Institution Press. 
Leech, N. L., Barrett, K. C., \& Morgan, G. A. (2005). SPSS for intermediate statistics: Use and interpretation (2nd ed.). Mahwah, N.J.: Lawrence Erlbaum.

Leigland, J. (1994). Public authorities and the determinants of their use by state and local governments. Journal of Public Administration Research and Theory, 4(4), 521-544.

Levy, J. M. (2006). Contemporary urban planning (7th ed). New Jersey: Upper Saddle River.

Lynn, L. E. (2006). Public management: Old and new. New York; London: Routledge.

MacManus, S. A. (1981). Special district governments: A note on their use as property tax relief mechanisms in the 1970s. The Journal of Politics, 43(4), pp. 1207-1214.

Marlow, M. (1995). The influence of special districts governments on public spending and debt. Applied Economics, 27(7), 569-573.

McCabe, C.B. (2000). Special district formation among the states. State and Local Government Review, 32(2), 121-131.

McCabe, B.C. (2004). Special districts: An alternative to consolidation. In J.B. Carr \& R.C. Feiock (Eds.). City-county consolidation and its alternatives: Reshaping the local government landscape (pp. 131-152). Armonk, N.Y.: M.E. Sharpe.

Miles, M. B., \& Huberman, A. M. (1994). Qualitative data analysis: An expanded sourcebook (2nd ed.). Thousand Oaks: Sage Publications.

Miller, D. Y. (2002). The regional governing of metropolitan America. Boulder, Colo.: Westview Press.

Milward, H. B., \& Provan, K. G. (2000). Governing the hollow state. Journal of Public Administration Research and Theory, 10 (2), 359-380.

Milward, H.B., Provan, K. G. \& Else, B.A. (1993). What does the hollow state looks like? In B. Bozeman (1993). Public management: The state of the art (1st ed.), (pp.309-322). San Francisco: Jossey-Bass.

Mitchell, J. (1999). The American experiment with government corporations. Armonk, N.Y.: M. E. Sharpe.

Mitchell, J. (2001). Business Improvement Districts and the management of innovation. American Review of Public Administration, 31(2), 201-217.

Mitchell, J. (2008). Business Improvement Districts and the shape of American cities. Albany: State University of New York Press. 
Morçöl, G., \& Zimmermann, U. (2006). Metropolitan governance and Business Improvement Districts. International Journal of Public Administration, 29(1), 5-29.

Mullin, M. (2009). Governing the tap: Special district governance and the new local politics of water. Cambridge, Mass.: MIT Press.

Mullin, M. (2010). Special districs versus contracts: Complements or substitutes? In R.C. Feiock \& J.T. Scholz (Eds.), Self-organizing federalism: Collaborative mechanisms to mitigate institutional collective action (pp. 142-160). Cambridge; New York: Cambridge University Press.

Neuman, W. L. (2004). Basics of social research: Qualitative and quantitative approaches. Boston: Pearson.

Nicholas, J. \& Chapin, T. (2007). The fiscal theory and reality of growth management in Florida. In T. Chapin, C. Connerly \& H. Higgins (Eds.), Growth management in Florida: Planning for paradise (pp. 51-66). London: Ashgate.

Nunn S., \& Schoedel, C. (1997). Special districts, city governments and infrastructure spending in 105 US metropolitan areas. Journal of Urban Affairs, 19(1), 59-72. doi:10.1111/j.1467-9906.1997.tb00397.x

Oakerson, R. J. (1999). Governing local public economies: Creating the civic metropolis. Oakland, Calif.: ICS Institute for Contemporary Studies Press.

Osborne, D., \& Gaebler, T. (1992). Reinventing government: How the entrepreneurial spirit is transforming the public sector. Reading, Mass.: Addison-Wesley Pub. Co.

Ostrom, E. (1999). Metropolitan reform: Propositions derived from two traditions. In M.D. McGinnis. Workshop in Political Theory and Policy Analysis. Polycentric governance and development: Readings from the workshop in political theory and policy analysis (pp.139-159). Ann Arbor: University of Michigan Press.

Ostrom, V., Bish, R. L., \& Ostrom, E. (1988). Local government in the United States. San Francisco, Calif.; New York, NY: ICS Press.

O'Sullivan, E., \& Rassel, G. R. \& Berner, M. (2003). Research methods for public administrators (4th ed.). New York: Longman.

Pagano, M. A. \& Perry, D. (2008). Financing infrastructure in the $21^{\text {st }}$ century. Public Works Management and Policy, 13(1), 22-38.

Patton, M. Q. (2002). Qualitative research and evaluation methods (3rd ed.). Thousand Oaks, Calif.: Sage Publications. 
Pelham, T. G. (2001). Restructuring Florida's growth management system: Alternative approaches to plan implementation and concurrency. University of Florida Journal of Law and Public Policy, 12(2), 299-310.

Pelham, T.G. (2007). A Historical Perspective for Evaluating Florida's Evolving Growth Management Process. In T. Chapin, C. Connerly \& H. Higgins (Eds.), Growth management in Florida: Planning for paradise. London: Ashgate

Pollitt, C. \& Bouckaert, G.(2000). Public management reform: A comparative analysis. Oxford, New York: Oxford University Press.

Porter, D. R. (1997). Managing growth in America's communities. Washington, DC: Island Press.

Porter, D. R. (2008). Managing growth in America's communities (2nd ed.). Washington, D.C.: Island Press.

Porter, D. R., Lin, B. C., Jakubiak, S. \& Peiser, R. B. (1992). Special districts: A useful technique for financing infrastructure (2nd ed.). Washington, D.C.: Urban Land Institute.

Roberts, N.C. \& King, P.J. (1991). Policy entrepreneurs: Their activity structure and function in the policy process. Journal of Public Administration Research and Theory, 1(2), 147-175.

Sbragia, A. M. (1996). Debt wish: Entrepreneurial cities, U.S. federalism, and economic development. Pittsburgh, PA: University of Pittsburgh Press.

Smith, S. R., \& Lipsky, M. (1993). Nonprofits for hire: The welfare state in the age of contracting. Cambridge, Mass.: Harvard University Press.

Smith, S. R., \& Smyth, J. (1996). Contracting for services in a decentralized system. Journal of Public Administration Research and Theory, 6(2, Symposium on the Hollow State: Capacity, Control, and Performance in Interorganizational Settings), 277-296.

Tabachnick, B. G., \& Fidell, L. S. (1989). Using multivariate statistics (2nd ed.). New York: Harper \& Row.

Tiebout, C. (1956). A pure theory of local public expenditures. Journal of Politicall Economy 64, 416-424

Turner, R. S. (1990). Intergovernmental growth management: A partnership framework for state-local relations. Publius, 20(3, The State of American Federalism, 19891990), 79-95. 
U.S. Census Bureau. (1950). Census of Population: Florida. Characteristics of the population (Volume II, Part 10). Washington: Government Printing Office

U.S. Census Bureau. (1960). Census of Population: Florida. Characteristics of the population (Volume I, Part 11). Washington: Government Printing Office

U.S. Census Bureau. (2000). American fact finder fact sheet: Florida. Retrieved September $3^{\text {rd }}, 2010$ from http://factfinder.census.gov/servlet/DTGeoSearchByListServlet?ds_name=DEC_200 0 SF 1_U\& lang $=$ en\& ts $=301763542624$

U.S. Census Bureau. (2002). Census of Governments. Retrieved August 29, 2010 from http://www.census.gov/govs/cog/historical_data_2002.html

U.S. Census Bureau. (2007). Census of Governments. Retrieved August 29, 2010 from http://www.census.gov/govs/cog/.

U.S. Census Bureau. (2009). State and county quick facts: Florida. Retrieved September $3^{\text {rd }}, 2010$ from http://quickfacts.census.gov.

Van Assenderp, K. (n.d.). Unpublished manuscript. Copy in possession of author.

Vogt, A. J. (2004). Capital budgeting and finance: A guide for local governments. Washington, D.C.; Chapel Hill, N.C.: International City/County Management Association; Institute of Government, the University of North Carolina at Chapel Hill.

Walker, J. T. (1999). Statistics in criminal justice: Analysis and interpretation. Gaithersburg, Md.: Aspen Publishers. 
APPENDICES

Appendix 1 - Interview Guide for Semi-Structured Interviews 
1. If you had to describe CDDs in a paragraph/phrase, how would you do it?

2. How would you describe the functions that CDDs perform?

3. Do you know who provides and maintains local services such as roads, sanitary sewer, solid waste, drainage, potable water, recreation facilities and mass transit in your community? In your opinion, who do you think should provide and maintain the aforementioned services - a general-purpose or a local-purpose government?

4. As entrepreneurial entities of government, CDDs represent a means of funding facilities for new development. How would you describe the development (communities) that CDDs create?

5. Do you believe these developments and the accompanying infrastructure would exist if CDDs weren't in place?

6. Considering your experience with CDDs, what types of public improvements develop within or around CDDs?

7. Do you believe that residents understand that they are part of a government structure where public functions are split between CDDs and local governments such as counties/cities?

8. In your opinion, how do residents perceive CDDs' financial obligation? Do you think that residents distinguish between CDDs' assessments and fees and a general-purpose government property tax?

9. CDDs can be considered tools that fund infrastructure facilities \& services while fulfilling the concurrency requirement for new development. Is the infrastructure provided by CDDs included in the concurrency management system/capital improvement plan of your county? 
10. In your opinion, do CDDs coordinate their activities with local comprehensive plans/local general-purpose governments?

11. Who do you think benefits and who doesn't from the creation of CDDs? 
Appendix 2 - Cover Letter and Survey Instrument 


\section{FIU}

\section{Dear Sir/Madam:}

Community Development Districts (CDDs) may be considered viable institutional choices for managing and funding infrastructure needs within the State of Florida. The survey we are asking you to complete is concerned with the strengths and weaknesses of CDD implementation. Your professional expertise within local government provides a distinct vantage from which you can assess CDDs' strengths and weaknesses. This survey will require no more than 15 minutes to complete and does not require your retrieval of other information.

To our knowledge, this survey is the first to address CDDs and their place in infrastructure provision within "The Sunshine State." Hence your opinions are vitally important to this study. Results from this study will play an important role in the ongoing debates surrounding growth management in Florida and other states and we will be happy to send summaries of findings if so desired.

Your individual responses are confidential and participation is voluntary but as an inducement, we will contribute $\$ 1.00$ to the American Cancer Society for each completed survey.

Professor Frank and I look forward to your response. If you have any questions or wish to discuss this subject at greater length, please contact Gina Scutelnicu at (786) 218-9658 or gscut001@fiu.edu . We deeply appreciate your participation and thank you in advance for the important information you are providing.

With warmest regards,

Ms. Gina Scutelnicu

Doctoral Candidate
Dr. Howard Frank

Professor of Public Administration 


\section{COMMUNITY DEVELOPMENT DISTRICTS SURVEY}

This survey aims to assess your perceptions of Community Development Districts (CDDs) in terms of four issues: management structure, financial impacts, economic development impacts and administrative accountability. Each of these issues is addressed in separate sections. There are no "right" or "wrong" answers; we are seeking your perceived impact of CDDs on these critical aspects of public policy.

\section{STRUCTURE}

CDDs are considered to have a flexible structure due to their administrative and financial autonomy. On a scale of 1 to 5, please indicate your level of agreement with the following statements $(1=$ strongly disagree and $5=$ strongly agree $)$ :

$\begin{array}{ll}\text { 1.Strongly } & \begin{array}{c}\text { 3. Neither } \\ \text { disagree, nor }\end{array} \\ \text { disagree } & \text { 2.Disagree } \text { agree Strongly } \\ \text { 4.Agree agree }\end{array}$

CDDs remain self-supporting institutions over time

CDDs provide community-tailored services

CDDs enjoy little oversight from local generalpurpose governments

\section{FINANCIAL IMPLICATIONS}

This section asks questions about the financial implications of CDDs for general-purpose governments, developers and residents. On a scale of 1 to $5(1=$ strongly disagree and 5 $=$ strongly agree), please indicate your level of agreement with the following statements as they pertain to each of the three aforementioned groups:

\section{GENERAL-PURPOSE GOVERNMENTS}

1.Strongly
disagree $\quad \begin{gathered}\text { 3. Neither } \\ \text { disagree, nor }\end{gathered}$
$\begin{aligned} & \text { CDDs relieve general-purpose governments' property } \\ & \text { tax by levying independently }\end{aligned}$
$\begin{aligned} & \text { CDDs are a means of circumventing debt limits of } \\ & \text { general-purpose governments }\end{aligned}$
$\begin{aligned} & \text { CDD levies are more stable over time than the } \\ & \text { taxes and fees of general-purpose governments }\end{aligned}$




\section{IMPACT ON DEVELOPERS}

$$
\begin{array}{ll}
\text { 1.Strongly } & \text { 3. Neither } \\
\text { disagree } & \text { 2.Disagree } \\
\text { agree nor } & \text { 5. Strongly }
\end{array}
$$

CDDs increase short term profitability for developers

CDDs allow developers to enhance amenities at lower costs

\section{RESIDENTS/COMMUNITY}

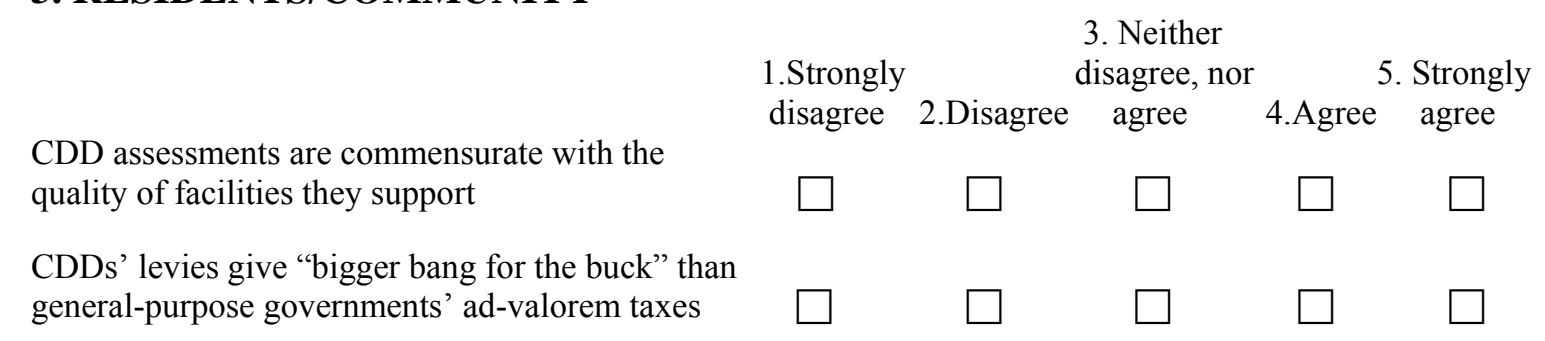

III. ECONOMIC DEVELOPMENT. CDDs act as both providers and maintainers of infrastructure for new communities. On a scale from 1 to 5 (where $1=$ strongly disagree and $5=$ strongly agree), please state your opinion for each of the following items:

\section{INFRASTRUCTURE PROVISION}

CDDs provide infrastructure in areas where general-purpose governments are not able to $\begin{array}{lll}\text { 1.Strongly } & \text { 3. Neither } \\ \text { disagree, nor } & \text { 5. Strongly } \\ \text { disagree 2.Disagree agree } & \text { 4.Agree agree }\end{array}$

CDDs build infrastructure faster than generalpurpose governments

CDDs provide infrastructure services cheaper Than general-purpose governments

CDDs impose hidden infrastructure costs to the surrounding general-purpose governments

\section{INFRASTRUCTURE MAINTENANCE}

CDDs offer residents higher quality infrastructure $\begin{array}{ll}\text { 1.Strongly } & \begin{array}{l}\text { 3. Neither } \\ \text { disagree, nor }\end{array} \text { 5. Strongly } \\ \text { disagree } & \text { 2.Disagree agree }\end{array}$ than general-purpose governments

CDDs better maintain infrastructure than generalpurpose governments due to their narrow purpose 
CDDs better maintain infrastructure than generalpurpose governments due to their smaller size

IV. ACCOUNTABILITY ISSUES. This section depicts CDDs' accountability issues in relation to local general-purpose governments.

On a scale from 1 to $5(1=$ strongly disagree and $5=$ strongly agree $)$ please indicate your level of agreement with the following statements:

1.Strongly
disagree 2.Disagree $\begin{gathered}\text { 3. Neither } \\ \text { disagree, nor }\end{gathered}$ 4.Agree $\begin{aligned} & \text { 5trongly } \\ & \text { agree }\end{aligned}$

CDD reports are used and relied upon by general-

purpose governments when local comprehensive

plans are designed

CDD infrastructure is coordinated with the capital

improvements plans of the surrounding governments

CDDs overstep their powers because of limited

oversight from general-purpose governments

V. GENERAL OVERVIEW. The following questions ask for your general opinion about various aspects of CDDs. Please select where you stand in regard to these issues presented as "bookends" of possible opinions:

1. CDDs

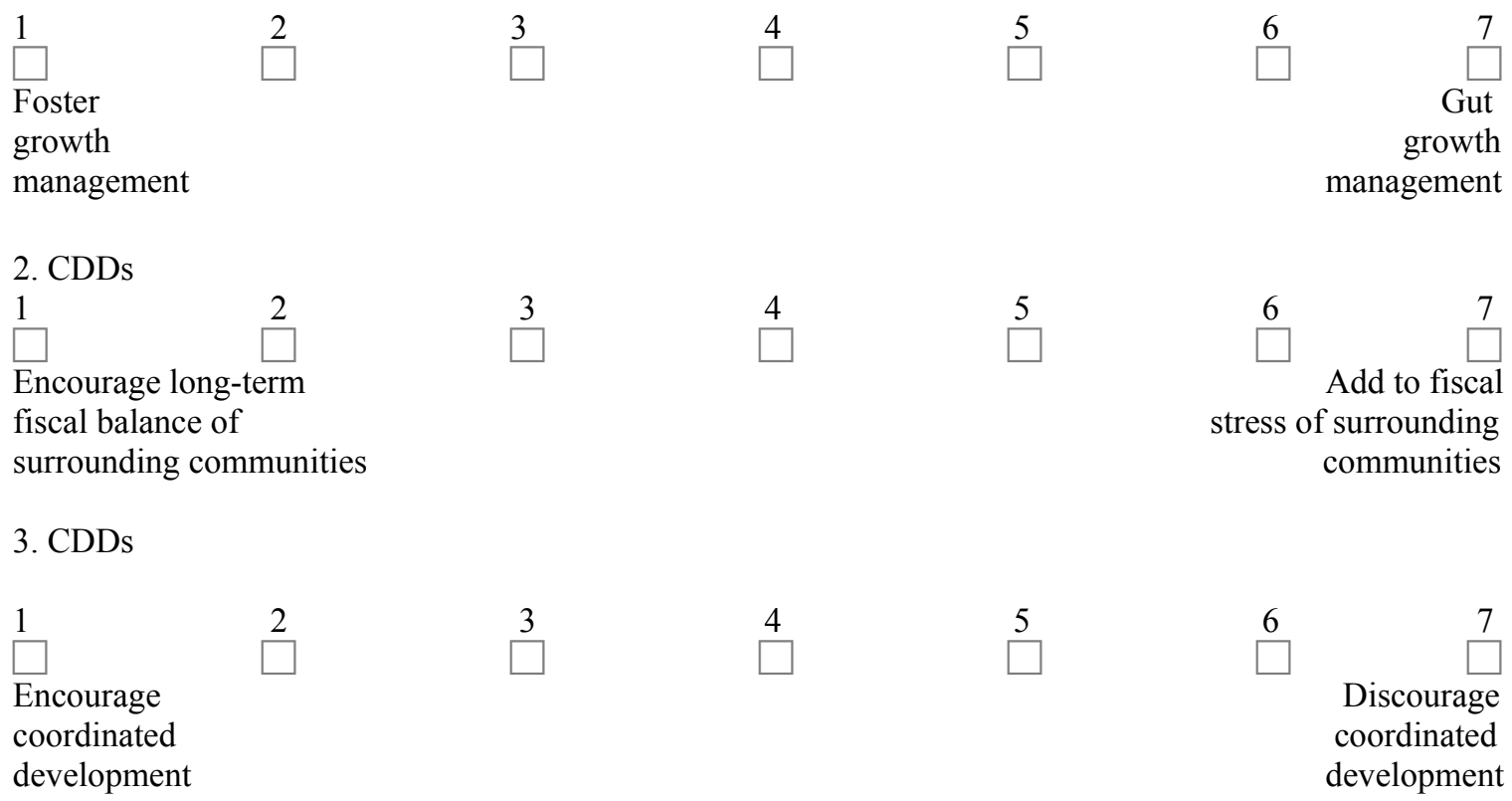


4. CDDs

1

Facilitates

stability of

housing prices

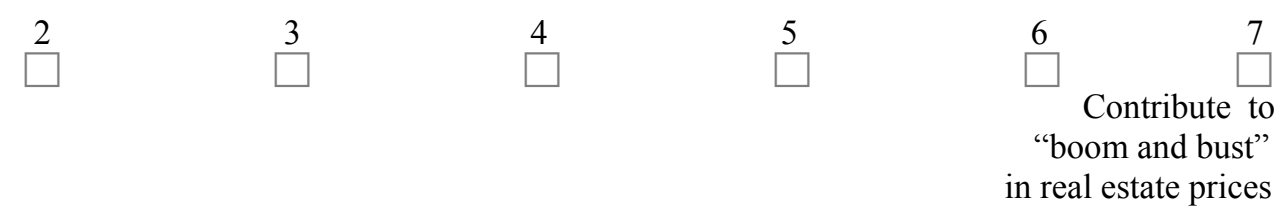

5. CDDs are likely to remain part of Florida's community development landscape for the foreseeable, but if there is one thing you could change in regard to their implementation, what would it be?

\section{A few questions about yourself:}

1. What year were you born in?

2. What is the highest level of education completed?

$\square$ High school $\square$ Associate degree $\square$ College degree $\square$ Master's $\square$ Advanced graduate
(J.D. or Ph.D)

3. Which Department/Division do you belong to?

4. Do you currently hold any professional certifications/licenses?

Yes $\square$ No

If yes, please indicate which ones:

$\square$ American Institute of Certified Planners (AICP)

$\square$ Certified Government Auditing Professional (CGAP)

$\square$ Certified Management Accountant (CMA)

$\square$ Certified Public Accountant (CPA)

$\square$ Professional Engineers (PE)

$\square$ Professional Surveyors (PS)

$\square$ Other (please specify) 
5. How many years have you been employed in your current position?

6. What type of position do you currently hold?

$\square$ Supervisory

$\square$ Non-supervisory

7. Do you have professional experience outside Florida?

$\square$ Yes

$\square$ No

Thank you very much for your participation! 
Appendix 4 - Techniques Employed in the Qualitative Analysis 
When analyzing data and generating meaning the author used various approaches suggested by Miles \& Huberman (1994). These are:

- identifying themes and patterns of variables through considering similarities and differences among categories as well as through processes which take place within a certain context;

- searching plausibility by drawing conclusions that seem reasonable and that make sense;

- $\quad$ clustering variables by subsuming particulars into general;

- counting words;

- making comparisons among categories;

- factoring variables by reducing large numbers of variables into smaller ones and

- drawing theoretical conclusions by moving from empirical to conceptual constructs and theories. 
Appendix 5 - Assumptions of Multiple Regression Analysis 
Before running the analysis, the assumptions of the multiple regression analysis were tested. The indicators included in the analysis were either interval level or dichotomous variables. Dichotomous variables may very well be used as independent variables in multiple regression analysis (O'Sullivan et. al., 2003). Normality of the variables was tested by inspecting the values of the skeweness and kurtosis coefficients and by visualizing histograms and normality plots of individual variables as well as scatterplots of residuals.

With the exception of the variable describing CDD estimated infrastructure costs which was positively skewed, all the other variables were fairly normally distributed. To make sure the assumption of normality is met, this variable was transformed using a logarithmic transformation.

Then, data were checked for univariate outliers on the dependent variable and multivariate outliers on the independent variables by looking at the studentized residuals and Mahalanobis distance scores. One univariate outlier (case 257) was identified and removed from analysis.

Bivariate scaterplotts between the independent and the dependent variables as well as plots between observed and predicted residuals showed that the variables were linearly related. Data were also checked for multicolinearity by looking at the variation inflation factor (VIF) value and at correlations between independent variables. The VIF values ranged from 1.044 to 1.424 and all the correlations between the independent variables were low and moderate. This indicated that multicolinearity was unlikely to be a problem. The correlations between the four predictors and the dependent variable were moderate and high indicating that data was suitably correlated with the dependent variable and, therefore, an examination through multiple regression was appropriate.

Homoscedasticity was tested both by looking at the residual plots and at scatterplots between each independent variable and the dependent variable The plots 
indicated reasonable consistency of spread through the distributions. Then, the independence of error terms was tested by looking at the Durbin-Watson statistic (1.26) as well as the autocorrelation plot of residuals. Results showed that successive residuals were not correlated.

Last but not least, the adequacy of the sample size was addressed. According to Tabachnick \& Fidell (1989) the ratio of number of cases to variables employed should be of 20:1 but no less than 5:1. With four independent variables for 233 cases, this analysis has a 58:1 ratio cases to variables, exceeding by far the minimum cases-to-variables ratio. 
Appendix 6 - Assumptions of Factor Analysis 
The assumptions of factor analysis (FA) can be classified in two broad categories. The first category refers to the suitability of the data for analysis. FA requires interval level measurement, but it may also be used with ordinal variables such as Likert scale data (O’Sullivan et. al., 2003). In this study all the variables used for factor analysis are measured by Likert scales. FA also assumes normality of observed variables (Barnes, Cote, Cudeck \& Malthouse, 2001; Ho 2006). The variables were tested for normality through the inspection of skewness and kurtosis coefficients. Skewness coefficients ranged from .01 to .99 being comprised within the \pm 1 accepted interval and kurtosis coefficients ranged from .04 to 1.24 being comprised within the \pm 2 accepted value range. Another assumption that falls within this category refers to the fact that factors and their supporting variables should be linearly related (Cudek \& MacCallum, 2007; Walker 1999). Matrix scatterplots were constructed and then visually analyzed to determine that the items were linearly related to the factors they generated.

Factor analysis also assumes that sample size is sufficient. While some authors use minimum accepted sample size for conducting factor analysis others consider the ratio of subjects-to-variables for determining the adequacy of the sample size. Minimum sample sizes for conducting FA have been recommended as low as 100 cases (Hatcher, 1994) and as high as 500 cases (Comrey \& Lee, 1992). Costello \& Osborne (2005) consider the 10:1 subject-to-item ratio as a rule of thumb when determining the adequacy of the sampling size but they document the utilization of 5: 1 and less than 5:1 subjectsto-items ratios Hatcher (1994) suggests a minimum of 5:1 subject-to-item ratio. The scholarly literature points out to the fact that cut-off numbers are not the only criteria for establishing an optimal sample size for conducting FA. Sample size should also be determined according to the nature of data (Costello \& Osborne, 2005) as well as to the theoretical and methodological issues of a study (Walker, 1999). The sample size of the present analysis consisted of 96 cases (after using listwise deletion), with over 5 cases per 
variable. The mean for communalities is .63 . Even if the sample size is fairly small, the results of the FA are expected to yield reliable results considering the sampling frame was not too big either (197 cases) and the first sampling cluster included the entire population.

The second main category of the FA assumptions refers to the factorability of variables. This implies the presence of many moderate correlations among variables (Ho, 2006; Leech, Barrett \& Morgan, 2005). There were several means of checking for data factorability that were used in this study. First, the correlation matrix showed that 16 out of 17 items included in the analysis had correlations of at least .3 with at least one other item, fact that indicated a good factorability of variables. Then the Kaiser-Meyer-Olkin measure of sampling adequacy was .74, more than the recommended value of .6 (Cudeck $\&$ MacCallum 2007), and Bartlett's test of sphericity was significant $\left(\chi^{2}(136)=556.137\right.$, $p<.01)$. Third, the diagonals of anti-image correlation matrix showed values of .47 and more, supporting the factorability of each of the seventeen items included in the analysis. Finally, most of the communalities were above .5 with a few in the upper .4s (see Table 7.10), fact that demonstrated that each item shared some common variance with other items. 
Appendix 7 - Histograms of Indexes 


\section{CDD Cost - Effectiveness}

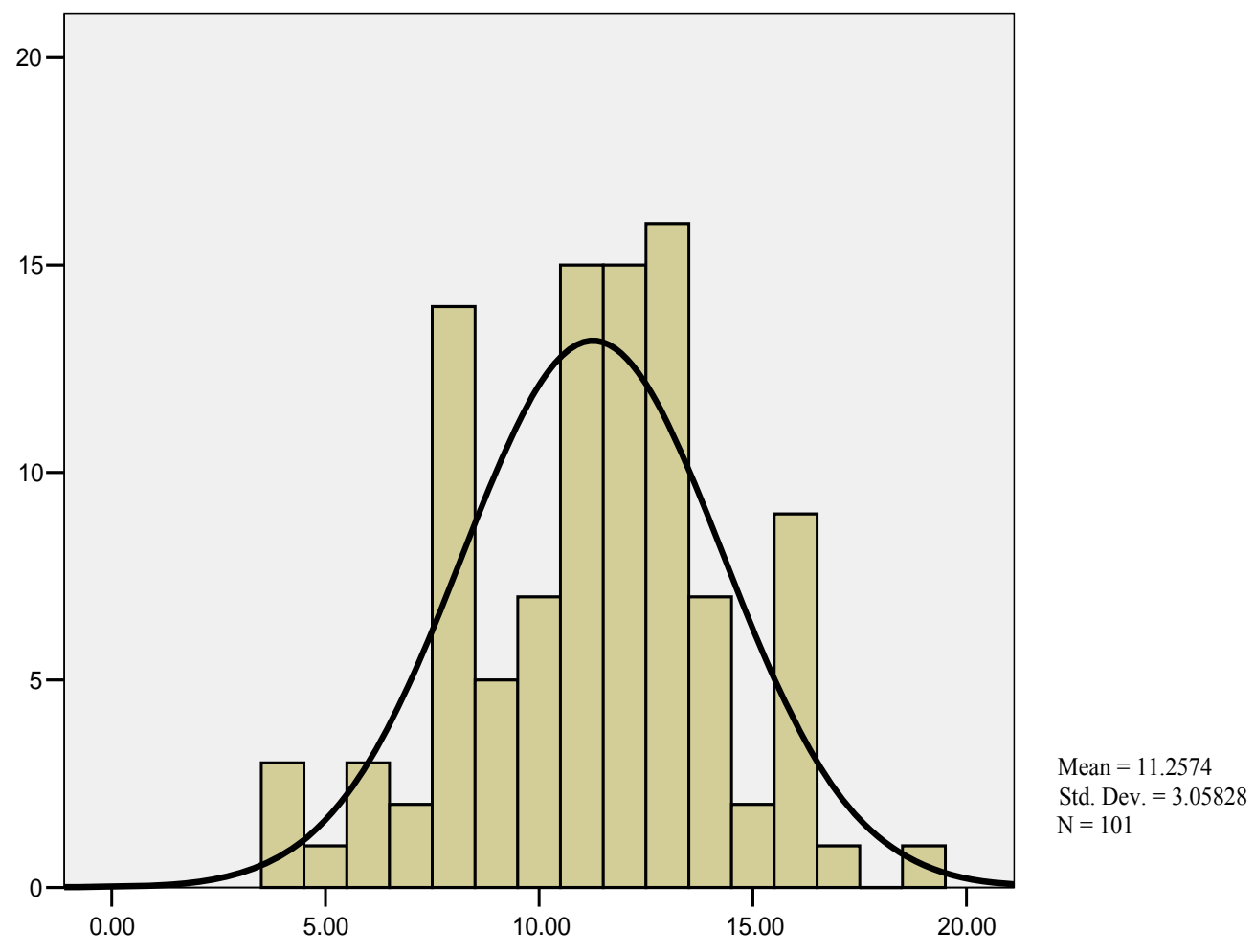




\section{CDD Managerial Responsiveness}

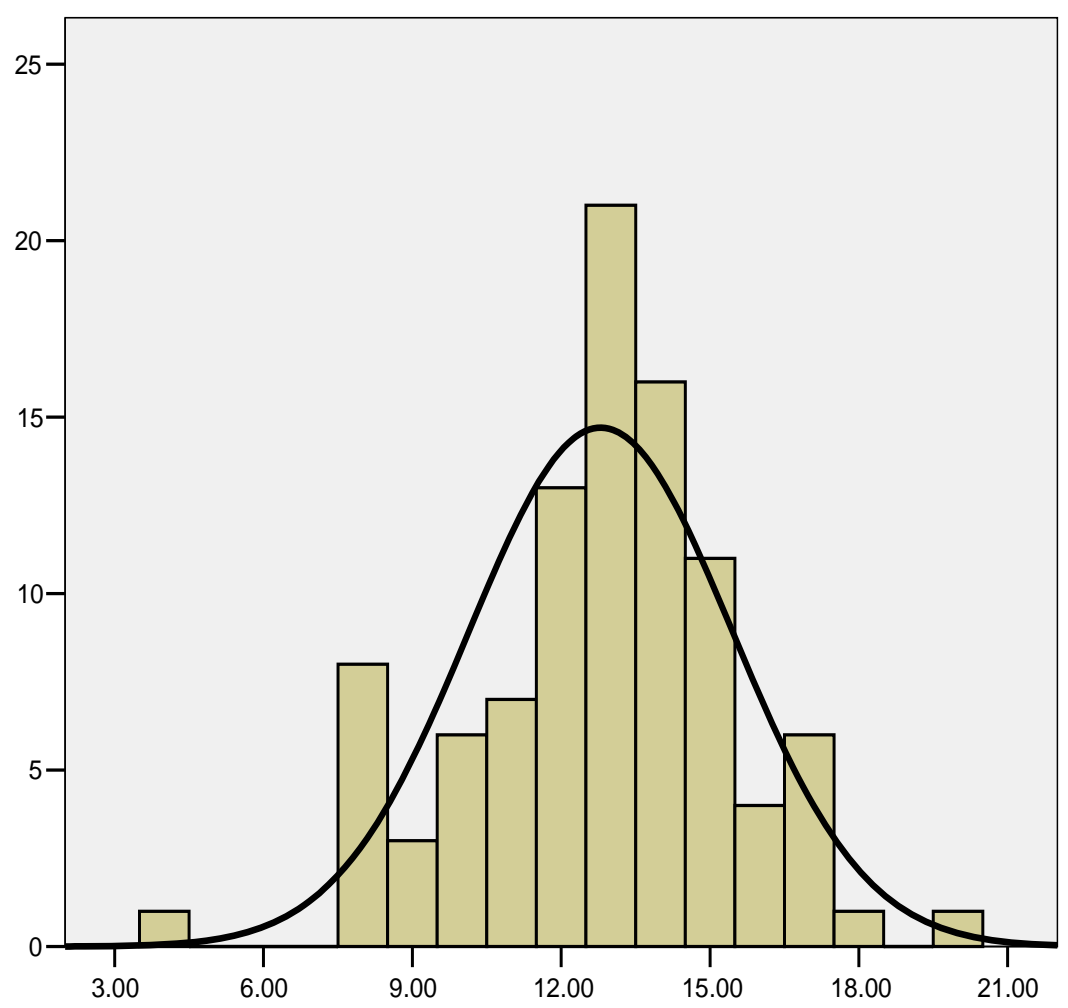

Mean $=12.7959$

Std. Dev. $=2.6592$

$\mathrm{N}=98$ 


\section{CDD Institutional Flexibility}

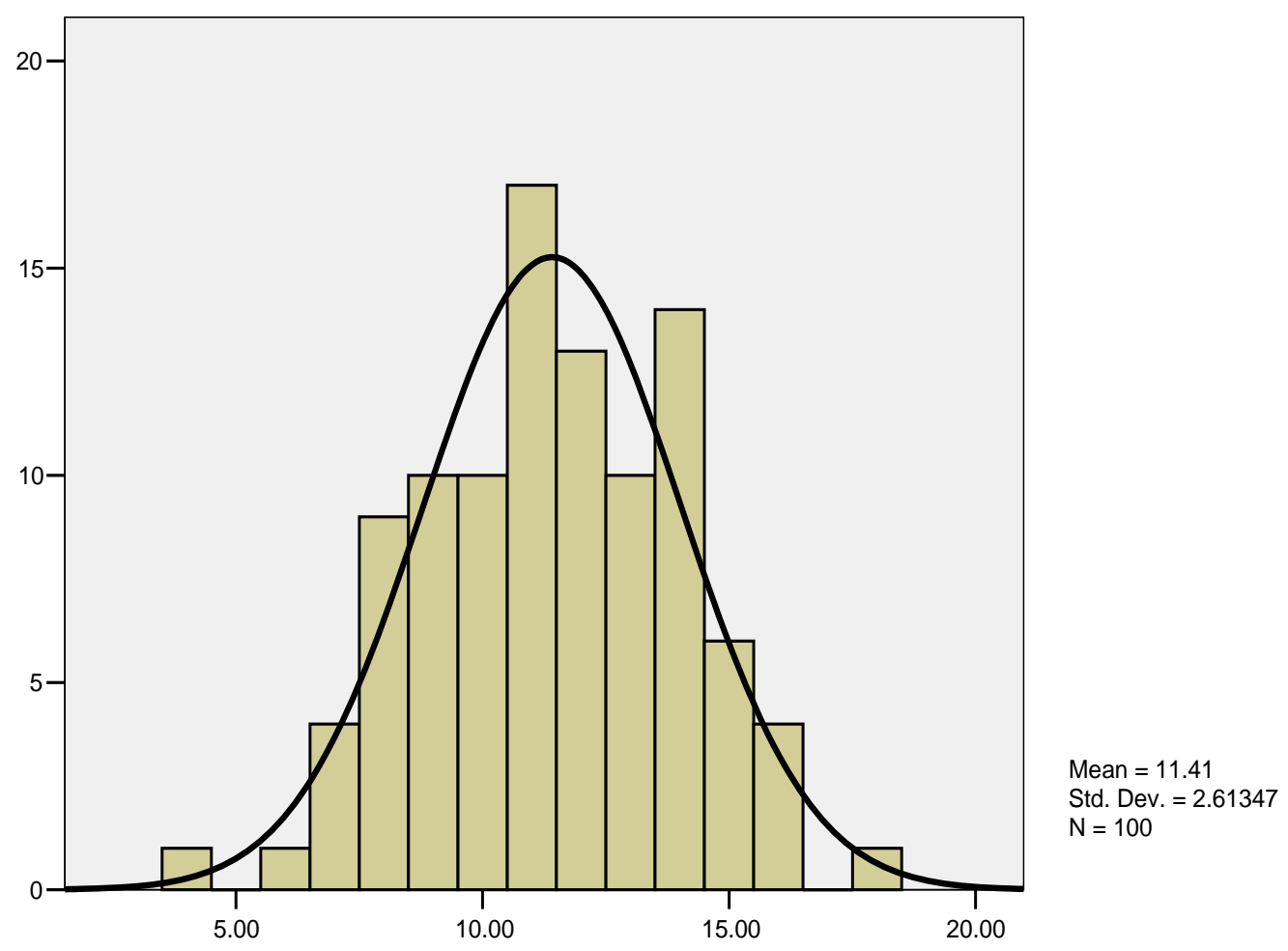


VITA

\section{GINA SCUTELNICU}

April 19, 1977

2000

2001

$2001-2004$

$2004-2006$

$2006-2007$

2010 - present
Born, Suceava, Romania

B.A., Public Administration

Babes-Bolyai University

Cluj-Napoca, Romania

M.A., Management of Public Services

Babes-Bolyai University

Cluj-Napoca, Romania

Teaching Assistant

Babes-Bolyai University

Cluj-Napoca, Romania

Trainer

Regional Center of Professional Training for Civil Servants Cluj-Napoca, Romania

Research Assistant

Florida International University

Miami, Florida

Teaching Assistant

Florida International University

Miami, Florida

\section{PUBLICATIONS AND PRESENTATIONS}

Scutelnicu, G. (2000). The Control of the Ombudsman over the Romanian Public Administration. Transylvanian Review of Public Administration, 5: 77-81.

Carroll, J., Shockley, G., Bell, P. and Scutelnicu, G. (April, 2005). Components of Homeland Security in Miami-Dade County: Government Structure, Management, Finance, and Technology. Paper presented at the Florida American Society for Public Administration Conference, Clearwater, Florida.

Bell, P., Celestine, T., Scutelnicu, G. and Young, S. (October, 2005). Determinants of Success: Lessons to be Learned from Rail Transit Systems Development in Miami-Dade 
and Dallas Counties. Paper presented at the Southeastern Conference of Public Administration, Little Rock, Arkansas.

Frank, H., Christian, P. and Scutelnicu, G. (September, 2006). Generating the Public Financial Management Knowledge Base: Analyzing Method and Direction as a SubDiscipline of Public Administration. Paper presented at the Southeastern Conference of Public Administration, Athens, Georgia.

Scutelnicu, G. (September, 2006). The Effects of Urban Growth Boundaries on Housing Affordability in South East Florida. Paper presented at the Southeastern Conference of Public Administration, Athens, Georgia

Bell, P., Scutelnicu, G. and Young, S. (2007). Determinants of Success: Lessons to be Learned from Rail Transit Systems Development in Miami-Dade and Dallas Counties. Transylvanian Review of Administrative Sciences, 19 E: 21-35.

Scutelnicu, G. (April, 2007). The Effects of Urban Development Boundaries on Housing Affordability in the Tri-County Area. Paper presented at the Graduate Student Association Scholarly Forum, Florida International University, Miami, Florida.

Scutelnicu, G. (April, 2008). Community Development Districts: An Entrepreneurial Model Of Governance. Paper presented at the Midwest Political Science Association Annual National Conference, Chicago, Illinois.

Frank, H. A., Christian, P. C. and Scutelnicu, G. (2009). Generating the Public Financial Management Knowledge Base: Analyzing Method and Direction as a Sub-Discipline of Public Administration. Journal of Budgeting, Accounting and Financial Management 21(2): 223-246.

Scutelnicu, G. (April, 2010). Community Development Districts as Institutional Mechanisms for Infrastructure Provision. Paper presented at the American Society for Public Administration National Conference, San Jose, California.

Scutelnicu, G. (October, 2010). Towards a Viable Institutional Choice of Infrastructure Delivery: The Case of Community Development Districts. Paper presented at the Southeastern Conference of Public Administration, Wilmington, North Carolina. 